Universidad de Lima

Escuela de Humanidades

Facultad de Comunicación

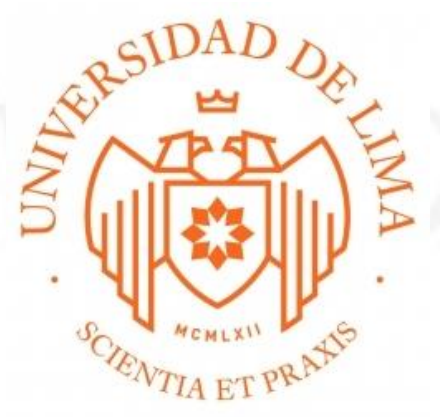

\title{
ANÁLISIS DE LAS NUEVAS PRINCESAS DE DISNEY Y SUS NARRATIVAS. CAMPAÑA "SOY PRINCESA SIENDO YO" Y LA FORMACIÓN DE ROLES DE GÉNERO EN NIÑOS Y NIÑAS DE 6 A 11 AÑOS
}

Tesis para optar por el Título Profesional de Licenciado en Comunicación

\author{
Polo Ferrer Andrea
}

Código 20121019

\section{Asesor}

Fernando Ruiz Dodobara

$$
\text { Lima - Perú }
$$

Marzo de 2019 


\section{ANÁLISIS DE LAS NUEVAS PRINCESAS DE \\ DISNEY Y SUS NARRATIVAS. CAMPAÑA "SOY PRINCESA SIENDO YO" Y LA FORMACIÓN DE ROLES DE GÉNERO EN NIÑOS Y NIÑAS DE 6 A 11 AÑOS}




\section{TABLA DE CONTENIDO}

CAPÍTULO I: PLANTEAMIENTO DEL ESTUDIO .............................................1

1.1. Presentación del problema y el contexto ........................................................ 1

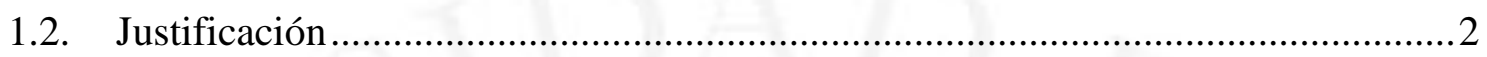

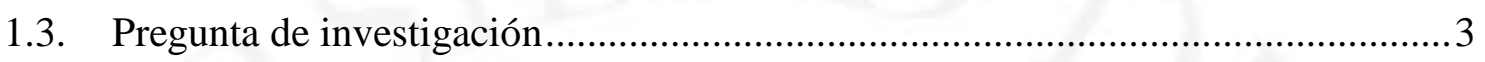

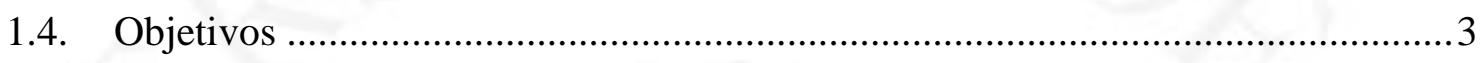

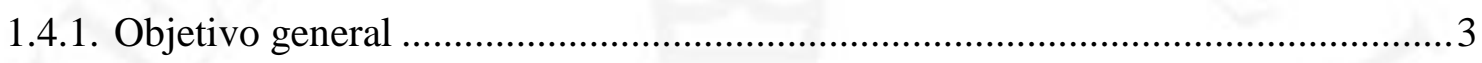

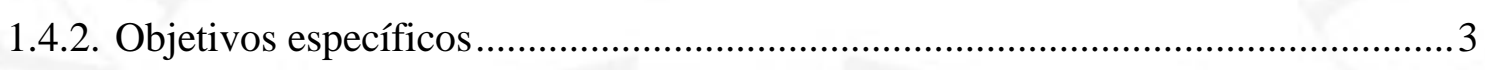

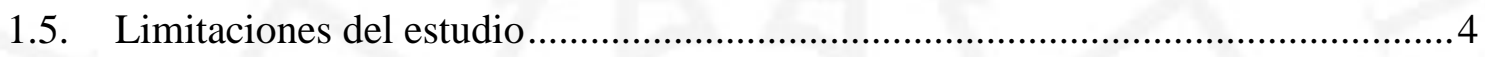

CAPÍTULO II: MARCO TEÓRICO ...................................................................5

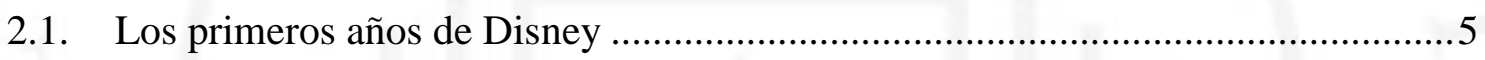

2.2. La evolución de los personajes animados femeninos de Disney ...........................5

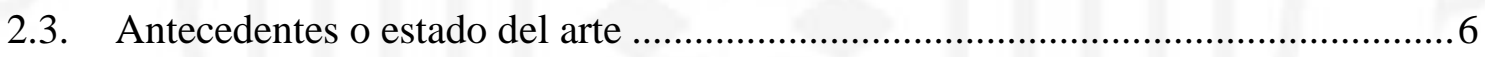

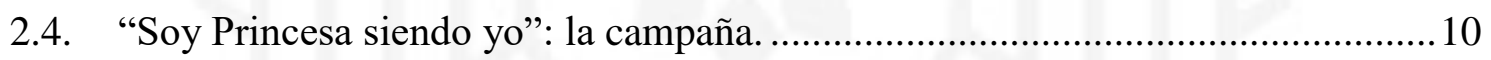

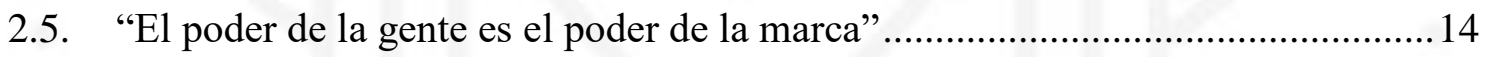

2.6. Sobre la teoría narrativa: el paradigma de Syd Field ........................................ 15

2.7. La identidad de género: La teoría multifactorial de la identidad de género ..........16

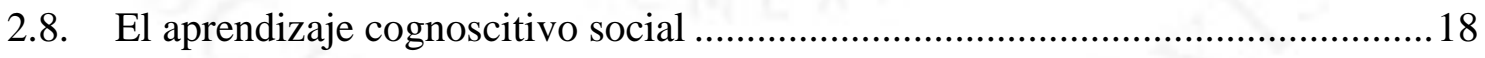

2.9. Nueva sociología de la infancia: enfoque construccionista...............................20

2.10 La evaluación de los roles sexuales: El inventario de los roles sexuales de Bem 22

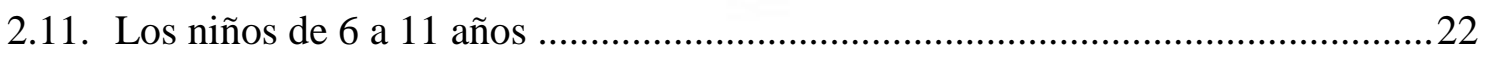

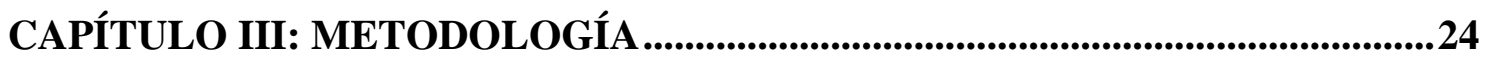

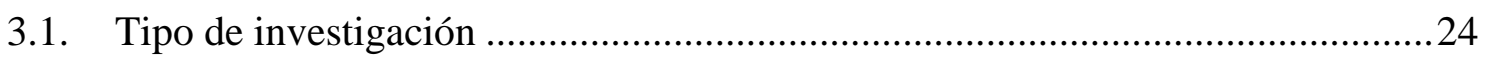

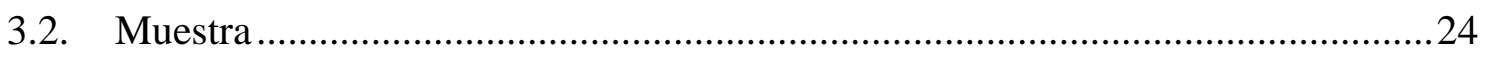


3.3. Recolección de información

3.3.1 Guía de observación de las películas con princesas de 1995 al 2017 (Anexo 2).25

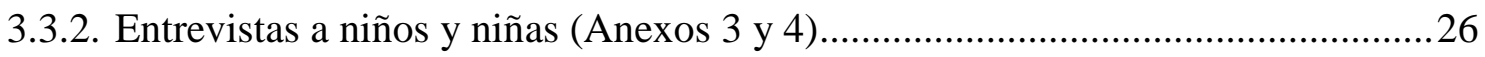

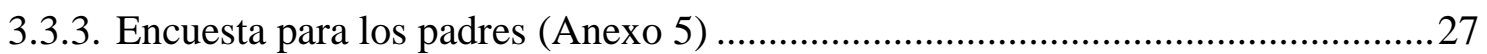

CAPÍTULO IV: RESULTADOS ............................................................................29

4.1. Las características planteadas en las películas de las protagonistas ....................29

4.1.1. Las características en la narrativa de las princesas..........................................29

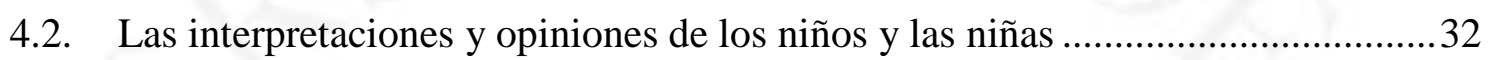

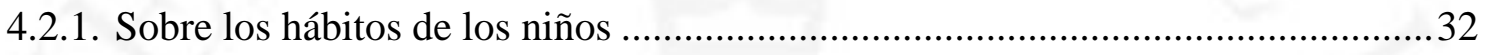

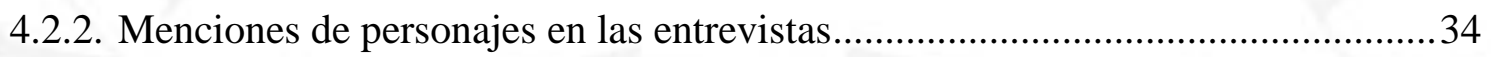

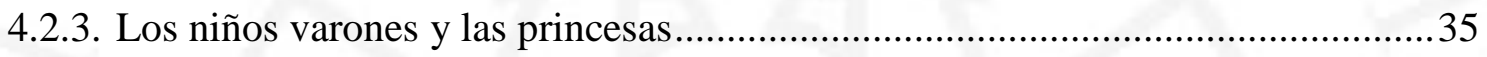

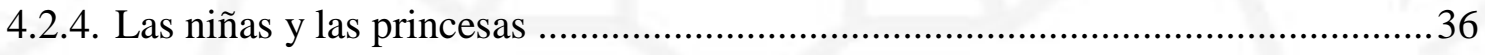

4.2.5. Percepciones de las historias de las princesas ................................................ 40

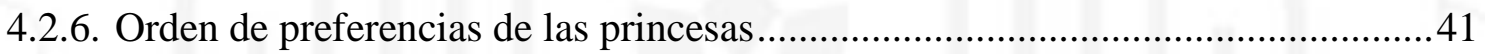

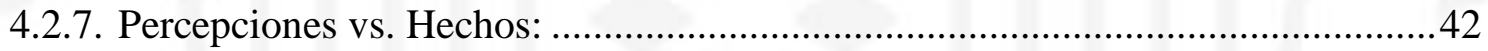

4.3. Relación entre el visionado de las películas y las costumbres, y pertenencia de

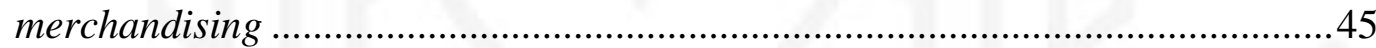

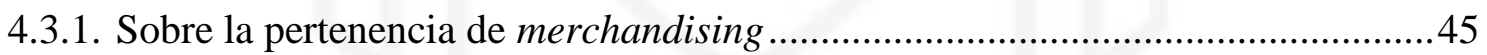

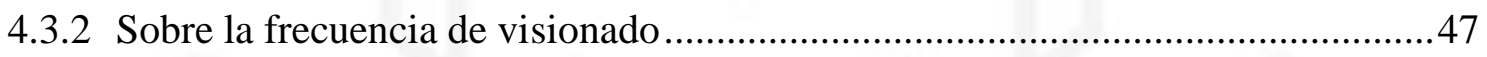

4.3.3 Cambios en el comportamiento en los niños …............................................. 48

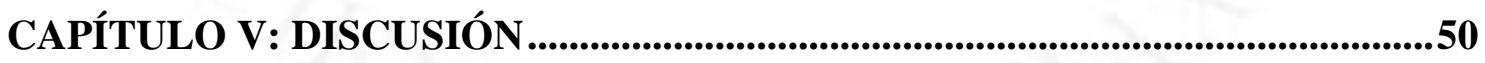

5.1. Recapitulando ................................................................................................................ 54

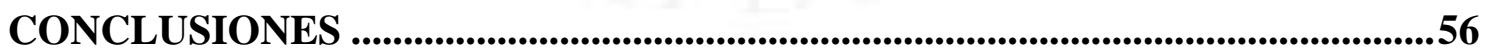

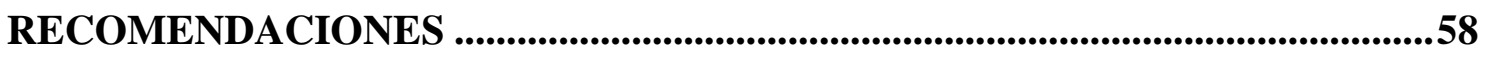

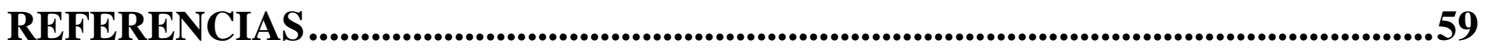




\section{ÍNDICE DE TABLAS}

Tabla 2.1. La formación de la identidad de género .17

Tabla 3.1. Objetivos específicos y herramientas metodológicas .25

Tabla 3.3.2. Ejemplos de características del Inventario de Roles Sexuales de Bem .....26

Tabla 4.1. El proceso evolutivo de las princesas y sus características masculinas, femeninas y neutras en sus actos narrativos .......................................................29

Tabla 4.2. Características más presentes en las películas por acto ................................ 30

Tabla 4.3. Orden de preferencias de cada princesa (suma total) ................................42

Tabla 4.4. Ubicación de cada princesa en el ranking (por grupos distritales) 42

Tabla 4.5. Contraste entre las características de las princesas y las menciones de las niñas 


\section{ÍNDICE DE FIGURAS}

Figura 2.1. Capturas del video Dream big, princess - Be A Champion .11

Figura 2.2. Cuenta de Instagram oficial de The Disney Princesses.............................. 11

Figura 2.3. Capturas de las páginas webs de "Dream big, Princess" en el mundo........ 12

Figura 2.4. Foto de campaña fotográfica Dream Big Princess ................................... 13

Figura 2.5. Línea de tiempo de películas de Disney .................................................. 14

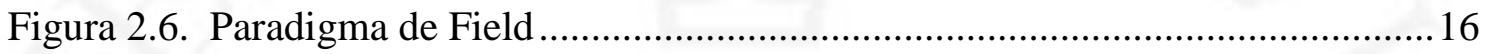

Figura 4.1. Características de las princesas de acuerdo al acto ................................... 31

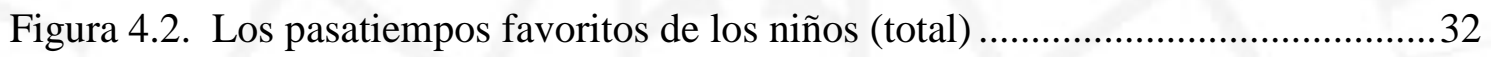

Figura 4.3. Los pasatiempos favoritos (comparando grupos distritales) ....................... 32

Figura 4.4. ¿Cómo te gusta jugar? (comparación por grupos distritales) ....................... 33

Figura 4.5. Preferencias de contenido en televisión (comparación en grupos distritales)

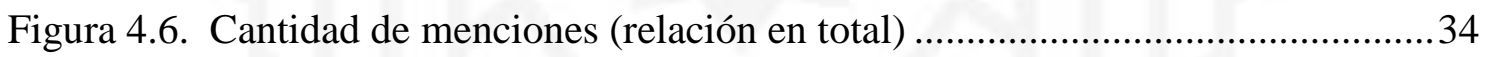

Figura 4.7. Las razones del favoritismo (total) ........................................................ 37

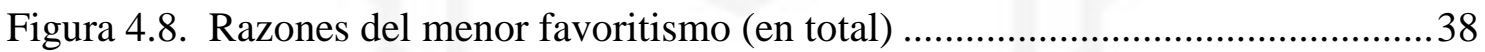

Figura 4.9. Menciones de las niñas por acto (en total en \%) ..................................... 40

Figura 4.10. Pertenencia de artículos en los dos distritos (porcentaje)..........................45

Figura 4.11. Pertenencia de artículos en los dos distritos (comparación en porcentajes)

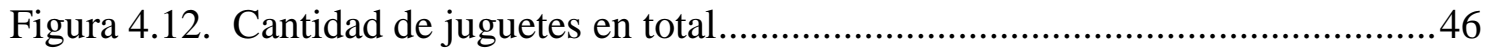

Figura 4.13. Frecuencia de visionado de películas animadas de Disney (total en \%) ...47

Figura 4.14. Frecuencia de visionado de películas animadas de Disney (SJL en \%) ....48 
Figura 4.15. Frecuencia de visionado de películas animadas de Disney (JM/PL en \%)48

Figura 4.16. Cambios o comportamientos relacionados a una película (total) .48

Figura 4.17. Cambios o comportamientos relacionados a una película (por grupos distritales) 


\section{ÍNDICE DE ANEXOS}

Anexo 1: Línea de tiempo de las princesas en las películas de Disney ...........................64

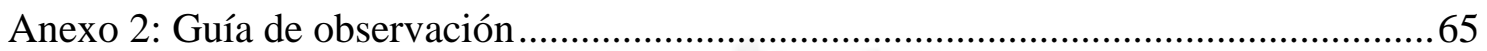

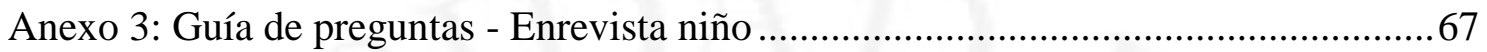

Anexo 4: Guía de preguntas - Entrevista niña ........................................................ 69

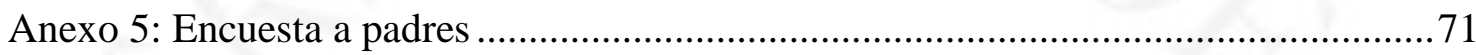

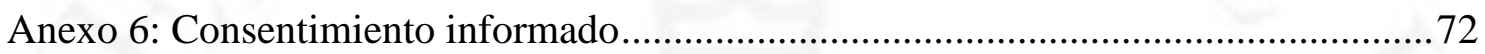

Anexo 7: Contraste entre las características de las princesas y las menciones de las

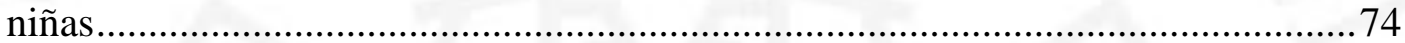




\section{CAPÍTULO I: PLANTEAMIENTO DEL ESTUDIO}

\subsection{Presentación del problema y el contexto}

Las corrientes de igualdad de género van adquiriendo más fuerza cada día y esta se refleja en diversos espacios del entretenimiento por su fuerte potencial de llegada a diferentes grupos etarios. Las luchas van cambiando de escenarios, pasando de las calles al triunfo de tener una Barbie que trata de ofrecer mayor variedad a sus consumidores ${ }^{1}$. Esta representación, que busca llegar a las nuevas generaciones y sus padres, ha llegado también a una de las marcas más importantes internacionalmente: Disney y, específicamente, la producción de sus películas animadas, cuyas protagonistas son las princesas de Disney.

Las situaciones, contextos y cualquier otro aspecto que termina siendo parte de la formación de los roles de género de las personas tienen un mayor impacto si se encuentran en un ámbito familiar y de confort (a través de educación informal). Los niños en etapa de formación van tomando las experiencias vividas y las van absorbiendo. Entre ellos, se encuentran los juguetes, ropa, series, videojuegos, dibujos, películas y demás productos audiovisuales (Cuadrado, 2010).

La sociedad occidental actual es la que forma y da vida a las nuevas historias en las industrias infantiles, en donde las diferentes producciones de Disney forman parte importante del mercado del entretenimiento ${ }^{2}$. Estas muestran diferentes tópicos en contraste a décadas pasadas, pues las sociedades cambian y con ellas, lo que se busca representar en los medios y sus personajes (England, Descartes, Coller-Meek, 2011)

Los nuevos conceptos, modelos y prioridades que maneja Disney son diferentes hoy en día. De una Bella Durmiente que despierta con el beso de su verdadero amor y se casan al día siguiente, pasamos a una Mérida $^{3}$ que se niega a casarse a la fuerza y quiere

\footnotetext{
${ }^{1}$ En enero del 2016, Mattel anunció una nueva colección de Barbie en la que se incluían versiones "tall”, "curvy" y "petite" de la muñeca, además de incluir diferentes tonos de piel y ojos. El impacto fue tal que Time le dedicó una portada (Dockterman, E., 29 de enero del 2017).

${ }^{2}$ Disney es la productora cinematográfica más rentable de Hollywood (Forbes, 2015). Además, se encuentra en el puesto siete como la marca más valiosa del mundo y la primera en el rubro de entretenimiento (Badenhausen, 2017).

${ }^{3}$ Mérida es la protagonista de Brave (Valiente), película animada producida por Walt Disney Pictures y Pixar Animation Studios en el 2012.
} 
solo dedicarse a su verdadera pasión: la arquería. O una $\mathrm{Elsa}^{4}$ que le prohíbe tajantemente a su hermana casarse con un hombre que acaba de conocer.

Pero, ¿cómo son realmente percibidos los mensajes de Disney por los niños y niñas? ¿Qué aprenden con sus personajes y sus aventuras? ¿Realmente terminan asimilando lo que ven y recreándolo en sus vidas?

"La segunda exportación más grande de Estados Unidos es el entretenimiento, inmediatamente después de la industria espacial" (Gitlin, 2001, p. 12). Dentro de estas grandes representaciones industriales, llenas de íconos occidentales, se distribuyen "algunos sueños compartidos de libertad, riqueza, comodidad, inocencia y poder" (Gitlin, 2001, p. 12). Aquí, se encuentra uno de los ejemplos más claros de la imponencia de una industria del entretenimiento: Disney.

En la presente investigación se busca conocer cuál es la percepción de los niños y niñas frente a un cambio de paradigma en las nuevas princesas. Con este objetivo, tomaremos en la presente investigación ocho películas protagonizadas por princesas de Disney, con técnicas de diseño y animación 2D y de género musical.

\subsection{Justificación}

En la presente investigación se parte del cambio de paradigma en relación a los roles de género mostrado y retratado por las princesas de Disney en sus respectivas películas. Es en este contexto, resulta interesante explorar, dado el alcance que posee Disney como empresa, la relación que se genera con los niños como espectadores y cómo consideran ellos estos cambios de narrativa y paradigma mostrados en las películas de princesas. Siguiendo a Hernández Sampieri, Fernández Collado y Baptista Lucio (2010), nos encontramos con tres implicancias:

- Implicancia social: La formación de las identidades y valores de los niños del ahora es importante para el futuro de nuestra sociedad, en donde la educación es vital. De encontrarse que, efectivamente, los niños entienden las nuevas propuestas de Disney relacionadas al género y que pueden terminar adoptando estas nuevas conductas postuladas, podrían empezarse la formación de niños y

\footnotetext{
${ }^{4}$ Elsa y su hermana Ana son las protagonistas de Frozen, película animada producida por Walt Disney Pictures y Pixar Animation Studios en el 2013.
} 
niñas más seguros de sí mismos, independientes, fuertes emocionalmente, con empatía y otras características retratadas en las películas.

- Implicancia práctica: Analizar a los personajes de Disney y sus narrativas es importante debido a que estas son herramientas accesibles para padres y maestros. Las películas pueden utilizarse como herramientas disponibles para tocar temas como empoderamiento y agencia de los niños.

- Implicancia metodológica: Se está creando un instrumento para evaluar las características mostradas por los personajes de producciones audiovisuales relacionadas a los roles de género. En este caso, las princesas de Disney.

\subsection{Pregunta de investigación}

¿Cuál es la percepción sobre las nuevas princesas de Disney respecto a los roles de género en niños y niñas de 6 a 11 años de San Juan de Lurigancho y Jesús María/Pueblo Libre?

\subsection{Objetivos}

\subsubsection{Objetivo general}

Describir la percepción de los niños y niñas de 6 a 11 años acerca de las nuevas princesas Disney respecto a los roles de género.

\subsubsection{Objetivos específicos}

- Identificar las características hacia las películas de Disney relacionadas a la formación de roles de género.

- Contrastar las interpretaciones y opiniones de los niños y las niñas frente a las nuevas princesas de Disney.

- Describir las costumbres y hábitos de niños y niñas de 6 a 11 años relacionados a las nuevas princesas de Disney. 


\subsection{Limitaciones del estudio}

Una de las principales limitaciones que se encontró es que se trabaja con niños en un momento preciso del tiempo. Ellos están expuestos a constantes y diferentes estímulos (producciones audiovisuales, colegio y amistades). Esto hace que sus respuestas no sean necesariamente elaboradas. Además, existe la posibilidad de que hayan respondido lo que ellos creían que el investigador quería escuchar.

Otra limitación es el tiempo que se utilizó para la realización de la investigación. Debido a que se debe realizar en un periodo corto (seis meses), no se pudo realizar un seguimiento especializado a cada niño. De la misma manera, no se pudo ahondar en los gustos de los chicos y chicas hacia las princesas o ver si había cambios en sus respuestas con el paso del tiempo.

Se aplicaron consentimientos informados para que los padres autoricen y aprueben su participación y la de sus hijos en donde se brindaba detalles de la presente investigación y los datos de contacto de la tesista. Además, se requirió consentimiento verbal por parte de los niños y las niñas participantes. Estas acciones permitirán tener limitaciones futuras. 


\section{CAPÍTULO II: MARCO TEÓRICO}

\subsection{Los primeros años de Disney}

Si bien Walt Disney no fue el primero en realizar dibujos animados ni tampoco necesariamente el mejor, sí incluyó un componente diferencial por primera vez en sus producciones: los efectos sonoros, música y voz a los personajes. También fue el primero en brindar otra novedad a la industria: el tecnicolor (Gitlin, 2001).

Hoy, Disney es un espacio de seguridad, bienestar, una "utopía universal" (Gitlin, 2001), representada y sentida ya sea en sus parques temáticos, dibujos, series, películas. Los consumidores sienten que estos personajes les pertenecen y se tiene ese sentimiento de familiaridad y de hogar personal, sin importar donde ellos se encuentren.

Es importante además recordar que Disney ha sido una de las pioneras en el uso de múltiples plataformas que complementan sus productos clásicamente audiovisuales: los parques temáticos, los juguetes, la ropa, la comida, las secuelas, las redes sociales... La lista podría seguir. Dentro de estas producciones, se encuentran las Princesas de Disney, una marca que incluye a todas las princesas de la casa del ratón. Estas ejercen cierta dominancia en los gustos de los consumidores y la mente de los padres, para bien o para mal, con disfraces, muñecas, etc. (Powers, 2014).

\subsection{La evolución de los personajes animados femeninos de Disney}

El primer largometraje de Walt Disney fue el de Blancanieves y los siete enanitos en 1937. Disney depositó sus esperanzas, sueños y todo su dinero en este proyecto, en el que obtuvo gran éxito en la taquilla y en las críticas (alcanzó un Oscar honorífico, López y De Miguel, 2013). Sin embargo, desde ese año al presente, la sociedad ha ido mutando $\mathrm{y}$, con ella, las producciones de entretenimiento, Disney incluida.

Siguiendo el estudio realizado por López y De Miguel (2013), en donde analizan una película por era en la línea de tiempo de Disney, tenemos un primer personaje que sigue la estructura de cine clásica (la dicotomía de la mujer fatal vs. la sumisa, que en este caso son la Madrastra y Blancanieves de 1937). Luego está Wendy y Campanita, de 
Peter Pan de 1953, en donde se puede observar que la misma fórmula dicotómica se repite: Wendy se convierte literalmente en la mamá de los niños perdidos y establece como normales estas funciones en ella porque es la mujer del grupo, mientras que el personaje de Campanita se maneja dentro de una ambigüedad muy confusa que no se aclara hasta el final, cuando se convierte en heroína de manera circunstancial; su sacrificio le permite la redención.

Sin embargo, ya se pueden observar cambios a partir de La bella y la bestia de 1991, nada más teniendo en cuenta que solo hay una protagonista femenina y no un enfrentamiento de personajes. Por otro lado, para López y De Miguel (2013), Dory es un personaje completamente diferente a los anteriores desarrollados por Disney: es una mujer posmoderna "urbana e independiente a la vez que complaciente, similar a la mujer real actual" (p. 139).

Estos autores sustentan esta trayectoria narrativa, donde observan estos cambios: mientras que Blancanieves solo se dedica a los cuidados del hogar de los enanitos; Wendy, además de los cuidados del hogar y los niños, practica la lectura. Bella se ocupa de su padre, es apasionada por la lectura y tiene interés por la ciencia. Para cerrar en esta evolución, vemos a Dory que, como pez, sabe leer y conoce diferentes idiomas.

Además, las grandes motivaciones de sus personajes también cambian. A Blancanieves lo que la mueve es encontrar a su príncipe y nada más. En cambio, Dory, quiere pertenecer a un lugar, a alguien, pero no románticamente, sino como una familia con Marlin y Nemo. (Lopez y de Miguel, 2013)

\subsection{Antecedentes o estado del arte}

Diferentes posturas se han sostenido sobre Disney, las narrativas que difunden, su naturaleza como industria y el poder que tienen por sobre las masas. Este poder es efectivamente innegable, su capacidad industrial le permite llegar a cada rincón alejado con sus nuevas producciones. También mucho se ha teorizado sobre los distintos mensajes o posturas que puede tener, por ejemplo, personajes o narrativas de Disney capitalistas e imperialistas en Para leer al Pato Donald (Dorfman y Matellart, 1972). Aquí, los autores sostienen que Tío Rico McPato es el clásico ejemplo de la avaricia y la explotación. Los autores consideraban que sus propias interpretaciones eran obvias y 
totalmente claras para el consumidor y defendían el estilo de vida contrario al que acusaban: el socialismo.

Sin embargo, como sostiene Gitlin (2001), el imperialismo de los Estados Unidos es la respuesta fácil (y engañosa) a la pregunta de cómo Disney adquirió su omnipresencia y poder. El autor termina la idea con que no se imponen imágenes a una población que no está dispuesta a verlas, mucho menos se obliga o secuestran ojos y oídos.

Avanzando un poco más en la historia, Disney empezó a cobrar fuerzas con sus películas musicales, en donde los personajes de las princesas representan aproximadamente la tercera parte de los protagonistas de la productora. Las princesas de Disney han sido blanco constante de las críticas hacia la desigualdad de género y su perpetuación de los estereotipos en las líneas narrativas propuestas. Ramos Jiménez (2006) comenta que: "En la propuesta llena de colores, música y mucha diversión se encuentran personajes milimétricamente concebidos para conseguir la empatía de nuestra infancia, seres animados que enseñan los valores más esenciales de la vida" (p. 23). El autor conoce que muchos especialistas del tema consideran y sostienen que Disney reproduce estereotipos de género y que estos pueden resultar adversos en la formación de los niños.

Gagó (2002) explica que cada sociedad tiene una concepción propia de género que va de acuerdo con los lineamientos sociales, políticos y económicos de la época y que responde a las necesidades específicas de estas mismas. Sostiene, además, que es esta concepción de género particular la que va formando la identidad debido a que es una construcción en constante cambio. Cada integrante de cada sociedad irá observando, se irá identificando con las producciones culturales y las audiovisuales que más se asemejen a ellos.

Aunque el autor reconoce tímidos intentos de un protagonismo equiparable entre hombres y mujeres (Indiana Jones, Matrix, El silencio de los inocentes), factores como el tiempo de pantalla de los personajes femeninos o el desarrollo de estos personajes, son reducidos y lentos. Este es el conservadurismo en el que la mujer cumple un rol que se encuentra entre los extremos de las dicotomías de "mujer natural (virgen, esposa, madre) y mujer artificial (amante, estéril)" (Gagó, 2002, p. 124). 
Una representación femenina equivocada, o la falta de esta, desfavorecen a las mujeres de la vida real. Sin embargo, y es donde queremos ahondar, la productora que ha hecho más avances en mostrar a mujeres como personajes reales con más de una personalidad o desarrollo es, efectivamente, Disney, con sus "tendencias de tradición y renovación" (Gagó 2002, p. 125)

Bella fue la mujer guapa e inteligente que sabe que la auténtica belleza es interior; (...) Pocahontas, sabia, virtuosa, valiente y políticamente correcta, se distinguió porque, aunque amaba a su príncipe, por primera vez, no lo sigue (sacrificio de amor): él se va y ella se queda. (...) Pero es Mulan la heroína disneyana más adulta, hasta el momento: encarna la superación personal y la lucha emocional en un mundo patriarcal y, dentro de él, en la institución machista por excelencia: el ejército. (p. 125)

Ramos Jimenez (2009) realiza un estudio en España sobre si los mensajes emitidos por Disney serían percibidos por niñas y niños de manera coherente o no con los mensajes coeducativos. Para él, la respuesta es “evidentemente negativa” (p. 31), pues las protagonistas femeninas están "encorsetadas en unos férreos estereotipos que poco han evolucionado desde 1937" (p. 24) y los niños reciben el mensaje de que "el hombre (o el macho) es poderoso y fuerte porque la naturaleza lo dicta así. (...) Reciben además la represión emocional de los personajes masculinos" (p. 28). El autor analiza las características de todos los personajes representados en las películas de Disney, sus comportamientos y las respuestas de quienes los rodean. Es así que llega a la conclusión de que "Las niñas quieren ser princesas y los niños no." (p. 30)

Por otro lado, un estudio realizado a un grupo de niñas inmigrantes coreanas en Estados Unidos (Lee, 2008) analizó la percepción de un público no occidental de productos audiovisuales producidos en y para una sociedad occidental estadounidense. La autora sostiene que mucho se ha dicho sobre lo peligroso y perjudicial que puede ser para los niños y niñas el consumir las producciones de Disney, pero que realmente es muy poco lo que se sabe sobre lo que terminan captando o aprendiendo con estas. Lee (2008) realiza el análisis de un público inmigrante joven, que solo ha tenido referencias sobre el país al que van a pasar a vivir a través de estas películas infantiles. El poder de la cultura estadounidense tiene tal fuerza y hegemonía sobre otras culturas (por ejemplo, Pocahontas) que es imposible no estudiar el impacto que estas películas puedan tener. 
Las niñas escogidas tenían, en el momento de la investigación de Lee (2008), un rango de entre 5 a 8 años, hablan inglés y coreano y crecieron viendo las películas de Disney escogidas para el estudio: La sirenita, Aladdin, La bella y la bestia y Pocahontas.

Lee conversa con las niñas y tocan el tema de política y género, que surge cuando comentan la película Aladdin. Narim (6 años) y Hanna (8 años) intercambian ideas sobre por qué Jazmín no puede tener su propio matrimonio, sin obligaciones, a lo que Hannah le explica que hay "una regla" que establece que solo los hombres pueden ser alguien o hacer algo. Ambas discuten sobre como esto no es justo, pero Hannah argumenta que, aunque sabe que no lo es, esa es la regla. Es así que siguen debatiendo esta "regla" y, como no existen mujeres presidentes, concluyen que la razón por la que una mujer no puede decidir ni ejercer en política es porque "no sería justo. Si una mujer fuera presidente, tendría mucho que hacer. Tendría que tener bebés, criarlos y... cocinar también. ¡Sería demasiado para ellas!” (p. 16).

Acercándonos a Sudamérica, encontramos una investigación realizada en México acerca de qué entienden y rescatan las niñas mexicanas de las películas de las princesas de Disney (específicamente: valores, antivalores, estereotipos, entre otros) (Gonzales Alafita, Villauso y Rivera, 2012). El rango de edad que manejaron los investigadores fue de 4 a 9 años debido a que consideraron que eran las edades con mayor exposición a estas películas.

En esta investigación, los autores encontraron que cada princesa de Disney maneja una trama en su respectiva película. Las acciones que toman las princesas marcan un aprendizaje en las niñas mexicanas sobre "valores y antivalores", como la bondad: la mayoría de niñas afirmó que las princesas "tenían que ser buenas" (Gonzales Alafitas et al., 2012, p. 1515). Las protagonistas pueden llegar a influir en el proceso de socialización y/o la construcción de identidad, pues las niñas y niños reproducen lo que observan que son cualidades aceptadas por la sociedad. Es por esto que, según los autores, debe mostrarse mayor equidad de género en pantalla, romper estos esquemas marcados en las personalidades masculinas y femeninas (Gonzáles Alafita et al., 2012).

La metodología utilizada por Gonzales Alafita et al. (2012) en esta investigación fue cualitativa, con entrevistas a profundidad, con un grupo de veinticinco niñas de un sector económico medio-alto que asistían a clases de ballet. Las preguntas incluían temas como los juegos que preferían ellas y sus amigas. Cuando se les preguntó por sus 
princesas favoritas y por qué lo eran, las razones eran estéticas, sus vestidos, cabello y no la trama de la historia. Sin embargo, cuando la princesa tiene características resaltantes que las diferenciaban, como con la Sirenita, las razones de preferencia de las niñas son relacionadas a características resaltantes y más porque era diferente, tanto por el cabello pelirrojo (es la única princesa con este color de cabello) o por el hecho de que no es humana.

También se les preguntó si tenían juguetes o accesorios de princesas, dónde viven las princesas, cómo son las princesas, cómo se comportan y cómo deberían comportarse. Además, se les preguntó si las princesas realizaban los quehaceres del hogar y sobre qué hacían en sus tiempos libres y, finalmente, si estas tenían un príncipe, a lo que veintiuna respondieron que sí. Finalmente, concluyeron que el impacto que las películas de princesas de Disney tenían en su muestra existía principalmente en tres aspectos: en cómo se desenvuelven y socializan con sus pares; esto se une al segundo aspecto: los valores y antivalores mostrados en pantalla pasan a ser un "parámetro ideal" en sus vidas. Por últimos, se perpetúan estereotipos que son mostrados por los personajes de las películas, siendo estos de género, raciales, sociales, etc.

England, Descartes y Coller-Meek (2011) dividen nueve películas de princesas de Disney en tres grupos, basándose en sus fechas de estreno. Estos son "las películas previas, las películas del medio y las más recientes películas"5. Siguiendo esta clasificación, el primer grupo, conformado por Blancanieves, La bella durmiente y Cenicienta tienden más tener un papel pasivo, esperando al rescate por el hombre o a realizar las labores del hogar. Es así que estos autores encontraron que, treinta años después, las acciones que mostraban características como valentía o fuerza realizadas por las princesas de esa época como La sirenita, Pocahontas o Mulán seguían siendo menores a las realizadas por sus contrapartes masculinas.

Sin embargo, es importante mencionar que La princesa y el sapo, estrenada el 2009, formó parte de esta investigación. England et al. (2011) notan un incremento de fuerza e independencia por parte de las princesas, por lo que asumen que, con el paso de los años, nacerían nuevos personajes femeninos que reflejarían este avance de manera sostenida.

\section{4. "Soy Princesa siendo yo": la campaña.}

\footnotetext{
${ }^{5}$ The earlier movies, middle movies, and the most current film.
} 
En el 2016, Disney lanzó una campaña llamada "Dream big, princess" (Soy princesa siendo yo, en español), que, al comenzar, constaba de una serie de videos que van en los cortes comerciales del canal de cable de Disney, en horarios considerados estelares. Estos fueron también colgados en las diferentes plataformas digitales de Disney (página web, redes sociales, YouTube, etc.) y exhibidos en cada continente. Los videos muestran a niñas como protagonistas de sus propias actividades, mostrándolas como valientes, atrevidas, independientes, mientras se colocan paralelos de escenas de películas de princesas (Disney, 2016).

Este movimiento fue creciendo y tomando importancia dentro de Disney, donde se comenzaron a crear plataformas para que las propias niñas creen videos o fotos sobre sus sueños; la celebración de cada princesa por mes en los resorts de Disney y las temáticas que cada una tiene (bondad, amistad, valentía, etc.) hasta la creación de una cuenta en Instagram de las Princesas Disney, donde la descripción es el slogan de la campaña: por cada niña que sueña en grande, hay una princesa que le muestra que es posible (DisneyChannelLA, 2016)

Figura 2.1.

Capturas del video Dream big, princess - Be A Champion ${ }^{6}$
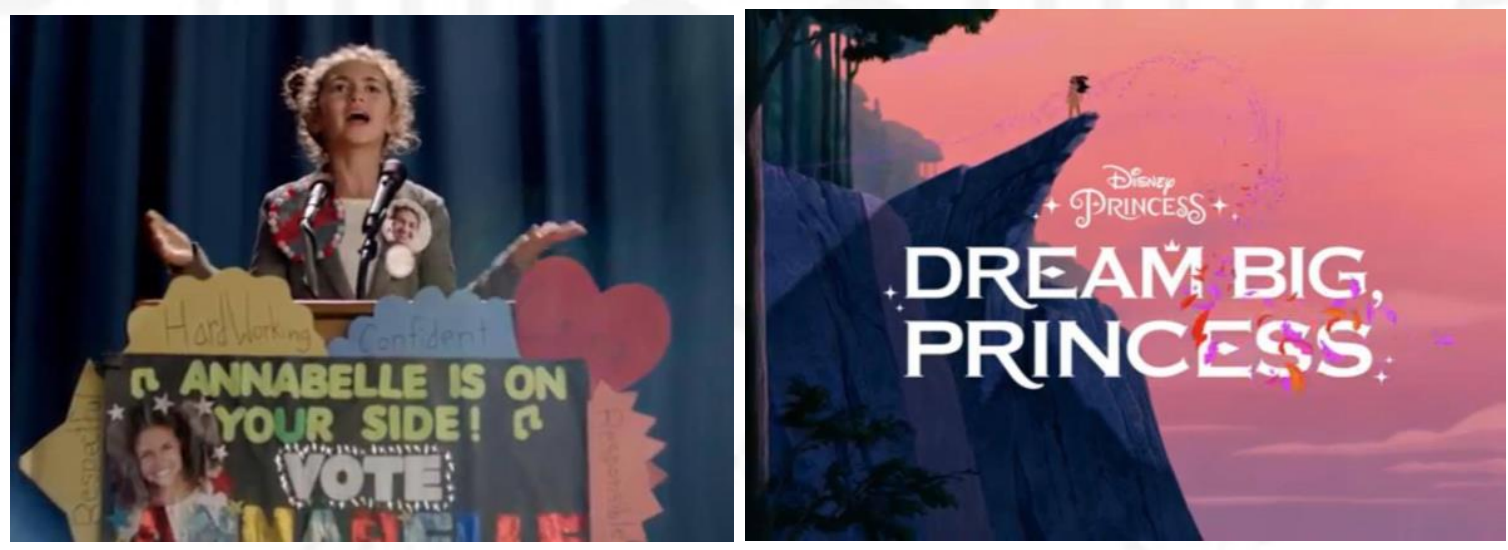

Fuente: YouTube (2016), Dream Big, Princess - Be A Champion | Disney

Figura 2.2.

Cuenta de Instagram oficial de The Disney Princesses

${ }^{6}$ https://www.youtube.com/watch?v=oYcGSeXiUI8 

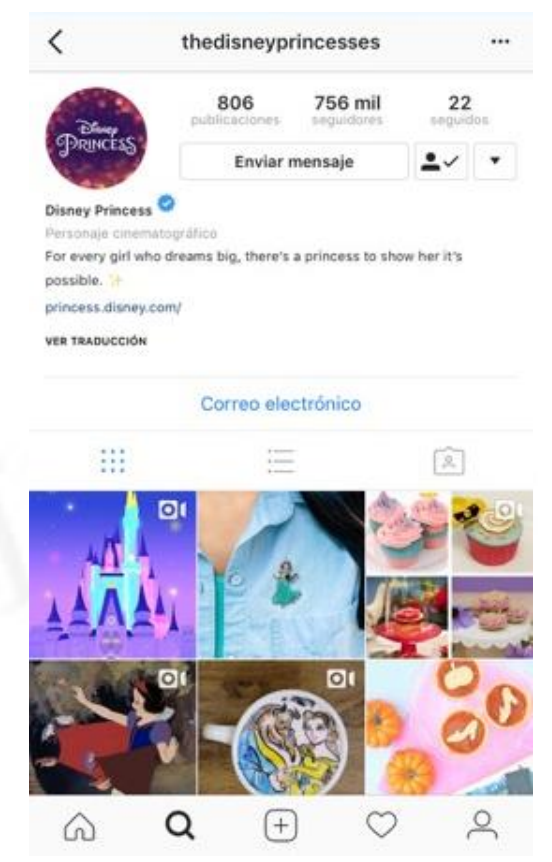

Fuente: Instagram @ thedisneyprincesses

Figura 2.3.

Capturas de las páginas webs de "Dream big, Princess" en el mundo

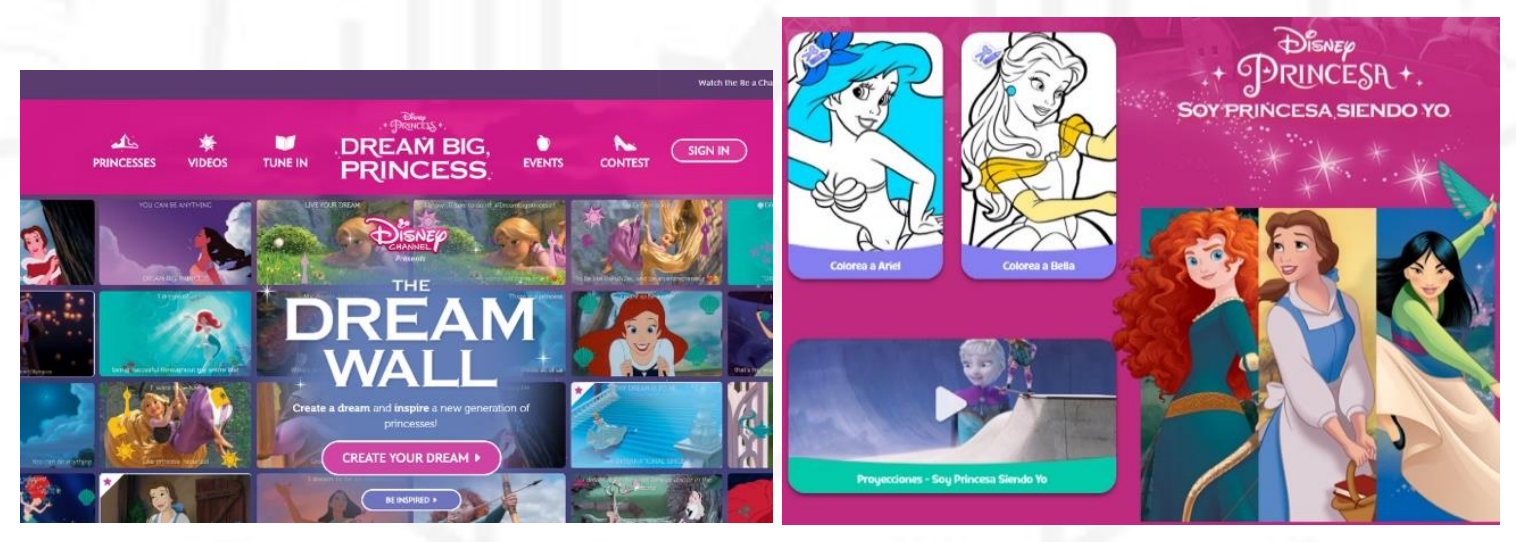

Fuente: www.dreambigprincess.asia y www.disneyjunior.disneylatino.com/princesas

Los videos comienzan con una voz en off que dice "por cada niña que sueña en grande, hay una princesa que le muestra que es posible" (Disney, 2016). El mensaje de la canción es que sean todo lo que pueden soñar: activistas, astronautas, bailarinas, científicas, porque pueden lograrlo.

La más reciente iniciativa del movimiento "Dream big, princess" es la Photography Campaign, en donde "Disney retó a un grupo de fotógrafas alrededor del mundo a crear fotografías impactantes de modelos a seguir en la vida real y ayudar a 
apoyar al programa de la fundación de las Naciones Unidas 'Girl Up"' (Disney, 15 de agosto del 2017). Esta campaña donará un dólar por cada foto compartida en redes sociales con el hashtag \#DreamBigPrincess a Girl Up, grupo de las Naciones Unidas que apoya las chicas adolescentes y su formación de liderazgo y empoderamiento.

Figura 2.4.

Foto de campaña fotográfica Dream Big Princess

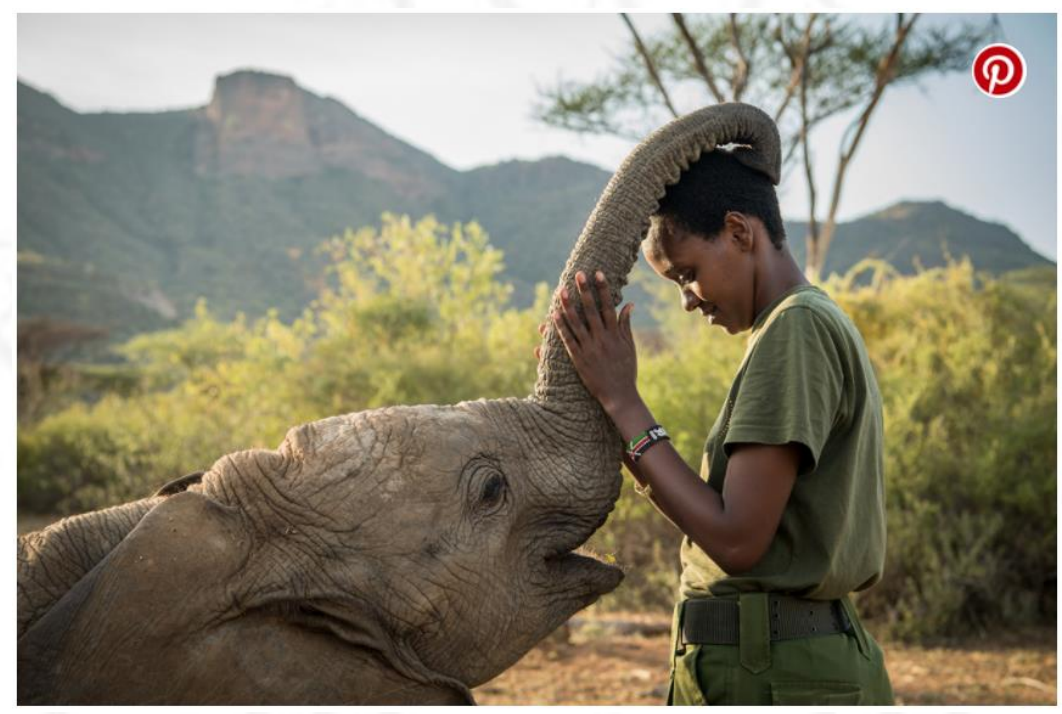

Nota: Mary trabaja en el Santuario de Elefantes Reteti en Kenia, ayudando a elefantes huérfanos a volver a su hábitat natural (traducción propia). Fotógrafa: Amy Vitale Fuente: Disney (2017)

Varios son los autores que sostienen que Disney y sus princesas perpetúan mensajes erróneos y estereotipos (Ramos Jiménez, 2009; England et al., 2011; Gagó, 2012; González Alafita et al., 2012). En la presente investigación no se busca contradecir a los autores citados, sino mostrar este cambio de paradigma. Los objetos de estudio son diferentes. Anteriormente se usaron princesas protagonistas que tenían roles pasivos. Con el paso de los años, Disney cambió sus narrativas y la manera en que están construidos sus personajes; ahora tienen roles activos (England et al., 2011).

Es así que se manejará la definición de "nuevas princesas de Disney", que parte como una manera de diferenciar a las nuevas generaciones de las películas clásicas. Estas etapas están separadas de manera cronológica y se pasa de era a era por diferentes motivos, tanto sucesos o quiebres internos en Disney (el crecimiento profesional de los jóvenes animadores, su paso a otras casas de animación, el envejecimiento de los que se quedaron) como externos (desde guerras hasta el papel y la importancia que fueron tomando Pixar y sus películas). Estas fueron definidas de manera no oficial y tomadas 
como herramientas para la clasificación y estudios de Disney. Sin embargo, en febrero del 2017, en una presentación exclusiva previa al D23 Expo ${ }^{7}$, Dave Smith $^{8}$ legitimó el uso de estas eras (con ciertas diferencias), lo que nos permite basarnos en ellas.

A continuación, se colocará la sección de la línea de tiempo que nos compete, que es a partir de 1995, contando solo películas de princesas.

Figura 2.5.

Línea de tiempo de películas de Disney
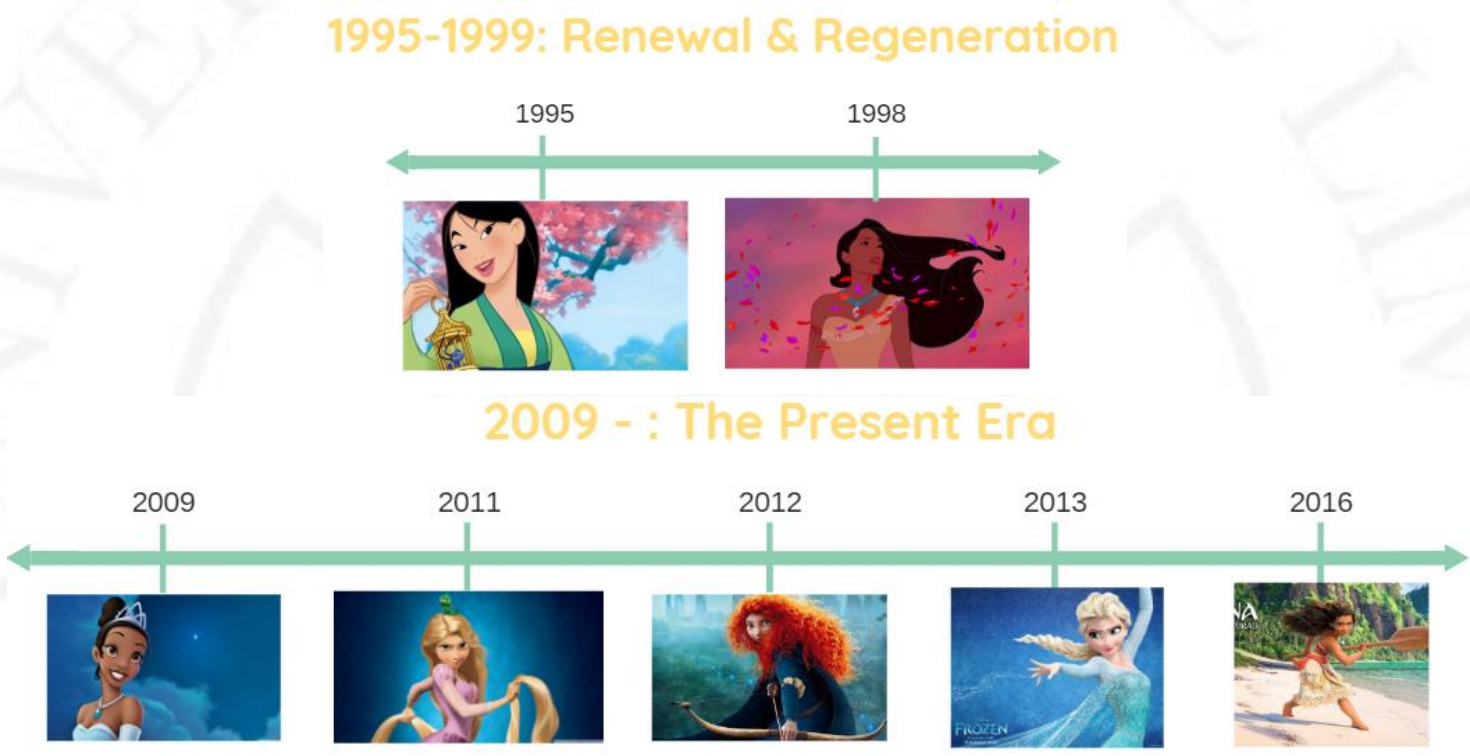

Fuente: Elaboración propia en base a @ disneysidekick (Instagram)

\section{5. "El poder de la gente es el poder de la marca"}

Ghio (2011) desarrolla el término oxitobrand como una nueva clasificación de "marcas humanas para un mercado emocional". Estas existen en sinergia con el vínculo afectivo que forman con su público consumidor y se sostienen diálogos en base a sus vivencias y valores compartidos. Esto genera confianza tanto en el consumidor como en la marca, lo que Ghio compara con una relación afectiva, que pasa por enamoramiento, diálogo, compromisos, etc.

\footnotetext{
${ }^{7}$ El D23 Expo es un evento organizado para los miembros oficiales fans de Disney, en donde se hacen presentaciones de las nuevas películas, series, etc. La siguiente será en Tokio, el 2019. (D23, s. f.) ${ }^{8}$ Dave Smith es el fundador y primer archivista de The Walt Disney Company. Fue la primera persona en ordenar y clasificar los objetos del Walt Disney, desde 1970 hasta el 2010. Tiene, además, el Disney Legends Award, otorgado a personas que han tenido una gran contribución a la compañía. Ha escrito múltiples libros recopilatorios de Disney, entre los que destaca Disney encyclopedia A to Z, que cuenta con cinco ediciones hasta la fecha. (D23, s. f.)
} 
Las oxitobrands son un postulado, dentro del branding emocional, que surge porque las marcas contemporáneas:

Se han visto en la necesidad de evolucionar en lo que refiere a su función identificadora inicial. La propuesta de una experiencia única en la que hoy se enmarcan es la consecuencia natural del proceso evolutivo de las mismas a lo largo del tiempo, incorporando nuevas estructuras vinculantes con sus públicos y estableciendo de este modo un lazo cada vez más duradero basado en atributos propios de la condición humana. (Ghio, 2011, p. 36)

Gestionar la marca utilizando el branding como estrategia es una tarea compleja que implica gestionar recursos tangibles e intangibles para construir o consolidar el posicionamiento. La meta es que esta sea el top of mind en la mente del consumidor, que sea deseable, adquirible y la preferida por el público. Si bien una buena estrategia de marca no asegura su éxito, una mala gestión de la marca sí puede traer consigo el fracaso (Ghio, 2011).

El autor menciona a Coca Cola como un ejemplo de marca que utiliza la expresión de valores humanos y positivos, y no atributos de producto: la alegría, lo bueno de la vida y compartirla con quienes amamos. Sus submarcas siguen este mismo lineamiento, pues Coca Cola Light invita a seguir una vida libre de prejuicios, despreocupada y más emocional (Ghio, 2011). De la misma forma, una marca peruana como Inca Kola se maneja en base al nivel de empatía que tiene con sus consumidores. Este vínculo se refuerza con cualidades como el amor, el orgullo peruano, la creatividad y la confianza (Ghio, 2011).

\subsection{Sobre la teoría narrativa: el paradigma de Syd Field}

Sobre la estructura narrativa en las producciones audiovisuales, se maneja el paradigma que postula Field desde 1995. Este ha ido evolucionando al brindar sus talleres de narrativa y guion, pues es "un modelo, un ejemplo, un esquema conceptual" (2005, p. 28). Está conformado por partes, que son: el planteamiento (primer acto, el inicio), la confrontación (segundo acto, el medio) y la resolución (tercer acto, el final).

Postula que los guiones tienen aproximadamente 30 minutos de planteamiento, 60 de minutos de confrontación y 30 de resolución (puede haber variaciones por minutos dependiendo de la duración de cada película). Estos están marcados por los plot points (o 
nudos en la trama): "un incidente, episodio o acontecimiento que se 'engancha' a la acción y le hace tomar otra dirección” (Field, 2005, p. 32).

Es así que cada acto funciona en base a los sucesos que van girando y llevando a cabo en la misma historia de la trama. El autor plantea un cuadro para entender visualmente el desarrollo de los actos y el paradigma dentro del desarrollo de las páginas.

Figura 2.6.

Paradigma de Field

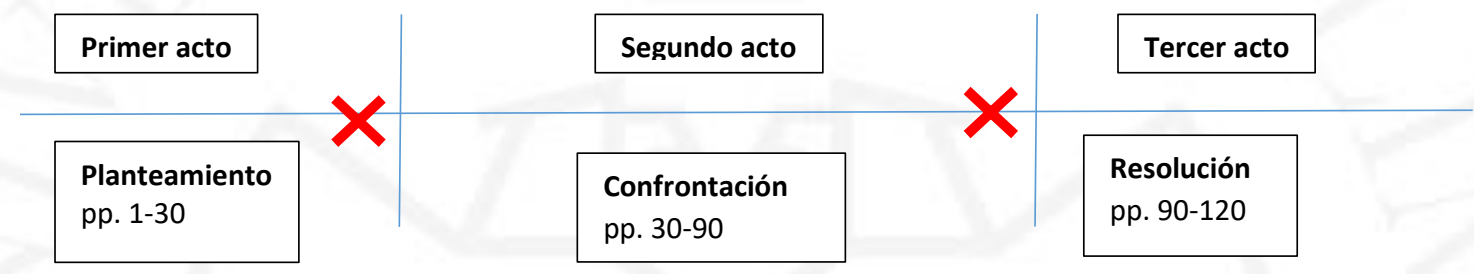

Primer nudo de

la trama

pp. $25-27$
Segundo nudo

de la trama

pp. $85-90$

Fuente: Elaboración propia en base a Field (2005, p. 29)

Donde las " $\mathrm{x}$ " representan los nudos (o plot points) en la trama. Estos "incidentes" marcan una situación y dan pase al cambio de un acto. Es así que se pasa al siguiente con una nueva meta trazada por este nudo. Esta es una estructura tradicional y si bien no es una norma obligatoria ${ }^{9}$ en la realización de guiones, es la más aceptada en la industria.

\subsection{La identidad de género: La teoría multifactorial de la identidad de género}

La identidad de género, en palabras de Papalia et al. (2012) es "la conciencia de la feminidad o masculinidad y sus implicaciones en la sociedad” (p. 256) Esta concepción es importante para el desarrollo del autoconcepto. Esta es formada por experiencias y

\footnotetext{
${ }^{9}$ La "narrativa clásica de Hollywood" es como se conoce a la narrativa específica que ha dominado el cine de ficción. Según Zepeda (2004), esta es "una predecible forma de expresión que se ha popularizado rápidamente y ha alcanzado a los espectadores de cine acostumbrándolos incluso inconscientemente a ver la vida de esta manera, con la linealidad y características de una película de Hollywood" (p. 54). Por otro lado, "existe un tipo de narrativa alternativa más experimental en la cual el autor no nos ofrece un relato como si se tratara de un cuento de hadas, sino que nos narra las historias de una manera no tan clara y formulada" (p. 55).
} 
expectativas que rodean a las personas y conforman los roles de género, la tipificación de género y los estereotipos de género.

Tabla 2.1.

La formación de la identidad de género

\begin{tabular}{cc}
\hline Roles de género & $\begin{array}{c}\text { "Conductas, intereses, actitudes, habilidades y } \\
\text { rasgos que una cultura considera apropiados para } \\
\text { cada sexo; son diferentes para hombres y mujeres" } \\
\text { (p. 257) }\end{array}$ \\
\hline Tipificación de género & $\begin{array}{c}\text { "Proceso de socialización por medio del cual los } \\
\text { niños aprenden a temprana edad los roles de } \\
\text { género apropiados" (p. 257) }\end{array}$ \\
\hline Estereotipos de género & "Generalizaciones preconcebidas acerca de la \\
conducta masculina o femenina" (p. 257)
\end{tabular}

Fuente: Realización propia con información de Papalia et al. (2012, p. 257)

Según Papalia et al. (2012), son varias las perspectivas que van formando la identidad de género de cada ser humano, como las experiencias. A esta se le suma además el rol de género, la tipificación y los estereotipos de género. Las psicólogas, por consiguiente, definen rol de género como:

las conductas, intereses, actitudes, habilidad y rasgos de personalidad que una cultura considera apropiados para los hombres o las mujeres. Todas las sociedades tienen roles de género. Desde una perspectiva histórica, en la mayoría de las culturas se esperaba que las mujeres dedicaran casi todo su tiempo al cuidado del hogar y de los niños, y que los hombres fueran activos, agresivos y competitivos. En la actualidad, los roles de género, sobre todo en las culturas occidentales, han alcanzado mayores grados de diversidad y flexibilidad. (p. 257)

Hay múltiples perspectivas teóricas y paradigmas que buscan dar una respuesta a la formación de la identidad de género (la perspectiva psicodinámica, la perspectiva del aprendizaje y el aprendizaje social, la perspectiva cognitiva, etc.). Sin embargo, una teoría ha sido más aceptada en las últimas décadas, la multifactorial de la identidad de género. Como postula Block (1973, citado por Rocha, 2009), hay seis etapas en un marco integrador, donde se ve la evolución de la identidad de género en la infancia hasta la formación de "una idea estructurada de un rol que encaja con el concepto de androginia psicológica propuesto por Bem (1974)" (Rocha, 2009, p. 255). 
Siguiendo los postulados de la teoría, hay características que se relacionan socialmente a un género. Es así que, en el 1981, Bem desarrolla la teoría del esquema de género, que sostiene que:

Las personas no solo difieren en términos de las características referidas a los aspectos deseables e indeseables en cada sexo (lo masculino y lo femenino), sino también en cuanto al tipo de estructuras cognoscitivas encargadas de codificar y procesar la información proveniente de la realidad de género (Rocha, 2009, p. 256).

Esto es que, mientras más tenga una persona las características asociadas socialmente a su género (de manera estereotipada), más rígidos serán sus esquemas mentales. De acuerdo a Bem, poseer rasgos y características más relacionadas a la androginia, “favorecería a una mayor salud mental” (Rocha, 2009, p. 256).

Entonces, Rocha (2009) resume la teoría multifactorial de la identidad de género diciendo que la identidad de género es "vista como un constructo factorial en tanto obedece a múltiples variables a través de los individuos y las culturas” (p. 256). Menciona además que hay procesos importantes en la formación de la identidad, como la socialización, la endoculturación (absorber información sin percatarse de ello, a través del lenguaje y otros símbolos), presión social, estereotipos de género y la edad.

\subsection{El aprendizaje cognoscitivo social}

Cloninger (2003) sintetiza la teoría de aprendizaje cognoscitivo social de Bandura a "los seres humanos aprenden observando" (p. 360). Esta teoría se centra en el postulado de que el aprendizaje de los seres humanos está relacionado directamente con el "medio social", lo que los rodea, el ambiente, las personas y lo que observan en el espacio en donde se encuentran. Es así que esto les permite reaccionar y actuar siguiendo lo aprendido, según lo que el sujeto considere como conveniente. A lo largo de los años, en el desarrollo de esta corriente, la imitación fue considerada con el primer paso para el aprendizaje cognoscitivo, partiendo siempre del mismo punto: la observación (Schunk, 2012)

Sin embargo, la imitación limita este desarrollo (Shunk, 2012, p. 104). La imitación se da a través de la compresión de las situaciones que atraviesan los niños, mas no contempla dentro de este proceso las incongruencias. Antes de imitar, deben conocer 
el tema a plenitud, entenderlo integralmente para poder actuar. La imitación es un proceso posterior, no puede ser previo a una situación desconocida.

Cuando se ofrece un estímulo a un sujeto, este no necesariamente responderá como se espera. Es por eso que se introducen otras condiciones que permiten llegar a la respuesta, a través de diferentes "variables sociales" (Bandura y Walters, 1990, p. 16). Estas variables sociales que permiten que el proceso de aprendizaje pueda desarrollarse son el aprendizaje de acto y aprendizaje vicario. El aprendizaje de acto responde a las acciones que el sujeto experimenta en su vida, de manera real. El aprendizaje vicario ocurre por medio de la observación (sea esta de primera mano, de manera simbólica o electrónica) del modelo que se reproduce. Este se da cuando, a través de observar ciertas conductas o personas, se puede llegar a producir nuevas respuestas. De la misma manera, por medio de la observación, se puede reforzar y producir nuevas respuestas o modificar las existentes (Bandura, 1965, citado por Cloninger, 2003, p. 360).

Además, el proceso aprendizaje resulta más eficaz si se presenta y utiliza un tipo de fenómenos que se valora mucho (o desprecia mucho) por el grupo del que lo recibe. (Bandura y Walters, 1990, p. 24). Es así que lo que hará que una persona realice una acción, dependerá de cómo esta interpreta un grupo de situaciones y cómo decide actuar en un futuro.

Es así que el aprendizaje por observación de Bandura pasa a ser un modelado en el desarrollo infantil. Si bien una gran parte del aprendizaje social se forma de manera intencionada o no a través de lo que rodea al sujeto, aspectos como los valores humanos o maneras de comportarse se aprenden por medio del modelado simbólico de los medios masivos dentro del contexto (Bandura, 2001b). Aprendiendo por observación y a través del modelado a través de los medios masivos de comunicación, se puede transmitir y conocer aspectos y nuevas maneras de pensar y actuar. De esta manera, se puede llegar, de manera masiva y con un gran alcance e impacto social (Bandura, 2001b).

El modelamiento por aprendizaje por observación ocurre en cuatro procesos: la atención, en donde el sujeto observa los hechos y acciones y los percibe de manera significativa, a pesar de las distracciones o diferentes acciones que puedan estar sucediendo alrededor o al mismo tiempo. El segundo proceso es el de retención, en donde el observador organiza la información que retuvo durante la atención para retenerla en su memoria (Schunk, 2012). En este proceso, el repaso es muy importante debido a que el observador revisa lo que retuvo a través de la atención. El tercer proceso es la producción, 
en donde se traslada lo organizado mentalmente a la práctica. Así como se consiguieron estos conocimientos a través de la observación, es a través de la práctica en la producción que se utiliza lo aprendido. A través del ensayo y error y retroalimentación se refuerza lo aprendido, se vuelve tangible y se perfecciona. (Bandura, 1977, citado por Schunk, 2012). El cuarto y último proceso es el de la motivación. Este consiste en que el observador logre querer y realizar los tres primeros procesos, por lo que debe haber estímulos dentro del hecho observado para que el sujeto ponga en práctica todo lo que aprende (Bandura, 2001b).

Si bien estos procesos explican el aprendizaje observacional y cómo este se produce, existen más factores que pueden influir dentro de las decisiones. Primero, antes de empezar los cuatro procesos del aprendizaje de observación, el sujeto observador debe sentirse identificado con lo que está viendo (Cloninger, 2003). La identificación debe darse a través de un modelo. Es así que, mientras más similares sean las personas a las que observa el sujeto, encontrará más motivación y autoeficacia (Burney, 2008).

Además, se necesita que el sujeto observador tenga agencia y autoeficacia. La perspectiva de la agencia consiste en lograr y hacer que cosas sucedan a través de las acciones y de manera intencional, deliberadamente, escogiendo, regulando y evaluando lo que estas acciones pueden traer como consecuencia (Bandura, 2001a). Si bien la agencia forma parte del aprendizaje cognoscitivo social, no es suficiente la simple exposición a un estímulo para aprender o lograr resultado. La agencia requiere la exploración y manipulación del entorno además de la selección de estímulos que el sujeto decida poner en acción (Burney, 2008).

Por último, la autoeficacia es la confianza propia que tiene el sujeto sobre su capacidad de organizar y realizar ciertas acciones que le permitan llevar a cabo una situación específica. Permite que el sujeto cuente con la motivación necesaria para realizar ciertas acciones o se atreva a tomar decisiones que permitirán que el proceso de aprendizaje social tome su camino tanto en la observación como en la puesta en práctica, tomando en cuenta todas las variables mencionadas (Burney, 2008).

\subsection{Nueva sociología de la infancia: enfoque construccionista}

La nueva sociología de la infancia parte de la idea de ver a niños como sujetos y no solo como potenciales adultos en formación. Cuando los niños son parte de un estudio, 
estos no son los sujetos de, sino que se investigan las instituciones encargadas del proceso socializador de los niños en vez de hablar sobre la niñez. Se busca lo que los rodea, en vez de ver a los niños, que se encuentran en el centro. Esta nueva perspectiva los reconoce como actores sociales (Corsaro, 2018).

Dentro de esta nueva corriente, resaltan tres enfoques de la nueva sociología de la infancia: estructural (la infancia como parte de la estructura social, Gaitán, 2006), construccionista (el niño como actor y no como ente pasivo, Corsaro, 2018) y relacional (generación como proceso y punto fundamental en la infancia, Gaitán, 2006).

El enfoque construccionista gira, como se mencionó, en torno a un rol activo en la infancia más que uno pasivo. El niño es un actor que está envuelto y se apropia de la información dentro del ambiente que lo rodea para poder organizar y construir, desde su propia perspectiva e interpretación, el mundo (Corsaro, 2018). Este enfoque está sustentado por Piaget con la teoría de desarrollo intelectual, que postula que los hechos o las habilidades adquiridas no son simplemente una acumulación, sino un proceso de desarrollo (Corsaro, 2018). De la misma manera, Vigotsky (citado por Corsaro, 2018) sostiene en la teoría sociocultural que se lidia con cambios a través y gracias a la interacción que tenemos con el mundo, de manera colectiva. Ambas posturas sostienen que el desarrollo infantil es resultado de las actividades que los niños realizan.

Si bien ambas teorías tienen puntos en común, también tienen diferencias. Mientras Piaget sostiene que el desarrollo de habilidades se forma a partir de estructuras y procesos cognitivos, Vigotsky da un paso más allá, sosteniendo que estas actividades y situaciones que atraviesan los niños los lleva a la apropiación, internalización y reproducción de estos (Corsaro, 2018).

Sobre la visión de los niños como actores sociales, Mayall (2002) sostiene, dentro de la misma corriente, que los niños tienen capacidad de agencia y, por lo tanto, deben ser considerados como en correspondencia dentro de la sociedad. Sin embargo, los términos agente y actor provienen de la misma raíz relacionada al actuar y al realizar, pero, según Mayall (2002), el significado de las acciones realizadas por el sujeto puede variar, pues un actor social tiene y reacciona a través de deseos relacionados a sus sentimientos de manera subjetiva, mientras que un agente demuestra mayor participación y deliberación a través del sujeto para poder tomar decisiones, a través de negociaciones e interacciones con el ambiente y las personas que lo rodean. 


\subsection{La evaluación de los roles sexuales: El inventario de los roles sexuales de Bem}

En 1972, Bem desarolló una lista de aproximadamente 400 características de las personalidades "masculinas" y "femeninas" deseadas por la sociedad estadounidense. Juntó a 100 estudiantes de la Universidad de Stanford a los que les indicó que:

nos gustaría que indique cuán deseable es en la sociedad estadounidense que un hombre o una mujer tenga cada una de estas características. Nota: No estamos interesados en su opinión personal sobre cuán deseables son estas características. En cambio, queremos su opinión en cómo nuestra sociedad evalúa cada una de estas en un hombre o una mujer. (citado en Auster y Ohm, 2000, p. 500; traducción propia)

Luego de la recopilación, se seleccionaron 20 características masculinas, femeninas y neutras. En el inventario, se le pide al usuario que puntúe en una escala del 1 al 7 (donde 1 es "nunca o casi nunca cierto" y 7 es "siempre o casi siempre cierto"). Esta es una autoevaluación en donde el usuario le otorga un número a las características para poder determinar la intensidad de presencia de estas en su persona.

Dependiendo de los resultados de la prueba, se puede determinar los niveles de masculinidad y femineidad, si es más uno que el otro, si tiene los dos de igual manera (andróginos) o los extremos de cada aspecto (hipermasculinidad o hiperfemineidad).

Desde entonces, el inventario ha sido utilizado para múltiples estudios y de diferentes maneras: desde contrastar los resultados, teniendo en cuenta el contexto o el lugar de procedencia (contrastando América del Norte con América del Sur) de los participantes que las responden. Auster y Ohm (2000, p. 502) comentan que, además, varios fueron los autores que buscaron la invalidación del inventario como herramienta, como "Ballard-Reisch y Elton (1992), Lara-Cantu y Suzan-Reed (1988), Schmitt y Millard (1988), Waters y Pincus (1977), pero con resultados y conclusiones inconsistentes".

\subsection{Los niños de 6 a 11 años}

El rango de edad en los niños es un aspecto muy importante a tener en cuenta debido a que cada año la niñez tiene sus propias características y cambios. Si bien es a 
partir del primer año de vida es que empiezan a haber diferencias conductuales en los niños, tanto como con la elección de juguetes o con quienes quieren jugar, a partir de los dos años es que empiezan a imitar acciones o tareas de "niños" o "niñas" a pesar de que no hay realmente una diferenciación entre sexos de manera motora o conductual (Papalia et al., 2012). Antes de los dos años los niños no tienen conciencia de la diferencia de sexo y género, pero es aquí cuando empiezan a notar que son diferentes entre ellos (Baron y Byrne, 2005; Papalia et al., 2012). No es hasta la pubertad en que aparecen diferencias entre niños y niñas, y estas son básicamente físicas y motrices.

A los tres, pueden distinguir además la realidad de la fantasía:

La capacidad de distinguir la fantasía de la realidad se desarrolla hacia los tres años, pero los niños de cuatro a seis años pueden imaginar que un personaje de fantasía es real (...) El pensamiento mágico tiende a declinar cerca del final del periodo preescolar. (como se cita en Papalia et al., 2012, p. 234).

Además, sobre la gramática y sintaxis, entre los cinco y los siete años, "el habla de los niños es más parecida al habla adulta. Sus oraciones son más largas y complicadas; usan más conjunciones, preposiciones y artículos; emplean oraciones compuestas y complejas y pueden manejar todas las partes del habla" (Papalia et al., 2012, p. 241). "La mayoría de los niños de cinco años pueden adaptar lo que dicen a lo que conoce quien escucha. (...) Casi la mitad de los niños de cinco años pueden ceñirse a un tema de conversación durante una docena de turnos si se sienten cómodos con el interlocutor y si conocen el tema y les interesa" (Papalia et al., 2012, p. 241).

A partir de 5 a 6 años empiezan realizar conexiones usando la lógica, el razonamiento y el porqué de ellas. Además, empiezan a tener nociones espaciales y conceptos de números y las matemáticas. Y, si bien no es hasta los ocho años en que hablan acerca de un concepto de autoestima, demuestran con sus conductas que la tienen (Papalia et al., 2012).

Todos estos cambios y procesos se dan en la niñez temprana, que va desde los 3 hasta los 6 años, en los que, resumiendo, según Papalia et al. (2012), se desarrolla "el autoconcepto, la identidad de género, aumenta la independencia, los juegos son más imaginativos y, por lo tanto, más sociales" (p. 8). 


\section{CAPÍTULO III: METODOLOGÍA}

\subsection{Tipo de investigación}

El diseño de la presente investigación sigue dos tipos de alcance: exploratorio y descriptivo. Según Hernandez Sampieri et al. (2010), el alcance exploratorio se realiza cuando el objeto de estudio ha sido poco o nada estudiado debido a su novedad. En nuestro caso, el cambio de paradigma de las princesas de Disney es reciente. Esto es demostrado también por la academia: si bien, existen investigaciones que tomen como objeto a las princesas de Disney (Lee, 2008; Ramos Jiménez, 2009; González Alafita, 2012; Whelan, 2012), hay escasez de trabajos relacionados a la formación de roles de género en niños y niñas frente a los nuevos perfiles narrativos que presenta Disney en los últimos años. Además, los resultados permitirán el posterior desarrollo que complemente y continúe con los objetivos propuestos en el presente trabajo, además de nuevas preguntas que puedan surgir del mismo.

También tiene alcance descriptivo debido a que se buscar conocer el perfil de los niños y niñas entre 6 a 11 años, consumidores de películas de princesas de Disney y las características relacionadas a los roles de género que estos presentan.

\subsection{Muestra}

La muestra utilizada es no probabilística y por oportunidad y conveniencia (Hernandez Sampieri et al, 2010). Se hizo la separación de dos grupos distritales: San Juan de Lurigancho y Jesús María/Pueblo Libre. Se entrevistó a 16 niños por grupo distrital, 32 en total. En San Juan de Lurigancho, se trabajó con 9 niñas y 7 niños, mientras que en Jesús María/Pueblo Libre, con 13 niñas y 4 niños. Se contactó a los padres y madres de un colegio en Jesús María a través de una madre de tercero de primaria y a los padres de un colegio en San Juan de Lurigancho a través de otra madre del mismo grado en el 2017. Sin embargo, para la participación del estudio se primó la disponibilidad de los niños, niñas y sus padres.

Se escogieron los distritos mencionados debido a la diferencia económica que existe entre estos. Siguiendo el Mapa de Pobreza realizado por el INEI (2013), el índice 
de pobreza de San Juan de Lurigancho linda entre 41,0\% hasta 13,5\% mientras que, en Jesús María, es de 1,5\%. Además, Jesús María y Pueblo Libre se encuentran en la lista de los distritos menos pobres del Perú: en los puestos 11 y 12 respectivamente, lo que marca la clara diferencia monetaria y, por consiguiente, oportunidades y consumo de sus habitantes.

Además de los colegios en los distritos escogidos, también se trabajó con vecinos del mismo colegio en SJL, estudiantes de un taller de marinera y de natación. En cuanto al grupo de JM/PL, se conversó, también con vecinos del colegio entre el límite de Pueblo Libre y Jesús María y a través de contacto y disponibilidad.

\subsection{Recolección de información}

Para la recolección de la información, se escogió trabajar con una ficha de observación para el visionado de las películas con princesas, una encuesta para padres y una entrevista cara a cara con los niños y niñas de 6 a 11 años de los grupos distritales.

Tabla 2.2.

Objetivos específicos y herramientas metodológicas

\begin{tabular}{lc}
\hline \multicolumn{1}{c}{ Objetivo específico } & Herramienta metodológica \\
\hline $\begin{array}{c}\text { Identificar las características hacia las películas de } \\
\text { Disney relacionadas a la formación de roles de género }\end{array}$ & $\begin{array}{c}\text { Guía de observación basada en el Inventario } \\
\text { de Bem }\end{array}$ \\
\hline $\begin{array}{c}\text { Contrastar las interpretaciones y opiniones de los niños } \\
\text { y las niñas frente a las nuevas princesas de Disney }\end{array}$ & Entrevistas a niños y niñas \\
\hline $\begin{array}{l}\text { Describir las costumbres y hábitos de niños y niñas de } 6 \\
\text { a 11 años con respecto a las nuevas princesas de Disney }\end{array}$ & Encuesta para padres \\
\hline Fuente: Elaboración propia &
\end{tabular}

\subsubsection{Guía de observación de las películas con princesas de 1995 al 2017 (Anexo 2)}

En base a la guía de observación se reconocieron los comportamientos y características de los personajes principales de cada película. La guía de observación cuenta con una lista de sesenta características. La ficha de observación fue desarrollada utilizando como base el Inventario de Roles Sexuales de Bem (IRSB) y el paradigma de Field y sus teorías de los actos, los cuales son llamados por el autor como el “Planteamiento, la Confrontación y la Resolución”. Además, se puso a prueba una primera versión de la guía de observación durante el visionado de otra película animada. 
Se utilizó como base del desarrollo de la guía a las características del inventario de Bem para la formulación de la guía de observación, donde se reconoció (a través de alguna acción o comportamiento de la princesa) la presencia de estas características masculinas, femeninas o neutras.

Dentro de la guía de observación, se utilizó la "M" como clasificación de características masculinas, "F" como femeninas y " $\varnothing$ " como neutras. Al final de cada acto terminado, se contabilizó cada característica observada para luego tener el panorama de cada película. Siguiendo el IRSB, los siguientes son algunos ejemplos de las características y los símbolos utilizados como parte del sistema de clasificación durante la observación.

Tabla 3.2.3.

Ejemplos de características del Inventario de Roles Sexuales de Bem

\begin{tabular}{ccc}
\hline Masculino - $\mathbf{M}$ & Femenino $-\mathbb{F}$ & Neutro $-\varnothing$ \\
\hline Autoritario & Tierno & Preocupado \\
Agresivo & Ingenuo & Celoso
\end{tabular}

Durante los tres actos se buscó marcar las características del inventario para clasificar las relacionadas al género y los roles de las princesas. Se realizaron tres guías de observación que corresponderán al primer, segundo, y tercer acto para plasmar la evolución o cambios del personaje en la historia.

Se observaron las películas Pocahontas (1995), Mulán (1998), La princesa y el sapo (2009), Enredados (2011), Valiente (2012), Frozen (2013) y Moana (2016). Se escogió hacer este análisis de las películas debido a que son la materia prima de la investigación. Este producto final, plasmado en la pantalla, es lo que los niños y niñas observan y dan juicio de valor. Además, se toma en cuenta el desarrollo narrativo de las películas para tener claros los cambios o evoluciones que las protagonistas experimentan dentro de sus arcos narrativos. Luego, se utilizaron estos resultados para contrastar con lo que los niños y niñas perciben.

\subsubsection{Entrevistas a niños y niñas (Anexos 3 y 4)}


La guía de preguntas para las entrevistas a niños y niñas fue realizada en base a la investigación de Gonzáles Alafita, Villasuso y Rivera (2012). Los autores realizaron entrevistas en profundidad con niñas de México. Además, la primera versión de la guía de preguntas pasó por una evaluación por parte del público objetivo, lo que permitió afinar el instrumento y se plantearon las preguntas necesarias para lograr cumplir los objetivos propuestos. Estas entrevistas a niños se realizaron para reconocer qué entienden de las películas, en donde los temas a tratar fueron:

- Preferencias por personajes y películas

- Opinión de los personajes con menor preferencia

- Opinión de las decisiones y comportamientos tomados por sus princesas/personajes preferidos y los menos preferidos.

- Costumbres, juguetes relacionados a Disney y a su tiempo libre

Se buscó conocer de primera mano y con las propias palabras de los niños y niñas, lo que ellos conocen, recogen, aprenden y si están o no de acuerdo con las princesas de Disney. Además, se les preguntó sobre sus pasatiempos, tipos de juegos y pertenencias para manejar un contexto en cada familia. Con respecto a las preferencias de las princesas, se les preguntó cuáles son sus favoritas y las menos favoritas. Esto nos permitió realizar un ranking en el que los primeros puestos recibieron más puntos (del 1 al 7): mientras más le gustó al entrevistado, más puntos recibió la princesa.

\subsubsection{Encuesta para los padres (Anexo 5)}

La encuesta para padres se realizó en base a los objetivos del trabajo, a modo de complementar lo que los niños y niñas respondían y para conocer datos más específicos de cada familia. Se evaluó la primera versión del instrumento con padres de una niña dentro del rango del estudio (6 a 11 años)

- Pertenencia de artículos (juguetes, ropa, DVD, etc.)

- Hábitos y periodicidad del visionado de películas

- Reconocimiento de comportamientos tomados a partir de películas (y su ejemplificación)

Esta encuesta se realizó para corroborar y tener con exactitud la información de pertenencias, pasatiempos y periodicidad del visionado de las películas. Además, se llevó 
a cabo para tener una perspectiva externa al niño, siendo el sujeto observador el padre o madre. 


\section{CAPÍTULO IV: RESULTADOS}

\subsection{Las características planteadas en las películas de las protagonistas}

\subsubsection{Las características en la narrativa de las princesas}

Se analizaron las películas de las princesas de Disney como parte de la investigación, en donde se buscó describir/identificar las características relacionadas al género establecidas por Bem. Esto debido a que se quería observar cómo estas iban evolucionando como respuesta a los conflictos narrativos. Dependiendo de la mayor cantidad de características encontradas, se colocó la M (masculino), F (femenino) o Ø (neutro). Es importante recordar que la clasificación de características proviene del Inventario de Roles Sexuales de Bem.

Tabla 3.1.

El proceso evolutivo de las princesas y sus características masculinas, femeninas y neutras en sus actos narrativos

\begin{tabular}{|c|c|c|c|}
\hline PRINCESAS & Planteamiento & Confrontación & Resolución \\
\hline Pocahontas & $\mathrm{F}$ & $\mathbf{M}-\mathbb{F}-\varnothing$ & $\mathbf{M}$ \\
\hline Mulán & $\mathbf{M}-\mathbb{F}-\varnothing$ & M & M \\
\hline Tiana & $\mathbf{M}$ & $\mathbf{M}$ & M \\
\hline Rapunzel & M & $\mathbf{F}$ & M \\
\hline Mérida & M & $\mathbf{M}-\mathbb{F}$ & $\mathbf{M}-\mathbb{F}$ \\
\hline Anna & $\mathbf{F}$ & $\mathbf{F}$ & $\mathbf{M}-\mathbb{F}$ \\
\hline Elsa & $\mathbf{M}-\varnothing$ & M & $\mathbf{M}-\mathbb{F}$ \\
\hline Moana & M & M & M \\
\hline TOTAL & $3 \mathrm{~F} ; 6 \mathrm{M} ; 2 \varnothing \rightarrow$ & $4 \mathbb{F} ; 6 \mathrm{M} ; 10 \rightarrow$ & $3 \mathrm{~F} ; 8 \mathrm{M} ; 0 \varnothing$ \\
\hline
\end{tabular}

Fuente: Elaboración propia

Son dos las princesas cuyas características no tienen cambios a lo largo de sus respectivas tramas: Tiana y Moana, quienes se mantienen con mayoría de características masculinas. Las otras seis princesas analizadas sí tuvieron evoluciones de sus primeros actos a sus terceros actos. Los clasificaremos en "M absoluto" (que terminan en el tercer acto con mayoría de características masculinas) y "M y F", las que terminan con la misma cantidad de características masculinas como femeninas. 
Pocahontas, Mulán y Raunzel tienen M absoluto en sus terceros actos. La primera muestra un cambio de tendencia en la narrativa, en donde empieza siendo F absoluta en el primer acto, misma cantidad entre M, F y $\varnothing$ en el segundo, y M absoluto en el tercero; mientras que Mulán empieza teniendo la misma cantidad entre M, F y $\varnothing$ y termina con M absoluto.

Mérida, Anna y Elsa terminan en el tercer acto con la misma cantidad de características masculinas y femeninas. Mérida pasa de un primer acto con predominancia de características masculinas, a un tercer acto con "M y F". Por otro lado, Anna y Elsa empiezan en los dos extremos cada una: la primera con predominancia femenina y la otra con la misma cantidad masculina y neutra. Sin embargo, las dos terminan encontrándose en el tercer acto con la misma cantidad de características masculinas y femeninas.

Tabla 3.2.

Características más presentes en las películas por acto

\begin{tabular}{|c|c|c|c|c|c|c|}
\hline & $\mathrm{M}$ & & $\mathrm{F}$ & & $\varnothing$ & \\
\hline I ACTO & $\begin{array}{c}\text { Deseosa de } \\
\text { tomar riesgos } \\
\text { Defiende sus } \\
\text { creencias }\end{array}$ & 5 & $\begin{array}{l}\text { Afectuosa } \\
\text { Alegre }\end{array}$ & 6 & Impredecible & 4 \\
\hline II ACTO & Independiente & 5 & $\begin{array}{c}\text { Leal } \\
\text { Sensible a las } \\
\text { necesidades de } \\
\text { los demás }\end{array}$ & 4 & Adaptable & 4 \\
\hline III ACTO & $\begin{array}{l}\text { Confiada en sí } \\
\text { misma }\end{array}$ & 8 & Afectuosa & 6 & Adaptable & 5 \\
\hline
\end{tabular}

Fuente: Elaboración propia

Dentro de las características masculinas que son puestas en práctica por las princesas durante sus películas, es que empiezan queriendo "tomar riesgos" y de “defender sus creencias" (cinco de ocho princesas mostraron estas características). En el mismo acto, 6 de las 8 princesas mostraron ser "afectuosas" y "alegres" como características femeninas, mientras que con las neutras, cuatro de ocho mostraron ser "impredecibles".

En el segundo acto, cinco de ocho princesas mostraron ser "independientes", cuatro fueron "leales" y "sensibles a las necesidades de los demás" y cuatro "adaptables". En el tercer acto se encontró mayor presencia de las características masculinas dentro de 
la ficha. Es así que ocho de las ocho princesas mostraron ser "confiadas en sí mismas", seis de ocho fueron "afectuosas" y cinco, "adaptables".

Recopilando las características de las princesas en base a la observación de sus películas y sus respectivos actos, se encuentra que hay coincidencias entre ellas. A continuación, se muestran a las tres princesas favoritas del grupo investigado:

Figura 3.1.

Características de las princesas de acuerdo al acto

\section{ACTO}

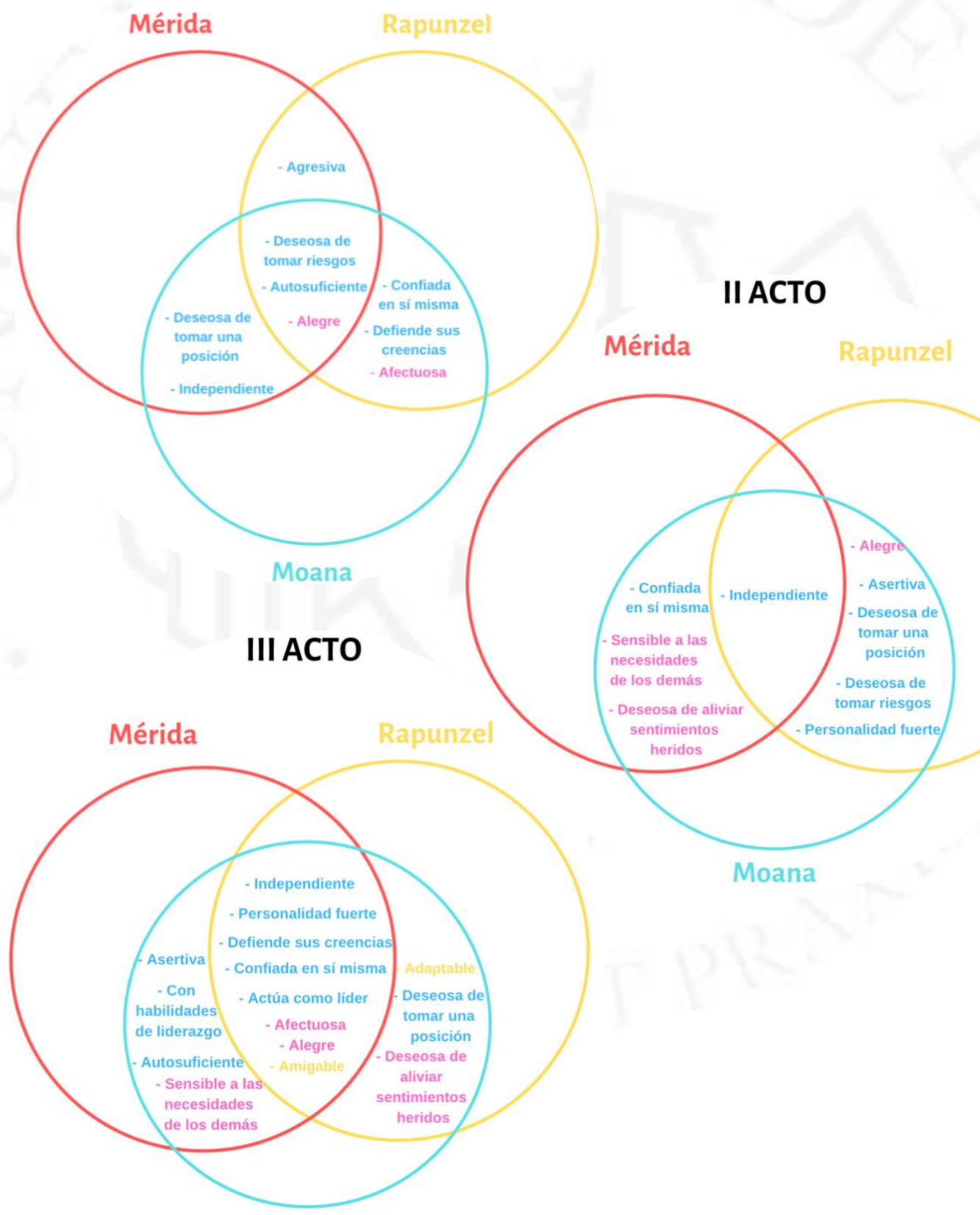

Moana

Fuente: Elaboración propia 


\subsection{Las interpretaciones y opiniones de los niños y las niñas}

\subsubsection{Sobre los hábitos de los niños}

El siguiente aspecto que tomamos en cuenta para conocer el contexto de los niños a entrevistar fue los hábitos en su tiempo libre y lo que les gusta hacer. Observamos que la mayoría de los niños, el 56\%, cuenta que su pasatiempo favorito es jugar.

\section{Figura 3.2.}

Los pasatiempos favoritos de los niños (total)

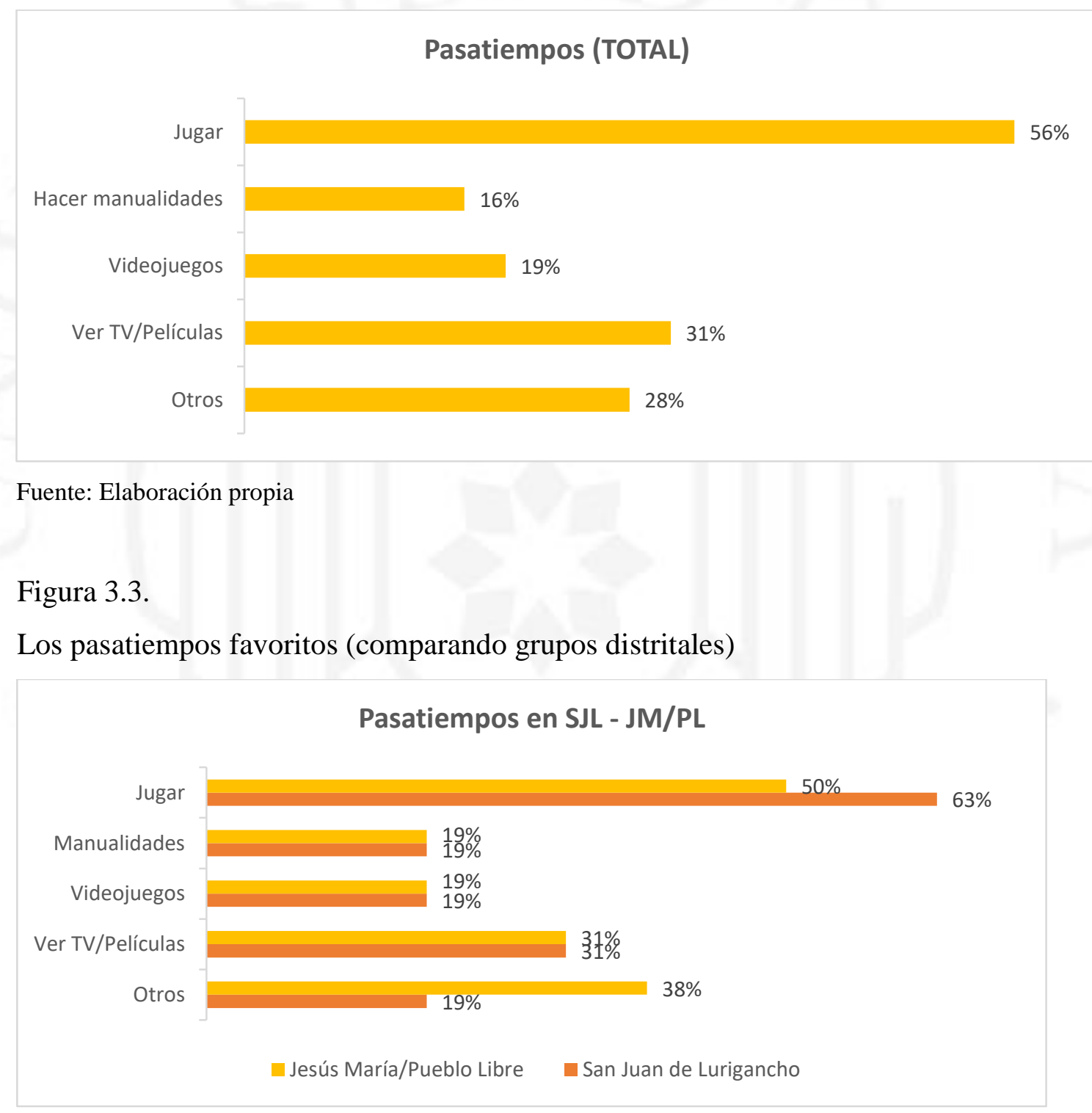

Fuente: Elaboración propia

Siguiendo esta línea, se les preguntó a qué les gusta jugar. Podemos observar que ahondan las diferencias de pasatiempos por distritos, de manera específica, el lugar de juego (los niños en SJL, al mencionar que juegan fuera de sus casas, hablan de "salir a la 
calle" y, en Jesús María y Pueblo Libre, se refieren a esto mismo como "salir al parque"). Otra diferencia marcada es la de jugar con juguetes, que en Jesús María y Pueblo Libre es la más común (el 44\% sostiene que juega con juguetes) y, por otro lado, en SJL, la mayoría sostiene que practican deportes o juegan juegos de exterior ("chapadas", “trompo"). Para terminar, hay una gran variedad de otros, pues estos ya responden a gustos específicos de cada uno ("me gusta leer", "investigo sobre animales venenosos" en Jesús María/Pueblo Libre y, por otro lado, "juego con mi hermano" "juego con mi mascota" en San Juan de Lurigancho).

Figura 3.4.

¿Cómo te gusta jugar? (comparación por grupos distritales)

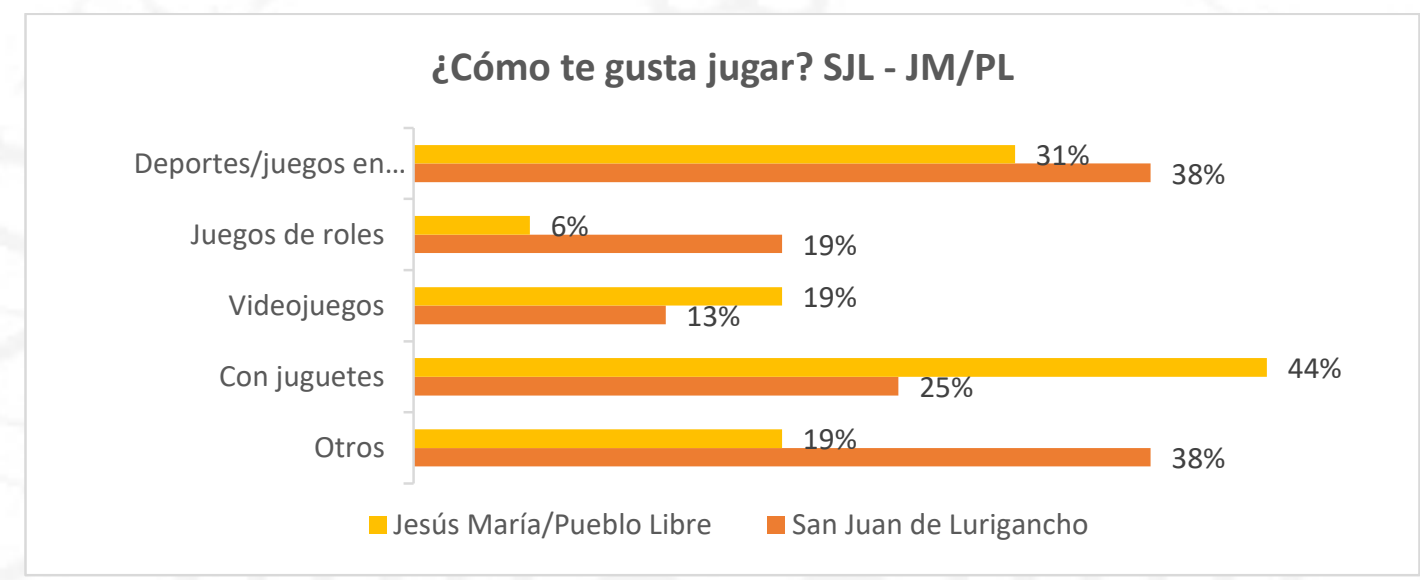

Fuente: Realización propia

El siguiente pasatiempo más común entre los niños de ambos distritos es ver televisión/películas. Por eso se les preguntó sobre sus preferencias; las respuestas variaron entre dibujos animados, series, mención de canales (tanto como nombre del canal como números "veo O11C", "Disney Chanell, Cartoon Network”, “el 408, 411”). También se observó una cantidad importante de contenido que consumen a través de YouTube, desde películas, youtubers y gameplays de videojuegos. 
Figura 3.5.

Preferencias de contenido en televisión (comparación en grupos distritales)

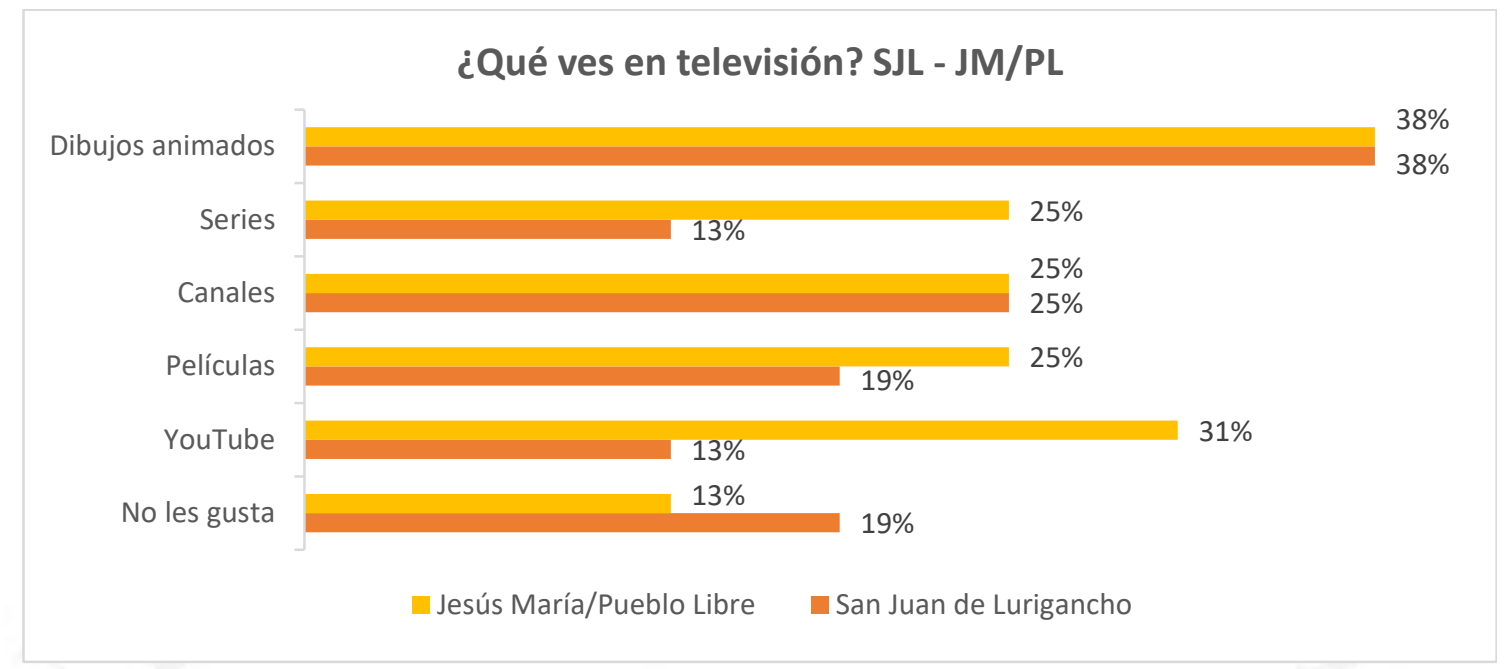

Fuente: Elaboración propia

\subsubsection{Menciones de personajes en las entrevistas}

Luego de tener un panorama más claro sobre los productos que nuestro público consume, pasamos a contar las veces en que mencionaban ciertos puntos que consideramos importantes para lograr esclarecer los objetivos propuestos. Estas menciones son respecto a aspectos que les gusta sobre sus películas favorita. Se agruparon en los siguientes ítems:

Figura 3.6.

Cantidad de menciones (relación en total)

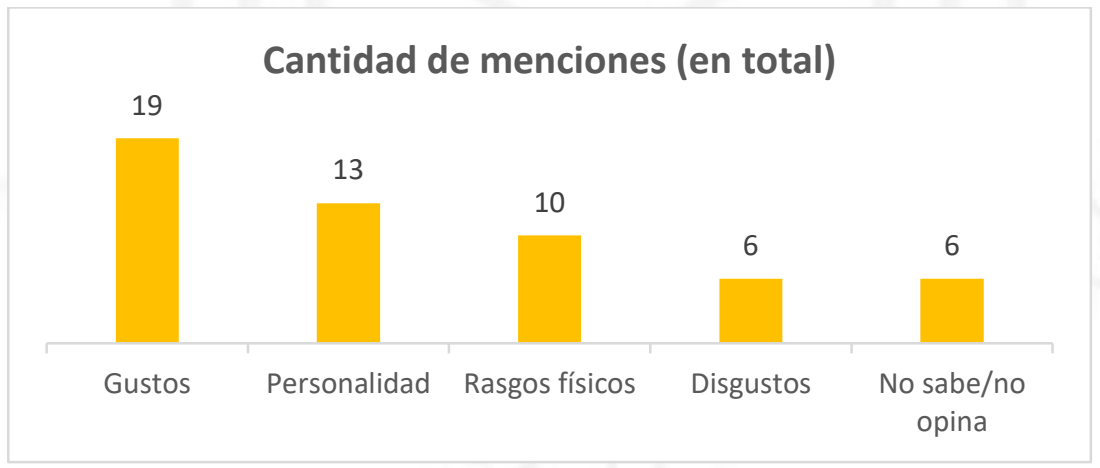

Fuente: Realización propia

Es importante tener en cuenta que estas menciones han sido contabilizadas a lo largo de toda la entrevista con cada niño y niña, sin distinguir entre preguntas. En primera 
instancia no detallaron una razón específica para describir sus gustos, solo mostraron su gusto.

La siguiente categoría, con mayor cantidad de menciones, es personalidad. Esto se debe a que se les pregunta sobre los gustos relacionados a las princesas de Disney. Explicaron qué aspectos de la personalidad de las princesas les gustaba y dieron ejemplos de dónde mostraban estas características.

(De Elsa) me gusta su personalidad, cómo es... Me gusta que tenga algo de magia ... por eso. (LA, 9 años, niña, SJL)

La tercera razón con mayor cantidad de menciones es con respecto a rasgos o aspectos físicos, como el cabello u otras características de sus personajes favoritos.

(Rapunzel es mi favorita) porque a mí de chiquita me gustaba tener el pelo largo; a mí me encantaba ser igualita a Rapunzel y yo he visto su película y es bonita. (YR, 11 años, niña, JM/PL)

La menor cantidad de menciones se da en la de disgustos, en donde comentaban cómo no les gustaba ciertos personajes y la razón de ello.

Star Wars ya no me gusta. A los 5 años lo dejé; hasta los 4 me gustó. (SR, 6 años, niño, SJL)

Para finalizar, hay que tener en cuenta que hubo seis entrevistados que no supieron explicar las razones de sus preferencias cuando se les preguntó de manera directa sobre la razón de este disgusto.

(Me gusta) el Hombre Araña. Uhmm, eso (...) porque... la araña... no sé. Es mi película favorita pero no tengo idea de por qué. (KC, 8 años, niño, SJL)

\subsubsection{Los niños varones y las princesas}

De los diez niños entrevistados, solo dos expresaron en primera instancia haber visto películas de princesas, pues las vieron con sus hermanas. Un tercer niño, sin embargo, aceptó, conforme la entrevista avanzó, reconocer a algunas princesas. Los primeros dos niños varones expresaron reconocer a las princesas y tener cierto conocimiento y gusto por ciertas características dentro de sus respectivas películas. 
Mi hermana me contó que había una samurái que después se volvió una guerrera samurái. (NI, 11 años, niño, SJL)

Más me gustó la de los enanitos. Uhmm (me gusta) los chiquititos esos. (OG, 9 años, niño, SJL)

Por otro lado, el tercer niño que luego aceptó reconocer algunas princesas, solo aceptó recordar algunos aspectos físicos de la princesa en cuestión, además de no aceptar haber visto la película en sí, sino que la reconoció por comerciales en la televisión.

Rapunzel será. ¿O princesa Sofía? La veo en las propagandas. (Rapunzel) tiene el pelo nomás (...). (VD, 9 años, SJL)

Es importante mencionar que la mamá de este niño mencionó que él sí ha visto algunas películas de princesas, acompañando a su hermana. Por otro lado, de los otros siete niños que no reconocían a las princesas, cinco tuvieron comentarios negativos hacia ellas. Algunas de las respuestas de los niños sobre qué piensan de estas películas y personajes están relacionadas a que estás estarían, para ellos, dirigidas a niñas y no a niños.

(No me gustan) porque son muy aniñadas. (TG, 8 años, niño, JM/PL)

(No me gustan) porque son para mujeres. (SB, 6 años, niño, SJL)

¡Ahh, no, eso no me gusta! Porque no me gusta, ;mala, mala, mala, mala! ${ }^{10}$ (...)

Porque son unas pequeñitas y son para niñas y yo no soy una niña. (SR, 6 años,

SJL)

Por otro lado, todas las niñas entrevistadas reconocieron a las princesas y tenían fuertes opiniones sobre sus preferencias y sus gustos. Es con sus percepciones y respuestas que se profundizaron las preguntas y se buscó tener más detalles al respecto.

\subsubsection{Las niñas y las princesas}

Se quiso analizar por qué es que tienen preferencia por una princesa (independientemente de cuál sea esta) y cuál es la razón por la que otra es la menos favorita. Se clasificaron estas razones y se llegó a los siguientes resultados ${ }^{11}$ :

\footnotetext{
${ }^{10}$ Un niño, mientras señalaba a todas las princesas gritaba.

${ }^{11} \mathrm{Al}$ preguntar aspectos más específicos de las princesas, solo las niñas respondieron. Solo 2 de los 10 niños entrevistados aceptaron haber visto películas de princesas de Disney, por lo que en la guía de
} 
Figura 3.7.

Las razones del favoritismo (total)

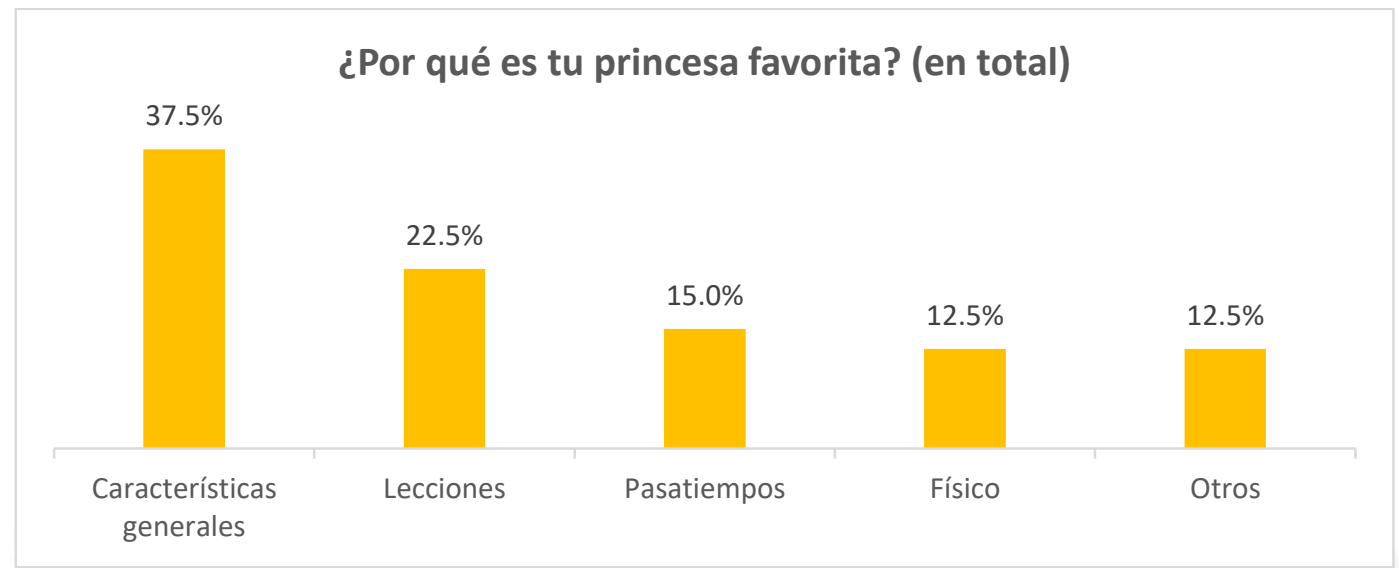

Fuente: Elaboración propia.

Las características generales son las más mencionadas a la hora de explicar sus gustos hacia sus princesas favoritas. Estas no son necesariamente la razón principal, pero es parte del porqué.

Creo que (Moana) es muy curiosa y viajera. (MC, 8 años, niña, SJL)

Me gusta (Elsa por) su personalidad, cómo es... -me gusta que tenga algo de magia, por eso. (LA, 9 años, niña, SJL)

También se mencionan las adversidades que atraviesan y que las niñas consideran que las han "inspirado". Estas menciones fueron colocadas en la categoría "lecciones"

(En Moana) me pareció muy lindo porque en el mar ya estaba cumpliendo sus sueños, estaba cumpliendo todo, estaba logrando todo ya para salvar su isla; ella no se rendía y me pareció muy bonito que no se rendía. (ZA, 9 años, niña, SJL)

(Mulan) me enseñó que todos tienen que ser tratados por igual, ya sea de donde vienen o por su sexo. (YL, 11 años, niña, SJL)

(Rapunzel) me enseña que puedo hacer cualquier tipo de cosas aunque te lo prohíba una persona y que tienes que ver el mundo del exterior que no solamente tienes que quedarte en un mismo lugar siempre. (AE, 8 años, niña, JM/PL)

entrevista se hizo una diferencia entre niños y niñas. Por esto, la cantidad de niños en estas preguntas baja: En SJL, de 16 a 9 niñas; y en JM/PL, de 16 a 13 niñas. 
(Mérida) me inspira para ser o cuando alguien me dice que no hagas o te prohíbo eso, ella aun así lo hace y eso me inspira a no ponerme ningún límite. (CD, 8 años, niña, JM/PL)

Otro punto son los pasatiempos y las actividades que las princesas realizan durante sus películas: si a ellas les gusta una acción y la princesa la realiza, la niña lo relaciona con sus propios gustos.

¡Ahhh!, porque ella (Moana) pasó una aventura en el agua, y como me gusta el agua, la vi. (LL, 8 años, niña, SJL)

Por último, el ítem con menores menciones dentro de las entrevistas es los aspectos físicos de las princesas.

(Rapunzel es mi favorita) porque me gusta su cabello largo. (MA, 8 años, niña, SJL)

Es importante mencionar que, con el mismo porcentaje de menciones sobre el físico de las princesas se encuentra "otros" (12.5\%). En esta categoría se encuentran respuestas variadas:

(Mérida es mi princesas favorita) porque hay como más animación y un poco más de ficción, en cambio que las otras son más despacitas (sic) y no parecen reales. (EV, 8 años, niñas, JM/PL)

Figura 3.8.

Razones del menor favoritismo (en total)

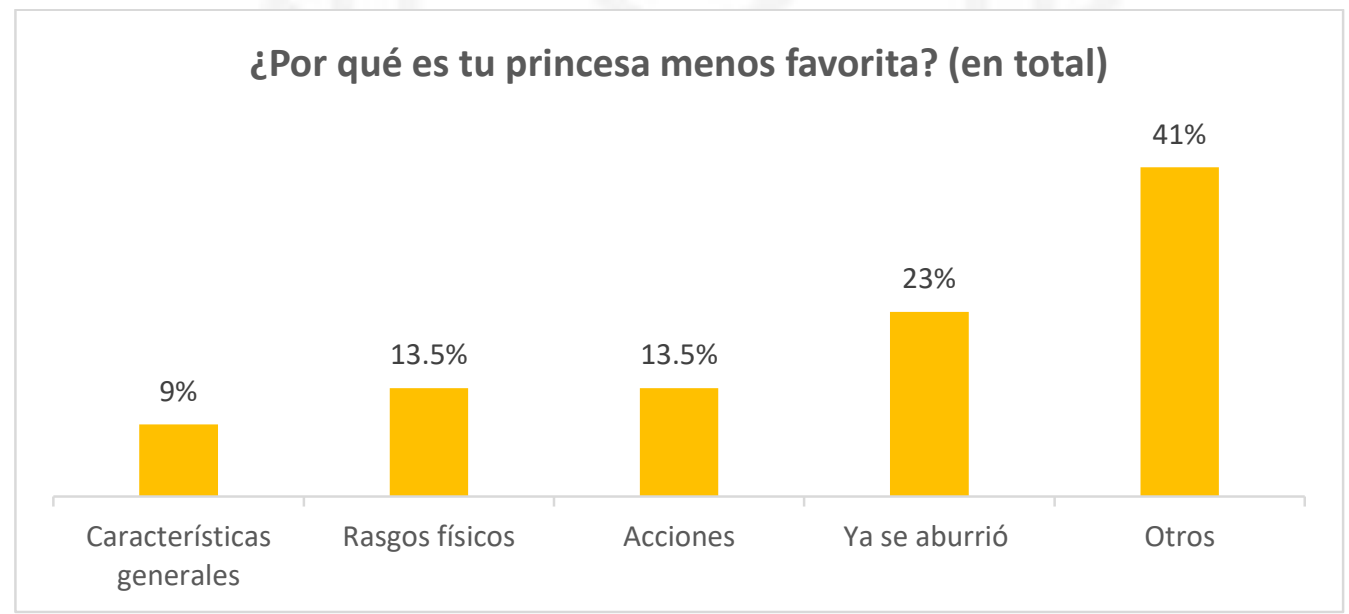

Fuente: Elaboración propia

En contraparte a los gustos, se preguntó también sobre las razones para que una princesa sea la menos favorita. La categoría con mayor cantidad de menciones durante 
las entrevistas fue "Otros". Cuenta con respuestas más personales de los niños, son variadas, por lo que no se pueden clasificar las respuestas.

(Pocahontas es mi princesa menos favorita) porque hay unas partes que no entiendo y no la he visto completa; por eso, no entiendo un poquito de la película. (MC, 8 años, niña, SJL)

(Tiana es mi princesa menos favorita) porque hay muchas cosas románticas. (YL, 11 años, niña, SJL)

(Anna es mi princesa menos favorita) porque no hace nada, solo se convierte en estatua de hielo. (EV, 8 años, niña, SJL)

(Tiana es mi princesa menos favorita) porque en verdad cuando era chiquita no me gustaba (...) y no me gustaba también (sic) el sapo. (YR, 11 años, niña, $\mathrm{JM} / \mathrm{PL})$

(Mérida es mi princesa menos favorita) porque no la he visto y dicen que su mamá se convierte en oso y no me gusta eso. (LG, 8 años, niña, JM/PL)

Otras de las categorías es la de "ya se aburrió". Esto se debe a que, como comentaron, han visto ciertas películas tantas veces que ya se cansaron de ella y ahora tienen nuevas princesas favoritas.

(Elsa es mi princesa favorita) porque esa película ya la he visto varias veces. (CL, 8 años, niña, JM/PL)

La siguiente categoría es sobre rasgos físicos. Mencionan que hay ciertos aspectos físicos de las princesas que no les gustan.

(Mulan es mi princesa menos favorita porque) prácticamente es cómo para... se viste de hombre para entrar a la guerra porque su papá está mal. Se ve bonito, sí, pero no me gustó la idea de que se cortó el cabello. (LL, 8 años, niña, SJL)

Por último, en las categorías de "características generales" se encuentran respuestas relacionadas a la historia o decisiones de la película con las que no están de acuerdo:

(Moana es mi princesa menos favorita) porque tiene el cabello ondulado, todo así, su cuerpo un poquito marroncito, trigueño y su palo también es mostaza. (DA, 7 años, niña, SJL) 
(Mulán es mi princesa menos favorita) porque se fue a la guerra y eso no me gusta. (TT, 9 años, niña, JM/PL)

\subsubsection{Percepciones de las historias de las princesas}

Continuando con los resultados, pasamos a las percepciones de las niñas entrevistadas sobre las historias de las princesas. En esta sección se busca mostrar las percepciones de las niñas durante el Planteamiento, Conflicto y Resolución de la película y mostrando la evolución de las princesas. Se seleccionaron cinco categorías, de las cuales cuatro fueron escogidas en base a sus mismas respuestas. Sin embargo, se incluyó también el ítem "príncipes" no por la cantidad de menciones, sino por cuestiones metodológicas.

Figura 3.9.

Menciones de las niñas por acto (en total en \%)

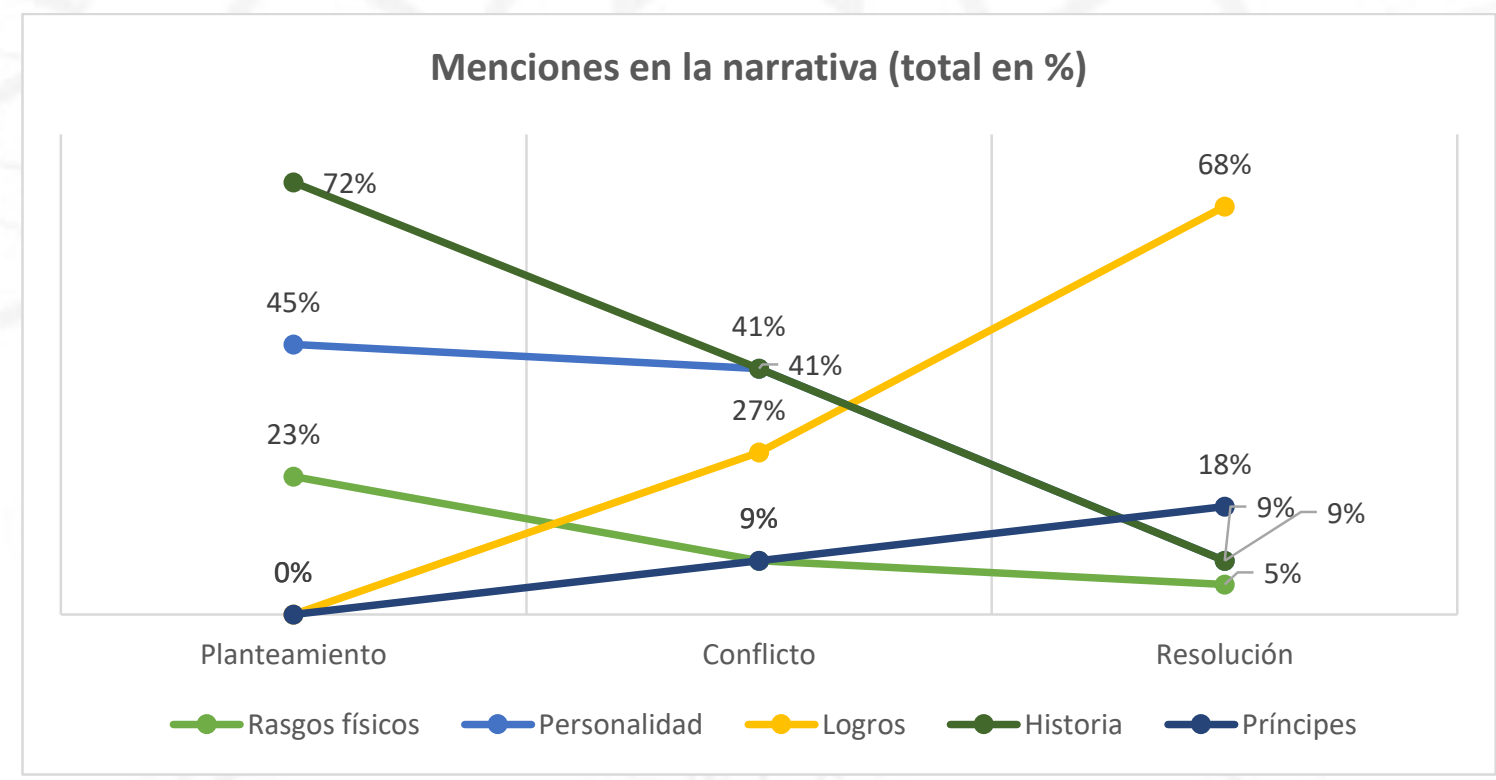

Fuente: Elaboración propia

De manera general, se puede observar que, en el Planteamiento, las respuestas más mencionadas estuvieron relacionadas con la historia en sí.

Al comienzo es cuando Elsa y Anna están jugando y Elsa le dispara y se le empieza a ablancar el cabello. Me da pena. (RG, 7 años, niña, SJL)

Es de una bruja que guarda una flor que cae del sol y a una princesa se embaraza y luego se enferma y todos buscan esa flor y la encuentran y le hacen una sopa 
de esa flor y la princesa se lo toma y nace de su hija que se llama Rapunzel. (MA, 8 años, niña, JM/PL)

El siguiente punto más mencionado fueron características de la personalidad o cualidades de cada princesa

Sí, es que ella es muy buena. (NL, 7 años, niña, JM/PL)

(Pocahontas) es valiente, como la película Valiente. (YL, 11 años, niña, SJL)

En el conflicto, los puntos más mencionados son los relacionados a la personalidad y a cómo se continúa desarrollando la historia. Dos puntos que no aparecen en el planteamiento empiezan a aparecer en el conflicto: los logros y la mención de "príncipes".

Cuando se les preguntó a los niños sobre el final de las historias y lo que pensaban de ellas, las respuestas relacionadas a los logros de los personajes, lo que las niñas como espectadoras aprendieron de las princesas y cómo esto es parte de lo que convierte a esas películas, sus favoritas. Por eso, la mención de logros se dispara en la resolución y deja atrás a los demás ítems.

Me pareció muy lindo porque ya estaba en el mar, ya estaba cumpliendo sus sueños, estaba logrado todo ya para salvar su isla. Ella no se rendía y me pareció muy bonito. (...) Sus padres estaban orgullosos de ella. (ZA, 9 años, niña, SJL)

Está bien porque ella (Elsa) no sabía cómo... que venga el verano, pero lo descongeló. (SR, 6 años, niña, SJL)

El segundo tema mencionado en las entrevistas en el segundo acto se relacionó a los príncipes y las bodas. Este punto no tuvo grandes cantidades de menciones (en comparación con los otros temas), pero se lo agrupó para ver ambas cantidades reflejadas en el gráfico.

Creo que (el final de Enredados) es un poco romántico porque al final se termina casando con Eugene. (LG, 8 años, niña, JM/PL)

\subsubsection{Orden de preferencias de las princesas}

Con respecto a las preferencias de las niñas por cada princesa, cuyas razones fueron detalladas anteriormente, se contabilizaron los puntajes obtenidos de las respuestas de las niñas a manera ranking para descubrir las princesas favoritas y las 
menos favoritas. A continuación, se muestran los puntajes acumulados por cada princesa en ambos grupos distritales.

Los puntos fueron otorgados de acuerdo a los gustos de las niñas, quienes puntuaron en un rango del 1 al 7: 7 puntos a las más favoritas y 1 punto a las menos favoritas. En el primer puesto se encuentra Rapunzel, con 131 puntos, mientras que en el último puesto, Pocahontas, con 71 puntos.

Tabla 3.3.

Orden de preferencias de cada princesa (suma total)

\begin{tabular}{c|cccccccc}
\hline PRINCESAS & Rapunzel & Moana & Mérida & Mulán & Elsa & Tiana & Anna & Pocahontas \\
\hline TOTAL & 131 & 124 & 122 & 104 & 85 & 84 & 72 & 71 \\
RANKING & $1^{\mathrm{r}}$ & $2^{\mathrm{o}}$ & $3^{\mathrm{r}}$ & $4^{\mathrm{o}}$ & $5^{\circ}$ & $6^{\circ}$ & $7^{\circ}$ & $8^{\circ}$ \\
\hline
\end{tabular}

Fuente: Elaboración propia

Sin embargo, las preferencias por parte de las niñas varían cuando se separan por grupos distritales. En San Juan de Lurigancho tienen en el primer puesto a Moana, mientras que en Jesús María/Pueblo Libre, tienen a Mérida. Si bien, Rapunzel es la favorita y tiene el puntaje mayor, cuando se separan los resultados por grupos distritales, pasa a ocupar el segundo puesto y Moana y Mérida pasan al primer lugar en San Juan de Lurigancho y Jesús María/Pueblo Libre respectivamente.

Tabla 3.4.

Ubicación de cada princesa en el ranking (por grupos distritales)

\begin{tabular}{cc|cc}
\hline & San Juan de Lurigancho & Jesús María/Pueblo Libre & \\
\hline $1^{\mathrm{r}}$ & Moana & Mérida & $1^{\mathrm{r}}$ \\
$2^{\mathrm{o}}$ & Rapunzel & Rapunzel & $2^{\mathrm{o}}$ \\
$3^{\mathrm{r}}$ & Elsa & Moana & $3^{\mathrm{r}}$ \\
$4^{\mathrm{o}}$ & Tiana & Mulán & $4^{\mathrm{o}}$ \\
$5^{\mathrm{o}}$ & Mérida - Mulán & Tiana & $5^{\mathrm{o}}$ \\
& & Anna & $6^{\mathrm{o}}$ \\
$6^{\mathrm{o}}$ & Pocahontas -Anna & Pocahontas & $7^{\mathrm{o}}$ \\
& & Elsa & $8^{\mathrm{o}}$ \\
\hline
\end{tabular}

Fuente: Elaboración propia

\subsubsection{Percepciones vs. Hechos:}

Cruzando la información entre el ranking y las preferencias de las niñas entrevistadas de ambos grupos distritales, podemos observar que en los tres primeros puestos se encuentran Rapunzel, Moana, Mérida. Si tomamos en cuenta la cantidad de características masculinas, femeninas y neutras en base a lo planteado por Bem, podemos 
ver que las niñas prefieren personajes más activos en sus historias, que toman la rienda de sus vidas en sus propias manos.

Rapunzel empieza con predominancia masculina, pues crece encerrada por su "madre" en una torre donde ella se vale por sí misma y solo interactúa con Pascal, su camaleón mascota. Luego, adquiere más cualidades femeninas (preocupación por Eugene y Pascal, y enamoramiento) sin dejar de lado su fuerza e independencia (se sabe defender ella misma a punta de una sartén). Este personaje termina con predominancia masculina, pues se enfrenta a sus miedos y a su raptora.

Tanto Moana como Mérida tienen una evolución parecida a lo largo de sus películas. Empiezan con gran predominancia de características masculina y con el paso de los actos desarrollan nuevas características neutras y femeninas relacionadas a sus historias. Las niñas entrevistadas reconocieron estas situaciones que atraviesan sus princesas favoritas y se sintieron identificadas con ellas.

Me gusta (Moana) porque me pareció como cuando yo era chiquita y exploraba el mundo. (LK, 8 años, niña JM/PL)

Además, se sienten inspiradas a lograr nuevas metas y objetivos. Si bien no muchos padres reconocieron comportamientos trascendentales relacionados a las películas (ver figura 5.14 y 5.15), el discurso de los niños y sus opiniones nos dicen más sobre lo que sus padres logran observar en sus juegos

Porque ella (Moana) no se rinde, intenta seguir adelante, le gusta tener aventuras, quiere aprender como su papá; ella quiere lograr salvar a su isla porque es muy graciosa y divertida. (ZA, 9 años, niña, SJL)

Porque (Mulán) me enseñó a que todos tienen que ser tratados por igual, ya sea de donde vienen o su sexo. (OM, 10 años, niña, SJL)

Porque me enseña que puedo hacer cualquier tipo de cosas, aunque te lo prohíba una persona y que tienes que ver el mundo del exterior que no solamente tienes que quedarte en un mismo lugar siempre. (AE, 8 años, niña, JM/PL)

Por último, se identificaron las características encontradas en la observación de las películas en el discurso y las respuestas que las niñas otorgaron. A continuación, se colocarán las más resaltantes de Rapunzel y Moana (ver Anexo 7 para todas las princesas). 
Tabla 3.5.

Contraste entre las características de las princesas y las menciones de las niñas ${ }^{12}$

\begin{tabular}{|c|c|c|c|}
\hline PRINCESA & $\begin{array}{l}\text { CARACTERÍSTICAS } \\
\text { INVENTARIO }\end{array}$ & & CITAS \\
\hline \multirow{8}{*}{ RAPUNZEL } & Alegre & MA, SJL, 8 & Luego Rapunzel se divierte mucho \\
\hline & Tierna & AE, JM, 8 & Creo que es tierna y valiente \\
\hline & Independiente & AE, JM, 8 & $\begin{array}{l}\text { Porque me enseña que puedo hacer } \\
\text { cualquier tipo de cosas }\end{array}$ \\
\hline & & AE, JM, 8 & Aunque te lo prohíba una persona \\
\hline & Defiende sus creencias & AE, JM, 8 & $\begin{array}{l}\text { Fue muy valiente porque se atrevió a } \\
\text { desobedecer a su supuesta madre }\end{array}$ \\
\hline & $\begin{array}{l}\text { Deseosa de tomar una } \\
\text { posición }\end{array}$ & AE, JM, 8 & $\begin{array}{l}\text { Fue muy valiente porque se atrevió a } \\
\text { desobedecer a su supuesta madre }\end{array}$ \\
\hline & Veraz & $\mathrm{AE}, \mathrm{JM}, 8$ & Que es muy sincera, muy honesta \\
\hline & Adaptable & AE, JM, 8 & $\begin{array}{l}\text { Que no solamente tienes que quedarte en } \\
\text { un mismo lugar siempre }\end{array}$ \\
\hline \multirow{8}{*}{ MOANA } & Alegre & ZA, SJL, 9 & Porque es muy graciosa y divertida \\
\hline & $\begin{array}{c}\text { Sensible a las necesidades } \\
\text { de los demás }\end{array}$ & ZA, SJL, 9 & $\begin{array}{l}\text { Le gusta tener aventuras, quiere aprender } \\
\text { como su papá, quiere lograr salvar su isla }\end{array}$ \\
\hline & Deseosa de tomar riesgos & LL, SJL, 8 & $\begin{array}{l}\text { Lo que pasó es que, aunque sus papás le } \\
\text { decían que no podía porque el mar era } \\
\text { peligroso, pero demostró a sus papás que } \\
\text { podía }\end{array}$ \\
\hline & & ZA, SJL, 9 & $\begin{array}{l}\text { Le gusta tener aventuras, quiere aprender } \\
\text { como su papá, quiere lograr salvar su isla }\end{array}$ \\
\hline & Indenendiente & HA, JM, 8 & $\begin{array}{l}\text { Porque ella quiere ser libre y no quiere } \\
\text { seguir haciendo las ordenes que le dan }\end{array}$ \\
\hline & maependente & ZA, SJL, 9 & $\begin{array}{l}\text { Porque ella no se rinde, intenta seguir } \\
\text { adelante }\end{array}$ \\
\hline & Personalidad fuerte & LL, SJL, 8 & $\begin{array}{l}\text { Lo que pasó es que, aunque sus papás le } \\
\text { decían que no podía porque el mar era } \\
\text { peligroso, pero demostró a sus papás que } \\
\text { podía }\end{array}$ \\
\hline & Adaptable & $\mathrm{MC}, \mathrm{SJL}, 8$ & Es muy curiosa y viajera \\
\hline \multirow{7}{*}{ MÉRIDA } & $\begin{array}{c}\text { Deseosa de aliviar } \\
\text { sentimientos heridos }\end{array}$ & $\mathrm{EV}, \mathrm{SJL}, 8$ & $\begin{array}{l}\text { Su mamá la ayudaba en muchas cosas, } \\
\text { pero la perdió }\end{array}$ \\
\hline & Alegre & $\mathrm{SB}, \mathrm{JM} / \mathrm{PL}, 9$ & Alegre \\
\hline & Deseosa de tomar riesgos & $\mathrm{CD}, \mathrm{JM} / \mathrm{PL}, 8$ & $\begin{array}{l}\text { Cuando alguien me dice que no hagas o te } \\
\text { prohíbo eso, ella aun así lo hace y eso me } \\
\text { inspira a no ponerme ningún límite }\end{array}$ \\
\hline & & $\mathrm{EV}, \mathrm{SJL}, 8$ & Puede lanzar flechas \\
\hline & Independiente & $\mathrm{CD}, \mathrm{JM} / \mathrm{PL}, 8$ & $\begin{array}{l}\text { Cuando alguien me dice que no hagas o te } \\
\text { prohíbo eso, ella aun así lo hace y eso me } \\
\text { inspira a no ponerme ningún límite }\end{array}$ \\
\hline & & $\mathrm{SB}, \mathrm{JM} / \mathrm{PL}, 9$ & Porque es valiente \\
\hline & Defiende sus creencias & $\mathrm{EV}, \mathrm{SJL}, 8$ & $\begin{array}{l}\text { La pierde por no haber querer estado } \\
\text { casada }\end{array}$ \\
\hline
\end{tabular}

\footnotetext{
${ }^{12}$ Los colores utilizados en la tabla los relaciona con las características femeninas (rosa), masculinas (celestes) y neutras (amarillo).
} 


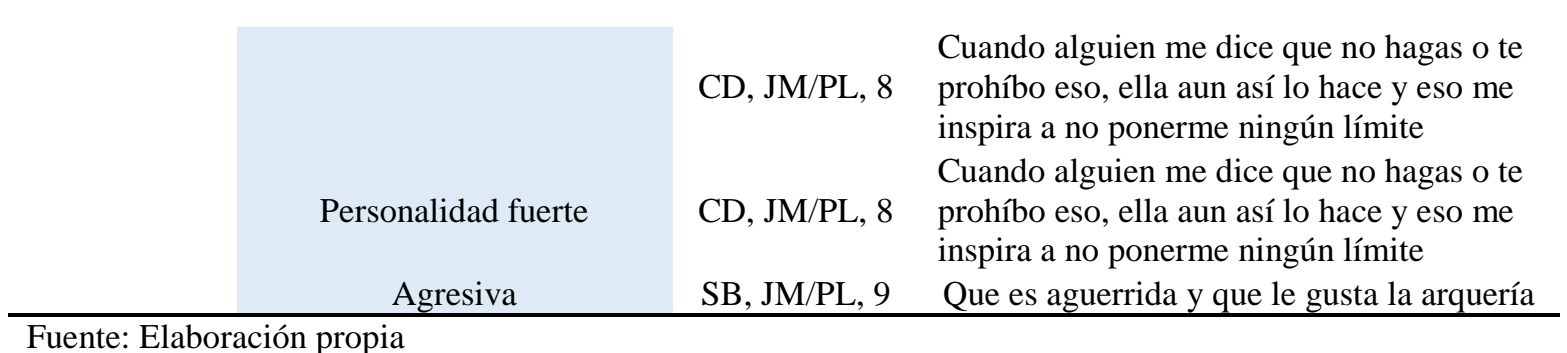

Se pueden observar similitudes en las características presentes en las tres princesas favoritas dentro del grupo investigado, como "independiente", "alegre" o “adaptable". De la misma manera, se encuentra que en las respuestas de las niñas se pueden mostrar diferentes características al mismo tiempo, y estas pueden ser tanto masculinas, femeninas o neutras, como "Le gusta tener aventuras, quiere aprender como su papá, quiere lograr salvar su isla”, que demuestra que Moana es "independiente" y “sensible a las necesidades de los demás". Como se puede observar en el Anexo 7, la mayor cantidad de respuestas dadas por las niñas se relacionan a las características masculinas detectadas en la observación de las películas.

Cabe resaltar que Tiana, personaje de La princesa y el sapo no cuenta con un cuadro de características contrastadas con las respuestas de las niñas debido a que ninguna de ellas la describió como su favorita.

\subsection{Relación entre el visionado de las películas y las costumbres, y pertenencia de merchandising}

Para entender un poco el contexto en el que se encuentran los niños entrevistados, se buscó conocer la pertenencia de merchandising, objetos o juguetes relacionados a sus gustos, los hábitos de consumo de material audiovisual y la frecuencia con la que suelen consumirlos. Para esto, acudimos a sus padres para tener una visión externa a los niños.

\subsubsection{Sobre la pertenencia de merchandising}

Figura 3.10.

Pertenencia de artículos en los dos distritos (porcentaje) 


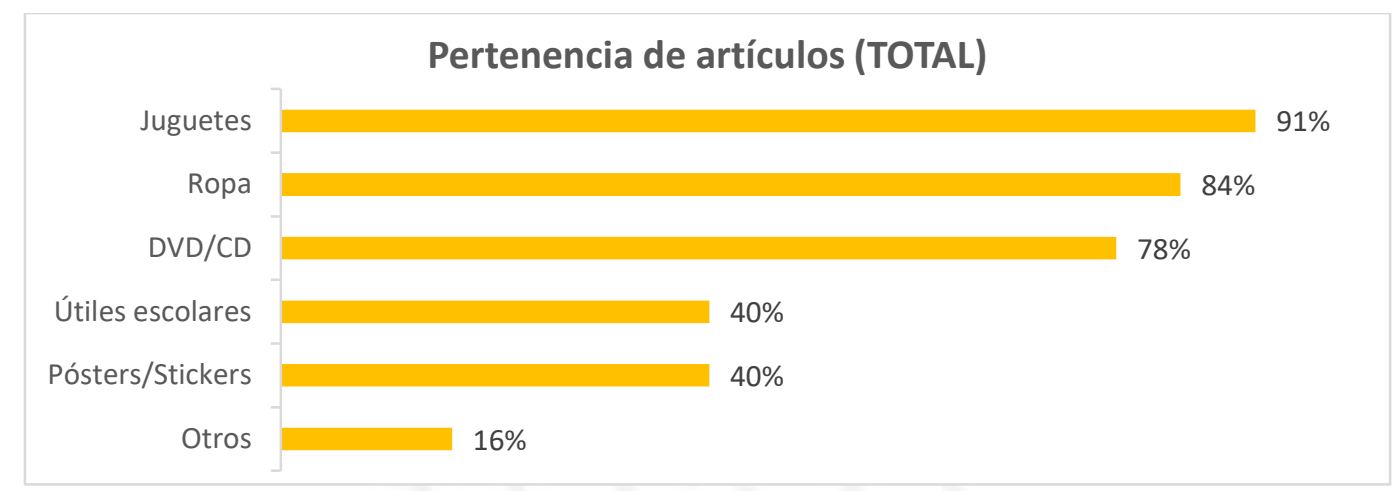

Fuente: Elaboración propia.

De los 32 padres encuestados de ambos distritos, el $91 \%$ de ellos sostiene que sus hijos tienen juguetes de películas. El segundo artículo más común que poseen es la ropa, con $84 \%$ de los encuestados, seguido por $78 \%$ de DVD/CD. $40 \%$ posee útiles escolares alusivos a Disney, $40 \%$ posee posters o stickers, y otros artículos, el 16\%.

Figura 3.11.

Pertenencia de artículos en los dos distritos (comparación en porcentajes)

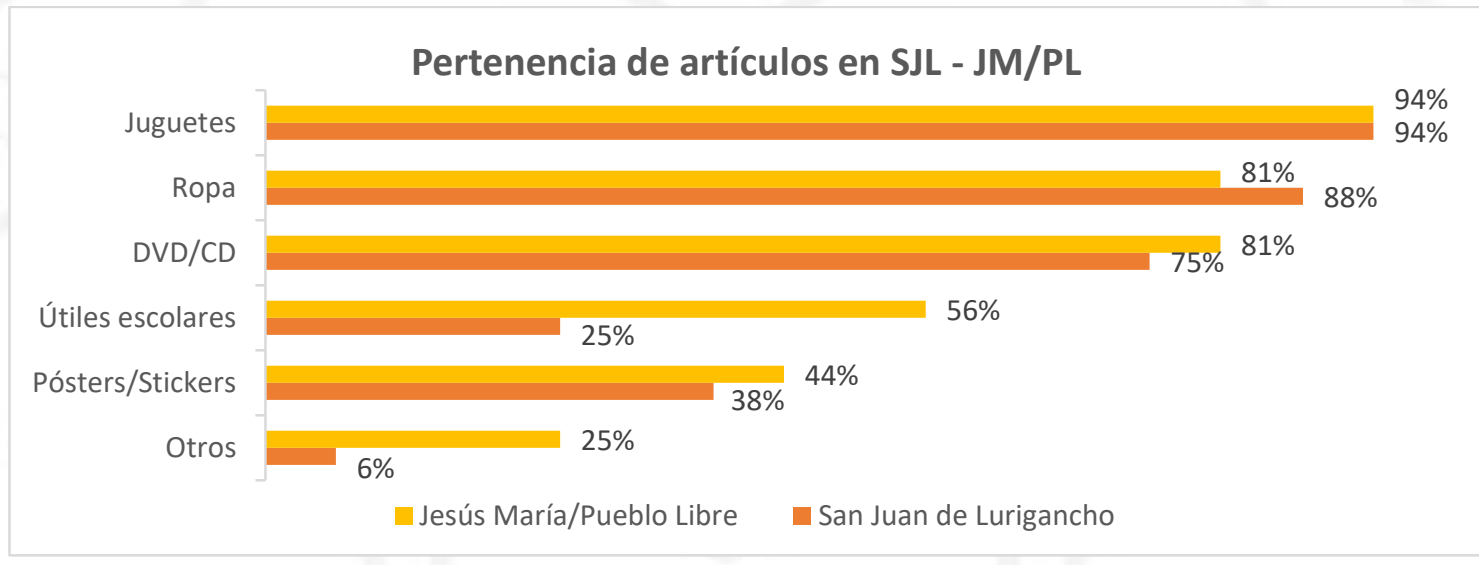

Fuente: Elaboración propia

Si observamos comparativamente entre grupos distritales, vemos que hay diferencias marcadas entre la pertenencia de los artículos como los útiles escolares, los “posters/stickers” y “otros”, en donde primaban las tazas, artículos de aseo o almanaques.

Si seguimos la línea de tendencia de los artículos más comunes que poseen, la categoría "juguetes" gana por amplia mayoría. Por ello se les preguntó sobre la cantidad de estos.

Figura 3.12.

Cantidad de juguetes en total 


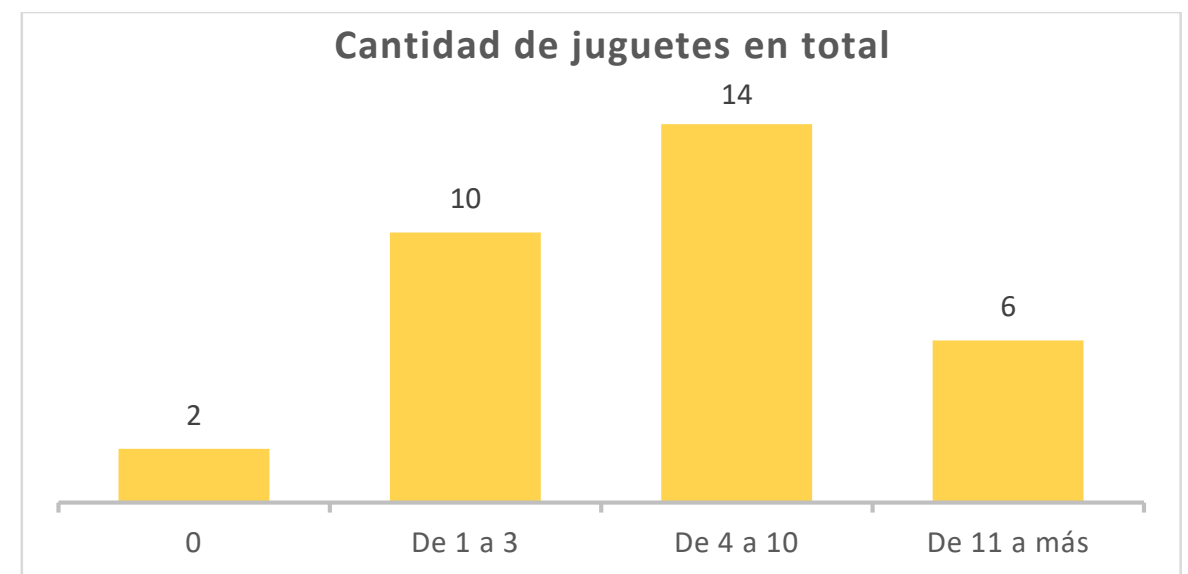

Fuente: Elaboración propia

\subsubsection{Sobre la frecuencia de visionado}

Para terminar de entender el contexto de los niños entrevistados, se les preguntó a sus padres sobre la frecuencia con la que sus hijos ven películas animadas de Disney, lo que nos mostró que, de manera general, la frecuencia era entre 1 y 2 veces a la semana y 1 y 2 veces al mes, seguido de cerca por entre 1 y 2 veces al día: el consumo es balanceado entre estas opciones. Esto nos muestra que la frecuencia con la que ven películas animadas de Disney es grande.

Figura 3.13.

Frecuencia de visionado de películas animadas de Disney (total en \%)

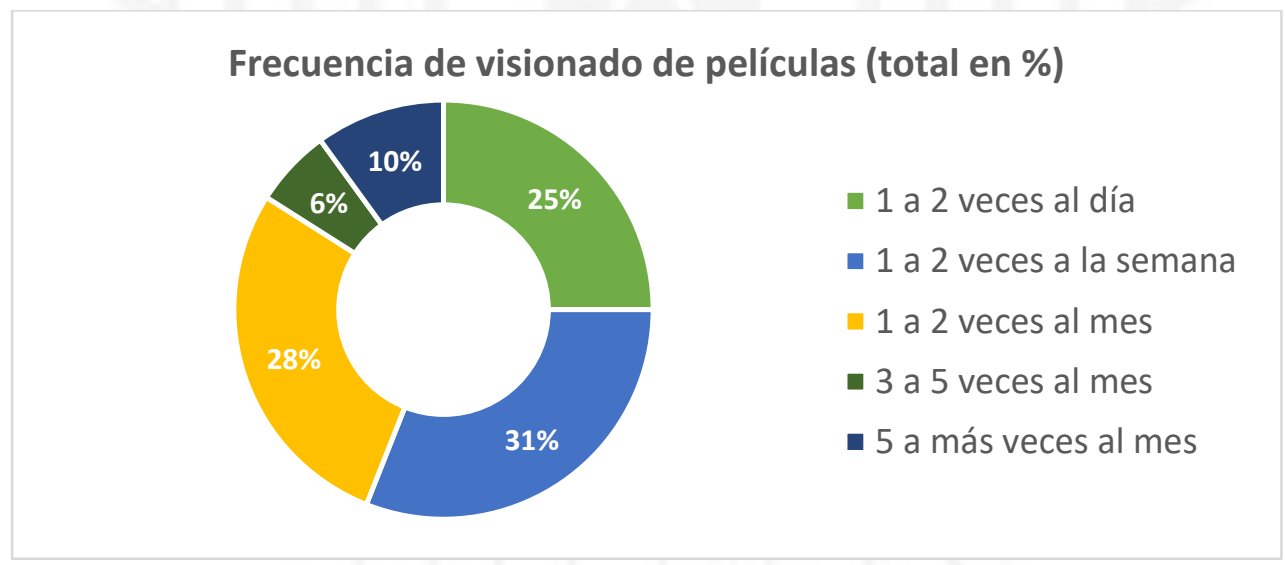

Fuente: Elaboración propia.

Sin embargo, sí encontramos diferencia entre la frecuencia más común entre ambos grupos distritales. En San Juan de Lurigancho, la más común es de 1 a 2 veces a la semana, mientras que en Jesús María/Pueblo Libre, la más común es de 1 a 2 veces al mes. En estas dos opciones, las respuestas son opuestas. 
Figura 3.14.

Frecuencia de visionado de películas animadas de Disney (SJL en \%)

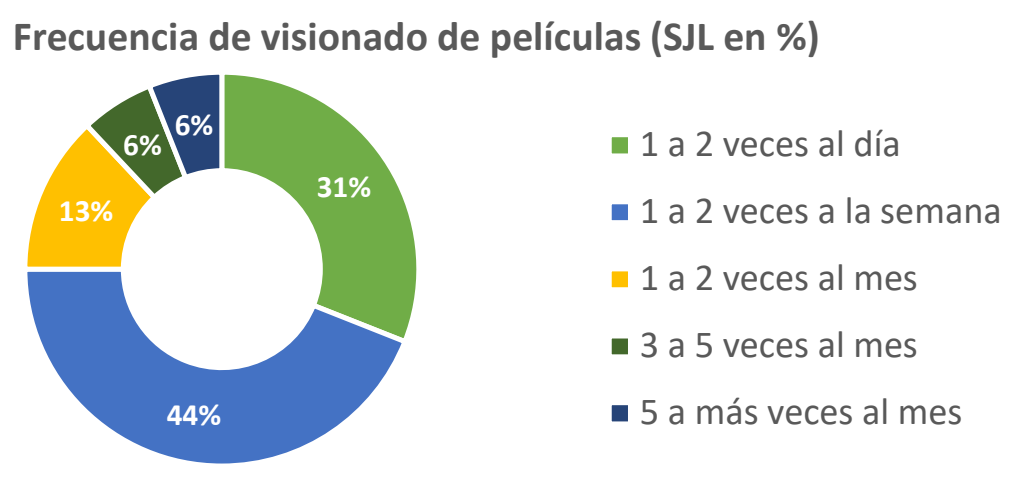

Fuente: Elaboración propia.

Figura 3.15.

Frecuencia de visionado de películas animadas de Disney (JM/PL en \%)

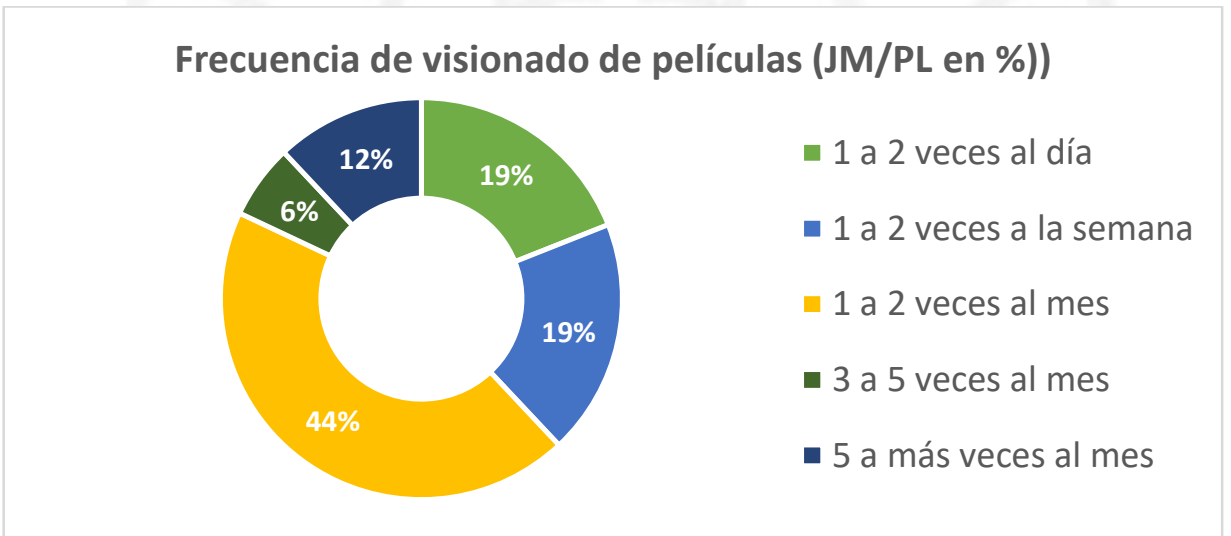

Fuente: Elaboración propia.

\subsubsection{Cambios en el comportamiento en los niños}

Para finalizar, se les preguntó a los padres sobre los comportamientos de sus hijos luego de ver una película. Esto no estaba necesariamente relacionado con las películas animadas de las princesas de Disney, sino más bien con cualquier película que haya generado algún comportamiento fuera de lo común o resaltante para ellos.

Figura 3.16.

Cambios o comportamientos relacionados a una película (total) 
¿Ha notado un cambio o un comportamiento relacionado

a una película? (total)

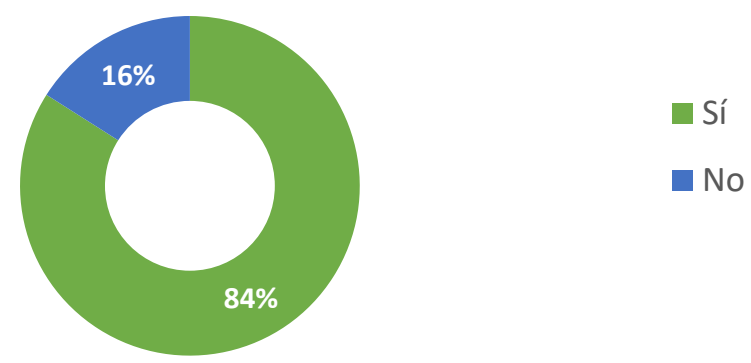

Fuente: Elaboración propia.

Estos porcentajes varían cuando se separa por grupos distritales, aunque la mayoría sigue sosteniendo que, efectivamente, ha notado un cambio o comportamiento relacionado a una película. Los comportamientos reconocidos por los padres van desde cantar, bailar, vestirse o peinarse como princesas hasta imitar movimientos, sonidos, superpoderes y jugar como juegos de roles de sus personajes favoritos.

Figura 3.17.

Cambios o comportamientos relacionados a una película (por grupos distritales)

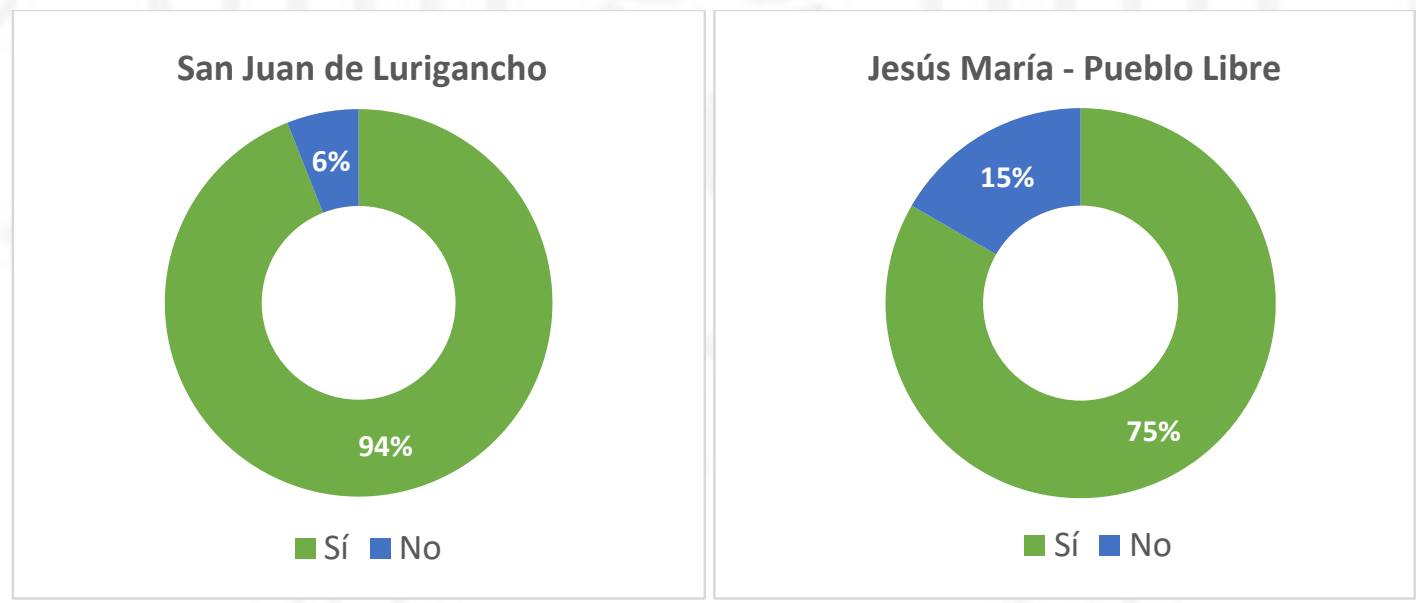

Fuente: Elaboración propia. 


\section{CAPÍTULO V: DISCUSIÓN}

En la presente investigación se quiso conocer y describir la percepción de los niños y niñas de 6 a 11 años acerca de las nuevas princesas de Disney respecto a los roles de género. El nuevo paradigma narrativo presentado por la productora trae consigo interpretaciones interesantes e importantes de analizar a través de la visión de las niñas participantes.

Las niñas entrevistadas en nuestra investigación mencionaron y explicaron que la razón principal para que una princesa sea su favorita era su personalidad, seguida de lo que aprendían de sus historias, pues se podían sentir identificadas. En cambio, González Alafita et al (2012) encontró en México que las razones de favoritismo de princesas se basaban principalmente en la estética de las películas, sus colores, vestidos o el cabello de las princesas. Si bien estos rasgos también son mencionados por nuestras niñas en Perú, estos tienen un porcentaje mucho menor en comparación.

Esta observación coincide con Lee (2009), quien encontró que el discurso de las niñas coreanas que entrevistó no era simplemente repetitivo, tenían una opinión e interpretaban las historias de las películas de Disney y las relacionaban a sus propios entornos socioculturales. Es importante mencionar la diferencia de los contextos de ambos estudios mencionados, el primero en México y el segundo en Estados Unidos, con niñas de familias migrantes coreanas.

De esta manera vemos que las princesas toman una importancia diferente a lo que Ramos Jiménez (2009), Gagó (2012) o González Alafita et al. (2012) nos mostraban. Dentro del análisis de las películas seleccionadas, se observó que hay un cambio en las motivaciones y obstáculos a superar por las princesas de las eras estudiadas (entre 1998 al 2017). Ellas pasan a ser un reflector de las nuevas prioridades del público objetivo, tanto de sus padres y de los consumidores directos: los niños.

Con respecto a la agencia que ejercen las niñas que participaron en el presente estudio, se puede observar que afirman y seleccionan a las princesas de Disney que son de su agrado. La principal razón que explicaría esta agencia es que las características generales relacionadas a la personalidad de las princesas que muestran en sus películas 
logran calar en el gusto de cada una de ellas: se sienten identificadas. Sin embargo, la principal razón de "no gusto" (la menos favorita y de la que escogen no aprender) es mucho más variada y difícil de clasificar debido a que cada niña representa una propia interpretación, personal y proveniente de su propio contexto.

Siguiendo la teoría aprendizaje cognoscitivo social, los niños aprenderían junto con las películas de Disney (en este caso, de las princesas) por medio del aprendizaje vicario; como sostiene Bandura (2001b), el desarrollo infantil es modelado por la observación.

Si bien las niñas responden con agrado a la mención de las princesas de Disney, esto no significa que todas las princesas sean de su agrado. Esto demuestra la agencia que ejercen las niñas entrevistadas frente a los diferentes estímulos de los medios masivos (Bandura, 2001b) que puedan atraerlas, pues finalmente escogen qué tomar en cuenta y poner en práctica. Ellas, dentro de sus apropiaciones e internalizaciones, escogen, ejercen su agencia y deciden lo que para ellas resalta en un personaje por sobre otro. No todas las niñas ven a Mulán como una princesa favorita; al contrario, a una le disgusta que se corte el cabello y se vaya a la guerra, o a otra le "dan asco" los sapos en La princesa y el sapo. Su interpretación personal y lo que rescatan de cada una (y por qué) es la prueba de ello.

Sin embargo, sí se encuentra tendencia hacia los gustos relacionados a la agencia de las mismas princesas de Disney. Estas no solo apreciadas por las niñas, sino que son reproducidas como enseñanzas o lecciones que ellas rescatan y encuentran en sus vidas (ver Figura 4.7. y 5.8.). Esta apropiación del discurso de sus princesas favoritas y menos favoritas (y posterior internalización y reproducción) responde al enfoque construccionista de Corsaro (1997), pues el niño es un sujeto que puede y construye de acuerdo a su perspectiva y su agencia.

Bandura (2001a) concuerda con Corsaro (2018) y van ambos en la misma línea de la agencia de los niños, pues son actores, no solo receptores. Eligen qué aprendizajes poner en práctica y los reinterpretan de acuerdo a sus propios discursos y contextos. Por un lado, Bandura resalta la importancia de la agencia del actor (en nuestro caso, las niñas) en donde mediante la identificación escogen un modelo a seguir. Como hemos podido encontrar, las niñas entrevistadas se sienten identificadas con algunas princesas (no con todas) y escogen qué aspectos tomar como aprendizajes y, posteriormente, poner en práctica. 
Las niñas responden y priorizan, en su mayoría, las lecciones y logros alcanzados de las princesas. Estas situaciones mencionadas dentro del discurso de las niñas están relacionadas a las características masculinas de protagonistas. Estos no giran en torno a los datos de la historia, colores o personajes, sino a las motivaciones y situaciones que ellas internalizan que las princesas muestran en pantalla. Además, su respuesta a estos varía de acuerdo a los arcos narrativos que toma cada película, sus intereses cambian y responden al desarrollo personal de cada personaje principal. Siguiendo el ejemplo de Mulán, a la misma niña que, por un lado, le disgustaba que se cortara el cabello y vaya a la guerra, sí le gustaban las situaciones que terminaba atravesando en el transcurso de la película.

Incluso van más allá. A una de las niñas le disgusta Anna debido a que ella percibe e internaliza que "no hace nada, solo se convierte en estatua de hielo". Esta inacción de Anna abriría paso a que, gracias al aprendizaje vicario y la agencia de esta niña, ella sepa qué priorizar y cómo reaccionar (o no) ante un problema que tenga que afrontar en su vida. Ella interpreta que Anna no hace nada, por lo que ella aprende que, al contrario, debería hacer "algo", pues observa las consecuencias que trae la inacción de la princesa.

De la misma manera, encontramos a una niña que afirma no gustarle Rapunzel “porque a veces no es muy impactante lo que uno ve". Si es que la niña no encuentra una razón de identificación o motivación que le permita conectarse con lo que está observando, no pondrá en práctica el aprendizaje.

Lo que ellas escogen priorizar o no responde también al contexto en el que se encuentran viviendo, las oportunidades o desventajas que puedan tener en esos momentos de sus vidas y el acceso que los niños tenían a objetos materiales y sus hábitos de consumo de medios audiovisuales. Mientras que Elsa se encuentra entre las tres preferidas dentro del grupo distrital de San Juan de Lurigancho, en Jesús María/Pueblo Libre, Elsa ocupa el último lugar. Esto podría explicarse con diferentes razones, entre ellas "esa película ya le he visto varias veces" o "tiene poderes de nacimiento y eso se me hace como que extraño" (ambas citas de JM/PL). Mientras que las razones por las que sí es favorita van con el exacto contrario "me gusta que tenga algo de magia", "porque trata de magia" (SJL). De la misma manera, mientras que a una niña le parece que Anna "solo se convierte en estatua de hielo" (JM/PL) a otra sí le gusta porque "me gusta su forma de ser y me gusta que le gusta ayudar a las personas" (SJL). Vemos que las respuestas y las razones 
cambian por grupos distritales, al igual que la cantidad de artículos que poseen los niños participantes.

Sobre las características encontradas durante la observación de las películas y la evolución de las princesas de Disney, se pudo encontrar relación entre lo que las niñas rescataban y contaban de sus personajes favoritos. Se puede ver que hay mayor recordación de características masculinas (independiente vs. alegre). Además, se puede observar que las respuestas relacionadas a las características masculinas (defiende sus propias creencias: "fue muy valiente porque se atrevió a desobedecer a su supuesta madre") tienden a tener mayor argumentación y desarrollo en la idea a comparación de las respuestas femeninas o neutras (tierna: "creo que es tierna y valiente").

Lo que las niñas rescatan y a lo que ellas deciden prestar atención, retener, producir y por lo que están motivadas a realizar los pasos del proceso de aprendizaje encaja con las características planteadas por las princesas en sus películas. Las respuestas que otorgaron calzan y son resumidas en pocas palabras con las características recopiladas por Bem en su inventario. Esto demuestra no solo que ellos reconocen la presencia de los roles que cumplen los personajes, sino también que aprenden, ejercen y adquieren autoeficacia para alcanzar sus sueños, metas y objetivos.

Los niños y las niñas entrevistados en ambos estudios tienen como principal pasatiempo jugar y ver televisión. En nuestro estudio, esto se repite y se puede observar que dentro de sus juegos favoritos refieren jugar con juguetes y en el exterior. Estos juguetes están, en su mayoría, basados en dibujos y películas animadas. Por eso, se encuentran similitudes de pertenencia de artículos y hábitos de consumo de las películas con el estudio González Alafita et al (2013).

La mayoría menciona que dentro de las actividades que realiza, es el juego el que más resalta, seguido del consumo audiovisual. Los niños tienen la facilidad de acceder a diversas plataformas para consumir los contenidos que buscan y están interesados en ver. No por ser niños tienen opiniones o percepciones simples de lo que los rodea. Teniendo en cuenta que sus modelos a seguir son fuertes y decididas, ellas también serán fuertes y decididas, pero sin dejar de lado que son niñas, que se divierten o que usan vestidos: estas características no son opuestas a la fuerza.

Para finalizar, es importante mencionar que si bien se les preguntó a los padres de los niños participantes del estudio si notaron cambios de comportamiento relacionados a 
películas que sus hijos consuman, mencionaron principalmente haber reconocido que sus hijos acostumbraban cantar y bailar, vestirse y hasta peinarse como princesas, a imitar movimientos, sonidos, superpoderes y jugar como juegos de roles de sus personajes favoritos. Sin embargo, si recordamos las respuestas de los niños, estas han sido mucho más elaboradas y profundas que simplemente cantar y bailar.

\subsection{Recapitulando}

Desde 1937, Disney ha pasado por muchos sucesos, cambios, películas, éxitos de taquilla. La casa del ratón maneja un fenómeno internacional del entretenimiento y con respecto a sus primeros años, la academia los ha estudiado (y acusado) como propulsor de imperialismo, consumismo y estereotipos de género. Esto es justificado, pues los personajes femeninos no han tenido una mayor evolución en su narrativa en casi 60 años (desde Blancanieves en 1937 hasta Pocahontas, 1995). Sus grandes motivaciones y las líneas argumentales de sus películas se basaban en ellas como mujeres buenas (amas de casa/madres) y la constante espera pasiva de un salvador. (Ramos Jiménez, 2009; Gagó, 2002; Gonzáles Alafita, Villasuso y Rivera, 2012).

Disney, como empresa, tenía que evolucionar, tenía que seguirle el ritmo a una sociedad que avanzaba constantemente. Además, siendo Disney una oxitobrand, no solo tiene la capacidad y el alcance monetario para hacerlo, sino que además se encuentra posicionada de manera muy cercana a su público objetivo. Esto sucede también con las princesas de Disney, forman parte de un producto estrella de la marca. Busca reinventarse con el paso del tiempo, sin negar su pasado, pero sacando a flote características que van más de acuerdo a lo que buscan sus espectadores.

El último intento de mostrar a todas las princesas juntas en un mismo espacio es Ralph rompe el internet (2018), donde se muestra a las Princesas como parte de la historia. En el tráiler, cuando Vanelope, una de las protagonistas de la película se encuentra con las princesas, Rapunzel le pregunta "¿todos creen que tus problemas se solucionaron porque un hombre grande y fuerte apareció?" a lo que ella responde que sí. De esta manera, Disney está apropiándose de un discurso del que no podía desprenderse, por lo que decide representarlo y contarlo a su manera, sin dejar de lado su historia ni negando a sus primeras princesas. 
Siguiendo la línea de videos previos que Disney escoge liberar al público antes del estreno de sus películas, Frozen II (2019) lanzó un uno en donde si bien, se carece de diálogos, se presenta a una Elsa intentando de manera constante perfeccionar sus poderes y a Anna se le muestra realizando acciones que el inventario de Bem calificaría como "masculinas".

En el presente estudio, hemos visto que las niñas perciben a las nuevas princesas como personajes que muestran roles de género mucho más activos en sus vidas y en sus historias. Ellas deciden qué les gusta y qué no les gusta, tomando una decisión y ejerciendo su agencia dentro de sus propios contextos y gustos. Ahora, las princesas interactúan con sus familias y amigos más que con príncipes o intereses amorosos y sus grandes motivaciones son proteger a su entorno cercano, mejorar, vencer sus miedos y alcanzar sus sueños, forjando así un camino que las niñas deciden tomar en cuenta en sus propias vidas. 


\section{CONCLUSIONES}

- Disney cuenta con la presencia de princesas en sus narrativas desde su fundación. Sin embargo, desde hace ya algunos años están mostrando y representando una nueva visión, más variada, con temas más inclusivos y personajes más autónomos. Las princesas son la muestra más clara de estos cambios de prioridades y paradigmas dentro de la empresa.

- Vemos un claro cambio de paradigma representado por las nuevas princesas de Disney. No solo tienen una gran cantidad de características masculinas, sino que se alcanza un balance entre las femeninas, masculinas y neutras. Además, se pasa de una presencia constante de una contraparte masculina (príncipe) a que se exploren otras relaciones que la princesa tiene, como con sus padres, abuelos o amigos.

- Los niños y niñas no son recipientes en los que podemos introducir pensamientos o ideas para que ellos continúen o imiten. Son agentes sociales, tienen voz sobre sus propios gustos y hábitos. No son solo futuros adultos y no pueden crecer $\mathrm{y}$ desarrollarse siguiendo solo una visión pragmática de la infancia. Son niños, con derechos y opiniones bien argumentadas.

- La percepción de la influencia de los medios masivos, en este caso, Disney en los niños debe ser estudiada. Esta agencia que los niños ejercen se percibe cuando interactúan con sus compañeros y pares en espacios de socialización (en el juego, en el colegio o espacios públicos). Pero, uno puede notarlo más claramente al escuchar lo que el niño quiere decir, escuchando sus puntos de vista y tomando en cuenta sus percepciones, viéndolos como agentes sociales, no solo como niños siendo observados con ojos de adulto.

- El tipo de narrativas analizadas en la investigación responde a hablarle a los niños con estímulos que ellos encuentren no solo agradables, sino interesantes y que les sumen a su día a día. Lo que rescatan las niñas, más allá de los detalles de la narrativa, es en función de la personalidad, logros y lecciones que ellas escogen dentro de un producto que deciden observar. 
- Las principales características que poseen las nuevas princesas de Disney son “defiende sus creencias" en el primer acto, “independiente" en el segundo acto y “confiada en sí misma” en el tercer acto. Las niñas se identifican con ellas a través de diferentes estímulos y las características mencionadas y ejercen agencia aprendiendo mediante la observación. Ellas observan y reinterpretan los roles de género desde sus perspectivas. 


\section{RECOMENDACIONES}

- Sería interesante continuar el análisis narrativo de López y De Miguel (2013) con las nuevas princesas. Tener un estudio que analice los personajes en sus roles como protagonistas, como actantes y como mujeres en el presente, enriquecería un futuro estudio como base para luego pasar a ver la opinión y percepción de sus consumidores.

- Los padres no suelen relacionar diferentes acciones en las que sus hijos ejercen agencia con el desarrollo de roles de género. La presente investigación muestra lo importante que puede ser escoger el contenido que los niños consumen. Debe haber una guía constante de los padres a los hijos tanto como para conversar lo que han visto, escuchado o percibido, sino también para que sean conscientes de lo que sus hijos están absorbiendo en sus contextos frente a diferentes estímulos. De esta manera se puede potenciar el aprendizaje a través de la agencia de los niños.

- Sería bueno tener en cuenta un estudio en retrospectiva: es decir, que las personas con las que se trabajara sean adolescentes y jóvenes y que ellos cuenten qué significaron en sus vidas y en su crecimiento las princesas o personajes de Disney. Esto podría mostrarnos con respuestas más conscientes y cambios que ellos sienten más reales que se han dado en base a lo que consumían tanto en contenido audiovisual como literario.

- Disney, al ser la empresa que es, con la llegada que tiene, puede ser fácilmente utilizada con fines educativos en colegios, por profesores y padres de familia. Ver las películas en el curso de Personal Social, o en clases donde se toquen temas de género y equidad puede ser un ejercicio interesante tanto para escuchar los que los niños rescatan o no de lo que observan como para generar un espacio de diálogo. Estas se pueden utilizar como herramienta en casa y en el colegio para discutir con compañeros, padres o profesores sobre lo visto.

- Se puede replicar este análisis con personajes masculinos y ver la evolución que tienen, si hay cambio a través de los años y cómo la industria cinematográfica los muestra en pantalla. Con esta información, se puede analizar lo que los espectadores y lo que los niños rescatan. 


\section{REFERENCIAS}

Auster, C., Ohm, S. (2000). Masculinity and Femininity in Contemporary American Society: A Reevaluation Using the Bem Sex-Role Inventory. Sex Roles, 43, 7/8, 499-528.

Badenhausen, K. (23 de mayo del 2017). Apple es la marca más valiosa del mundo por séptimo año consecutivo. Recuperado de https://www.forbes.com.mx/apple-lamarca-mas-valiosa-del-mundo-septimo-ano-consecutivo

Bandura, A. (2001a). Social Cognitive Theory: An Agentic Perspective. Annual Reviews Psychology, 52, 1-26.

Bandura, A. (2001b). Social Cognitive Theory of Mass Communication. Mediapsychology, 3, 256-299.

Bandura, A., Walters, R. H. (1990). Aprendizaje social y desarrollo de la personalidad. Madrid: Alianza.

Baron, R., Byrne, D. (2005). Psicología Social. Barcelona: Pearson

Burney, V. A. (2008). Applications of social cognitive theory to gifted education. Roeper Review, 30(2), 130-139.

Capriotti Peri, P. (2009). Branding Corporativo: Fundamentos para la gestión estratégica de la identidad corporativa. Santiago de Chile: Universidad Internacional de la empresa.

Cloninger, S. (2003). Teorías de la personalidad. México D. F.: Pearson Education.

Corsaro, W. (2018). The sociology of childhood ( $5^{\text {th }}$ ed.). California: SAGE Publications.

Cuadrado Esclapez, T. (2010). La enseñanza que no se ve: educación informal en el siglo XXI. Madrid: Narcea.

D23 (s. f.). About the autor: Dave Smith. Recuperado de https://d23.com/about-theauthor-dave-smith/

D23 (s. f.). About the expo. Recuperado de https://d23.com/d23-expo/about-the-expo/

D23 Members (13 de febrero del 2017). "See the Light" with Tangled At Disney Springs. Recuperado de https://d23.com/d23-event-recaps/d23-members-seethe-light-with-tangled-at-disney-springs/

Davis, A. M. (2007). Good Girls and Wicked Witches: Changing Representations of Women in Disney's Feature Animation, 1937-2001. John Libbey Publishing 
Disney (Productor). (11 de febrero del 2016). Dream Big, Princess - Be A Champion | Disney. Recuperado de https://www.youtube.com/watch?v=oYcGSeXiUI8

Disney (Productor). (15 de agosto del 2017). Dream Big, Princess Photography Campaign | Disney. Recuperado de https://www.youtube.com/watch?v=jHNPzyDD50I

Disney (Productor). (4 de junio de 2018). Ralph Breaks the Internet: Wreck-It Ralph 2 Official Trailer. Recuperado de https://www.youtube.com/watch?v=_BcYBBC6zfY

Disney (s. f.). Disney History. Recuperado de: https://d23.com/disney-history/

Disneysidekick. (5 de febrero del 2017). Disney legend and founder of the Disney Archives - Dave Smith spoke to us about 80 years of Disney Animation yesterday at the D23 Tangled event. Recuperado de https://instagram.com/p/BQI-lfXlacS/

Dockterman, E. (29 de enero del 2017). Barbie's got a new body. Time. Recuperado de http://time.com/barbie-new-body-cover-story/

Dorfman y Matellart. (1972). Cómo leer al Pato Donald. Siglo Veintiuno Editores: Buenas Aires

England, D. E., Descartes, L., Coller-Meek, M. (2011). Gender Role Portrayal and the Disney Princesses. Springer, 555-567. Recuperado de https://search.proquest.com/docview/857999236?pq-origsite=summon

Field, S. (2005). El manual del guionista. Madrid: Plot.

Gagó, F. (2002). Mujer y cine. El eterno femenino en el celuloide. En A. González y C Lomas (Coords.), Mujer y educación. Educar para la igualdad, educar desde la diferencia (pp. 113-130). Barcelona: Graó.

Gaitán Muñoz, L. (2006). La nueva sociología de la infancia: Aportaciones de una mirada distinta. Política y Sociedad, 43, 9-26)

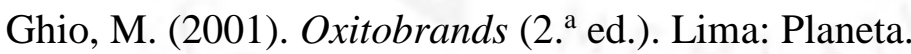

Gitlin, T. (abril 2001). La tersa utopía de Disney. Letras Libres, 28, 12-16.

González Alafita, E., Villasuso, M., Rivera, T. (2012). Las princesas de Disney: lo que aprenden las niñas mexicanas a través de las películas. Revista Comunicación, 10(1) $1505-1520$.

Hernández Sampieri, R., Fernandez Collado, C., Baptista Lucio, P. (2010). Metodología de la investigación. México D. F.: McGraw Hill.

Instituto Nacional de Estadística e Informática [INEI]. (2013). Mapa de pobreza provincial y distrital 2013. Recuperado de: http://www.inei.gob.pe/media/MenuRecursivo/publicaciones_digitales/Est/Lib1 261/Libro.pdf 
Interbrand. (2017). Best Global Brands 2017. Recuperado de http://interbrand.com/bestbrands/best-global-brands/2017/ranking/

Lee, L. (2008). Understanding gender through Disney's marriages: A study of young korean inmigrants girls. Early Childhood Education Journal. DOI: 10.1007/s10643-008-0260-5

López, M. y Miguel, M. de. (2013). La fémina Disney: análisis y evolución del personaje femenino en cuatro películas de la factoría Disney. Sociedad y Economía, 24, 121-142.

Mayall, B (2002). Towards a sociology for childhood. Thinking from children's lives. Open University Press, McGraw-Hill Education, Glasgow.

Papalia, D. E., Feldman, R. D., Martorell, G., Berber, M. E., Vázquez, H. M., Ortiz, S. M. E. y Dávila, J. F. J. (2012). Desarrollo humano. México: McGraw-Hill.

Powers, L. (2014). The evolution of the princess: Impact on perceptions (Tesis de maestría). School of Graduate Studies and Research Southeast Missouri State Universitym, Missouri. Recuperado de https://search.proquest.com/docview/1560881516?pqorigsite=summon\&https://search.proquest.com/embedded/M8YQ192CYQ7DSP B6

Ramos Jiménez (2009). Desmontado a Disney: hacia el cuento coeducativo. Andalucía: Junta de Andalucía.

Robehmed, N. (21 de mayo del 2015). Los 6 estudios cinematográficos más rentables de Hollywood. Recuperado de https://www.forbes.com.mx/apple-la-marca-masvaliosa-del-mundo-septimo-ano-consecutivo/

Rocha, T. (2009). Desarrollo de la identidad de género desde una perspectiva psicosocio-cultural: Un recorrido conceptual. Revista Interamericana de Psicología, 43, 250-259.

Schunk, D. H. (2012). Teorías del aprendizaje. México: Prentice Hall Hispanoamericana.

Zepeda Cruz, J. D. (2004). El fenómeno catártico y la narrativa cinematográfica (Tesis de licenciatura). Universidad de las Américas Puebla. Recuperado de: http://catarina.udlap.mx/u_dl_a/tales/documentos/lco/zepeda_c_jd/portada.html 


\section{BIBLIOGRAFÍA}

Alba Ambrós, R. (2007). Cine y educación. El cine en el aula de primaria y secundaria. Barcelona: GRAO.

Aston, J. M., Vásquez, E. (2013). Masculinity and femininity: Stereotypes/myths, psychology and role of culture. Nova Science Publishers, Inc.

Lindqvist, A. (2013). How to measure gender myths. En J. V. Anston, Masculinity and femeninity: Stereotypes/myths, psychology and role of culture (pp. 143-154). New York: Nova Publishers.

Paladino, D. (2006). Qué hacemos con el cine en el aula. En I. Dussel, D. Gutiérrez, Educar la mirada: políticas y pedagogías de la imagen (pp. 135-144). Buenos Aires: Manantial, Flacso, OSDE.

Pavez Soto, I. (2012). Sociología de la infancia: las niñas y los niños como actores sociales. Revista de Sociología, 27, 81-102). Recuperado de https://core.ac.uk/download/pdf/132236092.pdf

Ruiz Vallejos, F., Cabrera Vargas, L. (2015). La percepción pedagógica de películas de dibujos animados. XV Felafacs 2015 (pp. 387-398). Medellín: Felafacs.

Whelan, B. (2012). Power to the Princess: Disney and the Creation of the 20th Century Princess. Interdisciplinary Humanities, 21-34. 
ANEXOS 


\section{ANEXO 1: LÍNEA DE TIEMPO DE LAS PRINCESAS EN LAS PELÍCULAS DE DISNEY}

\section{7-1942: The Golden Age}

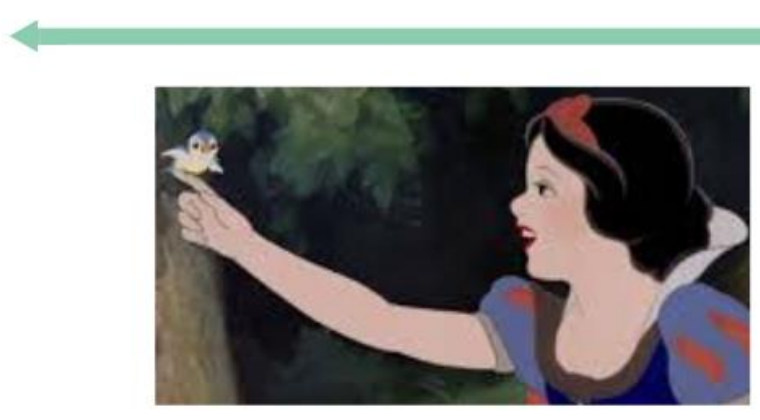

1937

\section{7-1967 The Silver Age}

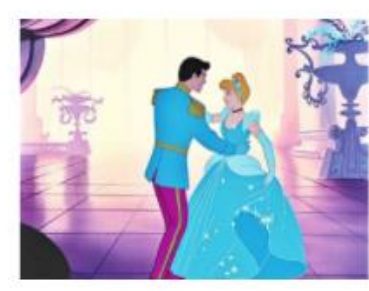

1950

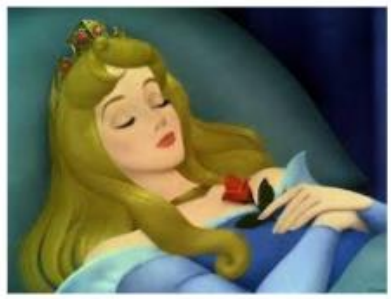

1957

1989-1994 The Second Golde Age

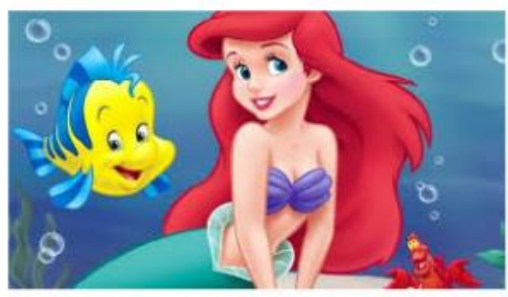

1989

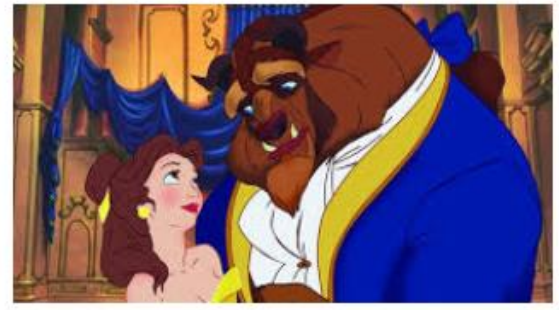

1991 


\section{ANEXO 2: GUÍA DE OBSERVACIÓN}

Película: Personaje:

Situación:

Planteamiento ( )

Confrontación ( )

Resolución ()

Resultados Finales

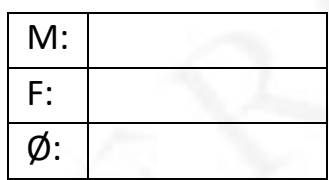

\begin{tabular}{|c|c|c|}
\hline & Característica & Situación en la que se presenta la característica \\
\hline $\bar{M}$ & 1. Confiado(a) en ti mismo(a) & \\
\hline $\mathrm{F}$ & 2. Complaciente & \\
\hline$\varnothing$ & 3. Servicial & \\
\hline $\bar{M}$ & 4. Defiendes tus creencias & \\
\hline $\mathrm{F}$ & 5. Alegre & \\
\hline$\varnothing$ & 6. Voluble & \\
\hline M & 7. Independiente & \\
\hline $\mathrm{F}$ & 8. $\quad$ Tímido(a) & \\
\hline$\varnothing$ & 9. Consciente & \\
\hline 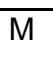 & 10. Atlético(a) & \\
\hline $\mathrm{F}$ & 11. Afectuoso(a) & \\
\hline$\varnothing$ & 12. Teatral & \\
\hline M & 13. Asertivo(a) & \\
\hline $\mathrm{F}$ & 14. Adulador(a) & \\
\hline $\bar{\varnothing}$ & 15. Feliz & \\
\hline $\bar{M}$ & 16. Personalidad fuerte & \\
\hline $\mathrm{F}$ & 17. Leal & \\
\hline$\varnothing$ & 18. Impredecible & \\
\hline $\bar{M}$ & 19. Fuerte & \\
\hline $\mathrm{F}$ & 20. Femenino(a) & \\
\hline $\bar{\varnothing}$ & 21. Confiable & \\
\hline $\bar{M}$ & 22. Analítico(a) & \\
\hline $\mathrm{F}$ & 23. Simpático(a) & \\
\hline$\varnothing$ & 24. Celoso(a) & \\
\hline
\end{tabular}




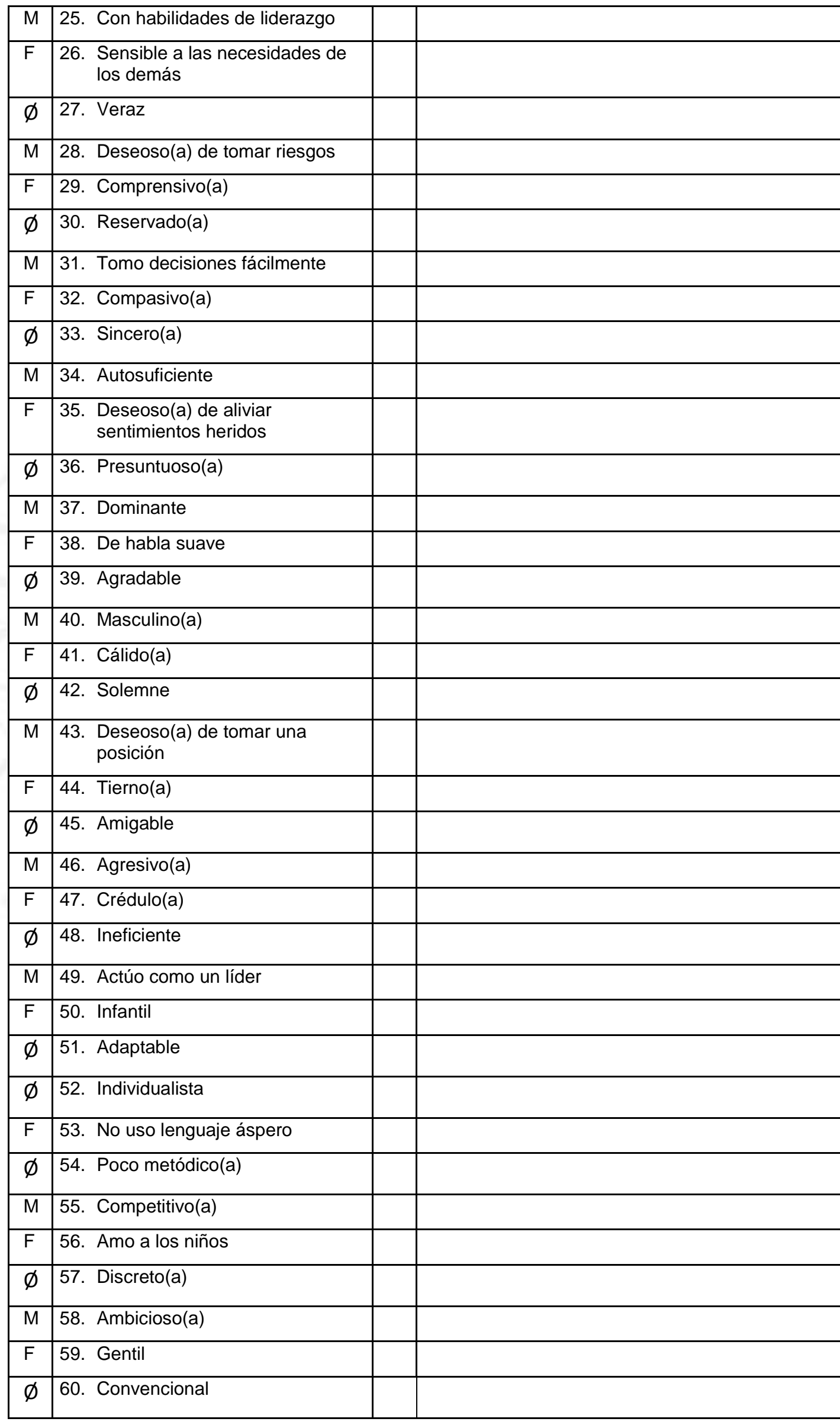




\section{ANEXO 3: GUÍA DE PREGUNTAS - ENREVISTA NIÑO}

Fecha:

Nombre:

Edad:

Sexo:

1. ¿Qué te gusta hacer en tus tiempos libres?

a. ¿Te gusta jugar? ¿A qué te gusta jugar?

b. ¿Te gusta ver televisión? ¿Qué te gusta ver?

2. ¿Te gusta ver películas? ¿Cuáles son tus películas favoritas? ¿Por qué?

3. -si no responden sobre películas de princesas- ¿Has visto las películas animadas de Disney de princesas?

¿Qué películas de princesas has visto? / ¿Qué princesa recuerdas?

4. ¿Te han gustado? ¿No te han gustado? ¿Por qué?

SI LE GUSTAN LAS PRINCESAS DE DISNEY:

5. Sobre tu(s) princesa(s) favorita(s), ¿qué piensas de ella(s) al comenzar la película, cuando (insertar situación del comienzo)? 
6. ¿Y qué piensas de ella al medio de la película, cuando (insertar situación del nudo)?

7. ¿Y al final, qué piensas de (ella) cuando (insertar situación del final)?

8. ¿Te pareció bien lo que hizo/decidió y cómo terminó?

9. ¿Tienes juguetes o ropa de esta película? 


\section{ANEXO 4: GUÍA DE PREGUNTAS - ENTREVISTA NIÑA}

Fecha:

Nombre:

Edad:

Sexo:

1. ¿Qué te gusta hacer en tus tiempos libres?

a. ¿Te gusta jugar? ¿A qué te gusta jugar?

b. ¿Te gusta ver televisión? ¿Qué te gusta ver?

2. ¿Te gusta ver películas? ¿Cuáles son tus películas favoritas? ¿Por qué?

3. -si no responden sobre películas de princesas- ¿Te gustan las películas animadas de Disney de princesas?

4. -mostrar guía de princesas- De estas princesas, califica del 1 al 8 a princesa favorita y a tu menos favorita

\begin{tabular}{|l|l|l|l|l|l|l|l|}
\hline Pocahontas & Mulán & Tiana & Rapunzel & Mérida & Elsa & Anna & Moana \\
\hline & & & & & & & \\
\hline
\end{tabular}

5. ¿Por qué ella es tu princesa favorita? 
6. ¿Por qué ella es tu princesa menos favorita?

\section{SI LE GUSTAN LAS PRINCESAS DE DISNEY:}

7. Sobre tu(s) princesa(s) favorita(s), ¿qué piensas de ella(s) al comenzar la película, cuando (insertar situación del comienzo)?

8. ¿Y qué piensas de ella al medio de la película, cuando (insertar situación del nudo)?

9. ¿Y al final, qué piensas de (ella) cuando (insertar situación del final)?

10. ¿Te pareció bien lo que hizo/decidió y cómo terminó?

11. ¿Tienes juguetes o ropa de esta película? 
Fecha:

Nombre:

Padre/apoderado de:

Edad:

1. ¿Tiene juguetes de películas animadas?

$$
\begin{aligned}
& \text { Sí ( ) No ( ) } \\
& -\quad \text { ¿Cuáles? } \\
& -\quad \text { ¿Cuántos? }
\end{aligned}
$$
De 1 a 3 ( )
De 4 a 10 ( ) De 11 a más ( )

2. ¿Cuáles de estos artículos tiene el niñ@ de películas animadas de Disney?
( ) Juguetes
( ) Ropa
( ) DVD/CD

( ) Útiles escolares

( ) Posters/Stickers

( ) Otros:

¿De qué personajes o películas?

3. ¿Con cuánta frecuencia mira películas animadas de Disney?

( ) 1-2 veces al día

( ) 1-2 veces a la semana

( ) 1-2 veces al mes

( ) 3-5 al mes

( ) 5 a más al mes

4. ¿Cuál es la película animada favorita de Disney de su niñ@?

5. - Si no responde una película de princesas- ¿Le gustan las princesas de Disney? ¿Cuál(es)?

6. Luego de haber visto una película, ¿ha notado un comportamiento o actitud parecidos o relacionados por parte de su(s) niñ@(s)? 


\section{ANEXO 6: CONSENTIMIENTO INFORMADO}

\section{Consentimiento Informado para Participantes de Investigación}

El propósito de esta ficha de consentimiento es proveer a los participantes en esta investigación con una clara explicación de la naturaleza de la misma, así como de su rol en ella como participantes.

La presente investigación es conducida por Andrea Polo (DNI 73191323), de la Universidad de Lima - Facultad de Ciencias de la Comunicación. La meta de este estudio es caracterizar la relación entre las princesas de Disney y los roles de género en la niñez media en niños y niñas de San Juan de Lurigancho y Jesús María/Pueblo Libre como proyecto de investigación para lograr el título de licenciatura.

Si usted accede a participar en este estudio, se le pedirá:

- Responder a una encuesta por parte del padre/madre, que consta de seis preguntas. Esto tomará aproximadamente 4 minutos de su tiempo.

- Responder una entrevista por parte del niño/a que consta de 9 preguntas. Esto tomará aproximadamente 8 minutos de su tiempo.

Lo que conversemos durante esta entrevista se grabará (audio), de modo que el investigador pueda transcribir después las ideas que usted haya expresado.

La participación en este estudio es estrictamente voluntaria. La información que se recoja será confidencial y no se usará para ningún otro propósito fuera de los de esta investigación. Una vez trascritas las entrevistas, las grabaciones se destruirán.

Si tiene alguna duda sobre este proyecto, puede hacer preguntas en cualquier momento durante su participación en él. Igualmente, puede retirarse del proyecto en cualquier momento sin que eso lo perjudique en ninguna forma. Si alguna de las preguntas durante la entrevista le parecen incómodas, tiene usted el derecho de hacérselo saber al investigador o de no responderlas.

Desde ya le agradecemos su participación. 
Reconozco que la información que yo provea en el curso de esta investigación es estrictamente confidencial y no será usada para ningún otro propósito fuera de los de este estudio sin mi consentimiento. He sido informado de que puedo hacer preguntas sobre el proyecto en cualquier momento y que puedo retirarme del mismo cuando así lo decida, sin que esto acarree perjuicio alguno para mi persona. De tener preguntas sobre mi participación en este estudio, puedo contactar a Andrea Polo al teléfono 961024375.

Entiendo que una copia de esta ficha de consentimiento me será entregada y que puedo pedir información sobre los resultados de este estudio cuando este haya concluido. Para esto, puedo contactar a Andrea Polo al teléfono anteriormente mencionado.

Si está de acuerdo con la información y en acceder a este estudio, por favor llene la información solicitada debajo. iMuchas gracias!

(Firma del padre) (DNI)

Andrea Polo Ferrer

DNI: 73191323 Fecha 


\section{ANEXO 7: CONTRASTE ENTRE LAS \\ CARACTERÍSTICAS DE LAS PRINCESAS Y LAS MENCIONES DE LAS NIÑAS}

\begin{tabular}{|c|c|c|c|}
\hline PRINCESA & $\begin{array}{l}\text { CARACTERÍSTICAS } \\
\text { INVENTARIO }\end{array}$ & & CITAS \\
\hline \multirow{15}{*}{ RAPUNZEL } & Alegre & MA, SJL, 8 & Luego Rapunzel se divierte mucho \\
\hline & Feliz & MA, SJL, 8 & $\mathrm{Y}$ vivieron felices \\
\hline & Servicial & CL, JM/PL, 8 & $\begin{array}{l}\text { La bruja cada vez le decía canta y su } \\
\text { cabello como que brillaba y se hacía } \\
\text { más... menos vieja }\end{array}$ \\
\hline & Tierna & AE, JM/PL, 8 & Creo que es tierna y valiente \\
\hline & Independiente & AE, JM/PL, 8 & $\begin{array}{l}\text { Porque me enseña que puedo hacer } \\
\text { cualquier tipo de cosas }\end{array}$ \\
\hline & & YR, JM/PL, 11 & Ya no piensa ser perdida otra vez \\
\hline & & AE, JM/PL, 8 & Aunque te lo prohíba una persona \\
\hline & & AE, JM/PL, 8 & $\begin{array}{l}\text { Y que tienes que ver el mundo del } \\
\text { exterior }\end{array}$ \\
\hline & Defiende sus creencias & $\mathrm{AE}, \mathrm{JM} / \mathrm{PL}, 8$ & $\begin{array}{l}\text { Fue muy valiente porque se atrevió a } \\
\text { desobedecer a su supuesta madre }\end{array}$ \\
\hline & & $\mathrm{CL}, \mathrm{JM} / \mathrm{PL}, 8$ & Que está bien, debe seguir sus sueños \\
\hline & & YR, JM/PL, 11 & Ya no piensa ser perdida otra vez \\
\hline & Personalidad fuerte & YR, JM/PL, 11 & Ya no piensa ser perdida otra vez \\
\hline & $\begin{array}{l}\text { Deseosa de tomar una } \\
\text { posición }\end{array}$ & AE, JM/PL, 8 & $\begin{array}{l}\text { Fue muy valiente porque se atrevió a } \\
\text { desobedecer a su supuesta madre }\end{array}$ \\
\hline & Veraz & $\mathrm{AE}, \mathrm{JM} / \mathrm{PL}, 8$ & Que es muy sincera, muy honesta \\
\hline & Adaptable & AE, JM/PL, 8 & $\begin{array}{l}\text { Que no solamente tienes que } \\
\text { quedarte en un mismo lugar siempre }\end{array}$ \\
\hline \multirow{7}{*}{ MÉRIDA } & $\begin{array}{l}\text { Sensible a las } \\
\text { necesidades de los } \\
\text { demás }\end{array}$ & $\mathrm{EV}, \mathrm{SJL}, 8$ & $\begin{array}{l}\text { Su mamá la ayudaba en muchas } \\
\text { cosas, pero la perdió }\end{array}$ \\
\hline & $\begin{array}{c}\text { Deseosa de aliviar } \\
\text { sentimientos heridos }\end{array}$ & $\mathrm{EV}, \mathrm{SJL}, 8$ & $\begin{array}{l}\text { Su mamá la ayudaba en muchas } \\
\text { cosas, pero la perdió }\end{array}$ \\
\hline & Cálida & $\mathrm{CD}, \mathrm{JM} / \mathrm{PL}, 8$ & Me parece muy tierno y familiar \\
\hline & Alegre & $\mathrm{SB}, \mathrm{JM} / \mathrm{PL}, 9$ & Alegre \\
\hline & $\begin{array}{l}\text { Deseosa de tomar } \\
\text { riesgos }\end{array}$ & $\mathrm{CD}, \mathrm{JM} / \mathrm{PL}, 8$ & $\begin{array}{l}\text { Cuando alguien me dice que no } \\
\text { hagas o te prohíbo eso, ella aun así lo } \\
\text { hace y eso me inspira a no ponerme } \\
\text { ningún límite }\end{array}$ \\
\hline & Asertiva & $\mathrm{CD}, \mathrm{JM} / \mathrm{PL}, 8$ & Porque ella me inspira para ser \\
\hline & Independiente & $\begin{array}{c}\text { EV, SJL, } 8 \\
\text { CD, JM/PL, } 8\end{array}$ & $\begin{array}{l}\text { Puede lanzar flechas } \\
\text { Porque ella me inspira para ser }\end{array}$ \\
\hline
\end{tabular}


Cuando alguien me dice que no

CD, JM/PL, 8 hagas o te prohíbo eso, ella aun así lo hace y eso me inspira a no ponerme ningún límite

SB, JM/PL, 9 Porque es valiente

\begin{tabular}{|c|c|c|}
\hline \multirow{3}{*}{ Autosuficiente } & $\mathrm{EV}, \mathrm{SJL}, 8$ & Puede lanzar flechas \\
\hline & $\mathrm{CD}, \mathrm{JM} / \mathrm{PL}, 8$ & $\begin{array}{l}\text { Cuando alguien me dice que no } \\
\text { hagas o te prohíbo eso, ella aun así lo } \\
\text { hace y eso me inspira a no ponerme } \\
\text { ningún límite }\end{array}$ \\
\hline & $\mathrm{SB}, \mathrm{JM} / \mathrm{PL}, 9$ & Porque es valiente \\
\hline \multirow[b]{2}{*}{ Defiende sus creencias } & $\mathrm{EV}, \mathrm{SJL}, 8$ & $\begin{array}{l}\text { La pierde por no haber querer estado } \\
\text { casada }\end{array}$ \\
\hline & $\mathrm{CD}, \mathrm{JM} / \mathrm{PL}, 8$ & $\begin{array}{l}\text { Cuando alguien me dice que no } \\
\text { hagas o te prohíbo eso, ella aun así lo } \\
\text { hace y eso me inspira a no ponerme } \\
\text { ningún límite }\end{array}$ \\
\hline \multirow[b]{2}{*}{ Confiada en sí misma } & $\mathrm{CD}, \mathrm{JM} / \mathrm{PL}, 8$ & Porque ella me inspira para ser \\
\hline & $\mathrm{CD}, \mathrm{JM} / \mathrm{PL}, 8$ & $\begin{array}{l}\text { Cuando alguien me dice que no hagas } \\
\text { o te prohíbo eso, ella aun así lo hace y } \\
\text { eso me inspira a no ponerme ningún } \\
\text { límite }\end{array}$ \\
\hline
\end{tabular}
Cuando alguien me dice que no hagas

$\mathrm{CD}, \mathrm{JM} / \mathrm{PL}, 8$ o te prohíbo eso, ella aun así lo hace y

Personalidad fuerte eso me inspira a no ponerme ningún límite

SB, JM/PL, 9 Que es aguerrida y que le gusta la arquería

SB, JM/PL, 9 Que es aguerrida y que le gusta la arquería

LK, JM/PL, 8 Que se sintió feliz, que los del pueblo se sintieron agradecidos de ella

Le gusta tener aventuras, quiere

ZA, SJL, 9 aprender como su papá, quiere lograr salvar su isla

Sí, porque puede hacer que su pueblo

MC, SJL, 8 entienda lo que debe hacer y no hacer lo que les conviene

\begin{tabular}{cll}
\hline Alegre & ZA, SJL, 9 & Porque es muy graciosa y divertida \\
\hline $\begin{array}{c}\text { Sensible a las } \\
\text { necesidades de los } \\
\text { demás }\end{array}$ & ZA, SJL, 9 & $\begin{array}{l}\text { Le gusta tener aventuras, quiere } \\
\text { aprender como su papá, quiere lograr } \\
\text { salvar su isla }\end{array}$ \\
\hline & Bien porque ella está en una isla que
\end{tabular}

MC, SJL, 8 no puede conocer muy bien y puede encontrar algunas cosas extrañas

LL, SJL, 8 Porque ella pasó una aventura en el agua

Deseosa de tomar riesgos

LL, SJL, 8 Lo que pasó es que, aunque sus papás le decían que no podía porque el mar era peligroso, pero demostró a sus papás que podía

ZA, SJL, 9 Porque ella no se rinde, intenta seguir adelante 
ZA, SJL, 9 Moana siempre quiso ir al agua a explorar y todo eso y hacer todo

HA, JM/PL, 8 Porque ella quiere ser libre y no quiere seguir haciendo las ordenes que le dan

Le gusta tener aventuras, quiere ZA, SJL, 9 aprender como su papá, quiere lograr salvar su isla

\begin{tabular}{|c|c|c|}
\hline \multirow{5}{*}{ Independiente } & MC, SJL, 8 & Es muy curiosa y viajera \\
\hline & LL, SJL, 8 & $\begin{array}{l}\text { Lo que pasó es que, aunque sus papás } \\
\text { le decían que no podía porque el mar } \\
\text { era peligroso, pero demostró a sus } \\
\text { papás que podía }\end{array}$ \\
\hline & HA, JM/PL, 8 & $\begin{array}{l}\text { Porque ella quiere ser libre y no quiere } \\
\text { seguir haciendo las ordenes que le dan }\end{array}$ \\
\hline & ZA, SJL, 9 & $\begin{array}{l}\text { Moana siempre quiso ir al agua a } \\
\text { explorar y todo eso y hacer todo }\end{array}$ \\
\hline & ZA, SJL, 9 & $\begin{array}{l}\text { Porque ella no se rinde, intenta seguir } \\
\text { adelante }\end{array}$ \\
\hline \multirow{5}{*}{ Defiende sus creencias } & $\mathrm{MC}, \mathrm{SJL}, 8$ & $\begin{array}{l}\text { Puede hacer que su pueblo vuelva a } \\
\text { ser como era antes }\end{array}$ \\
\hline & LL, SJL, 8 & $\begin{array}{l}\text { Lo que pasó es que, aunque sus papás } \\
\text { le decían que no podía porque el mar } \\
\text { era peligroso, pero demostró a sus } \\
\text { papás que podía }\end{array}$ \\
\hline & ZA, SJL, 9 & $\begin{array}{l}\text { Porque ella no se rinde, intenta seguir } \\
\text { adelante }\end{array}$ \\
\hline & ZA, SJL, 9 & $\begin{array}{l}\text { Moana siempre quiso ir al agua a } \\
\text { explorar y todo eso y hacer todo }\end{array}$ \\
\hline & HA, JM/PL, 8 & $\begin{array}{l}\text { Logra que siga sobreviviendo y le } \\
\text { puede demostrar a su padre que ella es } \\
\text { líder de su propia vida }\end{array}$ \\
\hline \multirow{3}{*}{$\begin{array}{l}\text { Con habilidades de } \\
\text { liderazgo }\end{array}$} & $\mathrm{MC}, \mathrm{SJL}, 8$ & $\begin{array}{l}\text { Puede hacer que su pueblo vuelva a } \\
\text { ser como era antes }\end{array}$ \\
\hline & MC, SJL, 8 & $\begin{array}{l}\text { Sí, porque puede hacer que su pueblo } \\
\text { entienda lo que debe hacer y no hacer } \\
\text { lo que les conviene }\end{array}$ \\
\hline & HA, JM/PL, 8 & $\begin{array}{l}\text { Logra que siga sobreviviendo y le } \\
\text { puede demostrar a su padre que ella es } \\
\text { líder de su propia vida }\end{array}$ \\
\hline \multirow[t]{2}{*}{$\begin{array}{l}\text { Deseosa de tomar una } \\
\text { posición }\end{array}$} & LL, SJL, 8 & $\begin{array}{l}\text { Lo que pasó es que, aunque sus papás } \\
\text { le decían que no podía porque el mar } \\
\text { era peligroso, pero demostró a sus } \\
\text { papás que podía }\end{array}$ \\
\hline & HA, JM/PL, 8 & $\begin{array}{l}\text { Porque ella quiere ser libre y no quiere } \\
\text { seguir haciendo las ordenes que le dan }\end{array}$ \\
\hline \multirow{3}{*}{ Actúa como líder } & LK, JM/PL, 8 & $\begin{array}{l}\text { Que se sintió feliz, que los del pueblo } \\
\text { se sintieron agradecidos de ella }\end{array}$ \\
\hline & HA, JM/PL, 8 & $\begin{array}{l}\text { Logra que siga sobreviviendo y le } \\
\text { puede demostrar a su padre que ella es } \\
\text { líder de su propia vida }\end{array}$ \\
\hline & ZA, SJL, 9 & $\begin{array}{l}\text { Le gusta tener aventuras, quiere } \\
\text { aprender como su papá, quiere lograr } \\
\text { salvar su isla }\end{array}$ \\
\hline
\end{tabular}


ZA, SJL, 9 Porque ella no se rinde, intenta seguir adelante

ZA, SJL, 9 Moana siempre quiso ir al agua a explorar y todo eso y hacer todo

Confiada en sí misma

Ya estaba cumpliendo sus sueños, estaba cumpliendo todo, estaba

ZA, SJL, 9 logrando todo ya para salvar su isla, ella no se rendía y me pareció muy bonito que no se rendía

\begin{tabular}{ll}
\hline Fuerte $\quad$ ZA, SJL, $9 \quad \begin{array}{l}\text { Ya estaba cumpliendo sus sueños, } \\
\text { estaba cumpliendo todo, estaba } \\
\text { logrando todo ya para salvar su isla, } \\
\text { ella no se rendía y me pareció muy } \\
\text { bonito que no se rendía }\end{array}$ \\
\hline
\end{tabular}
\begin{tabular}{lll} 
Personalidad fuerte & LL, SJL, 8 & $\begin{array}{l}\text { Lo que pasó es que, aunque sus papás } \\
\text { le decían que no podía porque el mar } \\
\text { era peligroso, pero demostró a sus } \\
\text { papás que podía }\end{array}$ \\
\hline
\end{tabular} papás que podía

Logra que siga sobreviviendo y le

HA, JM/PL, 8 puede demostrar a su padre que ella es líder de su propia vida

Sí, porque puede hacer que su pueblo

Asertiva

MC, SJL, 8 entienda lo que debe hacer y no hacer lo que les conviene

MC, SJL, 8 Puede hacer que su pueblo vuelva a ser como era antes

\begin{tabular}{cl}
\hline Impredecible & MC, SJL, 8 \\
\hline Adaptable & MC, SJL, 8
\end{tabular} Es muy curiosa y viajera

\begin{tabular}{|c|c|c|c|}
\hline \multirow{9}{*}{ ELSA } & Personalidad fuerte & LA, SJL, 9 & Me gusta su personalidad, cómo es \\
\hline & Confiada en sí misma & LA, SJL, 9 & \multirow{3}{*}{$\begin{array}{l}\text { Porque ella no sabía cómo... que } \\
\text { venga el verano, pero lo descongeló }\end{array}$} \\
\hline & Independiente & LA, SJL, 9 & \\
\hline & Autosuficiente & LA, SJL, 9 & \\
\hline & Tímida & LA, SJL, 9 & \multirow{2}{*}{$\begin{array}{l}\text { A veces tú puedes hacer algo malo a } \\
\text { quien tú quieres, o sea a su hermana. } \\
\text { Y bueno, no me parece tan malo, pero } \\
\text { a veces sucede }\end{array}$} \\
\hline & $\begin{array}{c}\text { Sensible a las } \\
\text { necesidades de los } \\
\text { demás }\end{array}$ & LA, SJL, 9 & \\
\hline & Discreta & LA, SJL, 9 & \multirow{2}{*}{$\begin{array}{l}\text { No le quiso hacer nada a Anna, pero } \\
\text { quiere alejarse para que no la vean }\end{array}$} \\
\hline & Individualista & LA, SJL, 9 & \\
\hline & Adaptable & LA, SJL, 9 & $\begin{array}{l}\text { Porque ella no sabía cómo... que } \\
\text { venga el verano, pero lo descongeló }\end{array}$ \\
\hline \multirow{7}{*}{ ANNA } & \multirow{2}{*}{$\begin{array}{l}\text { Toma decisiones } \\
\text { fácilmente }\end{array}$} & $\mathrm{EV}, \mathrm{JM} / \mathrm{PL}, 8$ & $\begin{array}{l}\text { Porque no hace nada solo se convierte } \\
\text { en estatua de hielo }\end{array}$ \\
\hline & & TT, JM/PL, 9 & Me gusta porque se va a buscar a Elsa \\
\hline & \multirow{2}{*}{$\begin{array}{l}\text { Deseosa de tomar una } \\
\text { posición }\end{array}$} & TT, JM/PL, 9 & $\begin{array}{l}\text { Sí me gusta porque dejaron abiertas } \\
\text { las puertas de Arendale y es bonito }\end{array}$ \\
\hline & & TT, JM/PL, 9 & Me gusta porque se va a buscar a Elsa \\
\hline & Independiente & TT, JM/PL, 9 & Me gusta porque se va a buscar a Elsa \\
\hline & Amigable & TT, JM/PL, 9 & \multirow{2}{*}{$\begin{array}{l}\text { Me gusta que le gusta ayudar a las } \\
\text { personas }\end{array}$} \\
\hline & Gentil & TT, JM/PL, 9 & \\
\hline
\end{tabular}




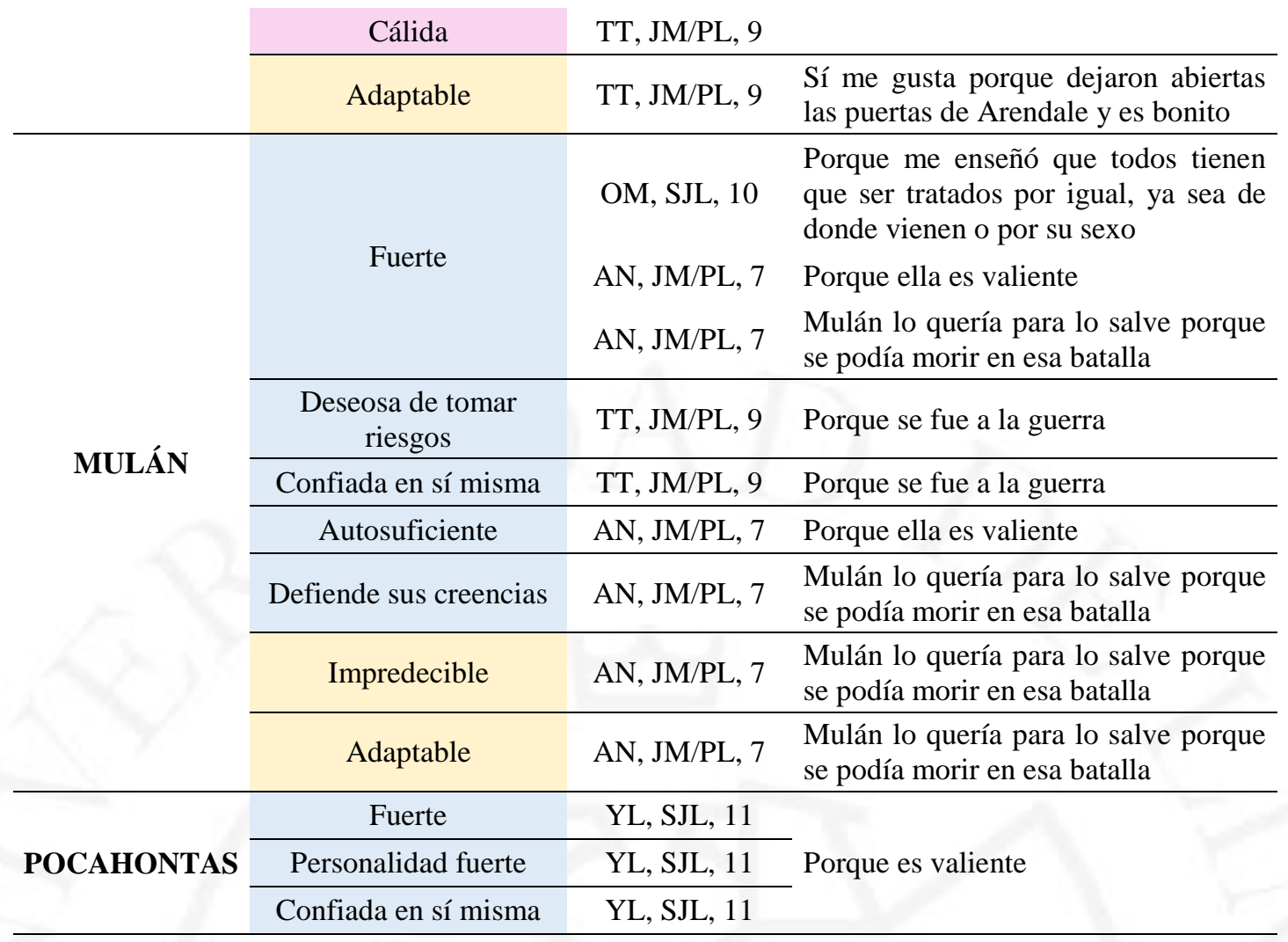

